Evaluation of the Emission, Transport, and Deposition of Mercury and Fine Particulate Matter from Coal-Based

Power Plants in the Ohio River Valley Region

\author{
Final Report \\ to \\ Department of Energy \\ Washington, D.C. \\ DOE Award Number: DE-FC26-03NT41723
}

Award Recipient:

Ohio University

Athens, Ohio 
Reporting Period Start Date Reporting Period End Date

Principal Author:

Issued Date

DOE Award Number:

Contractor:

Subcontractors:
April 2, 2003

December 31, 2008

Kevin Crist

Ohio University

June 2010

DE-FC26-03NT41723

\section{Ohio University}

Institute for Sustainable Energy and the Environment Building 21, The Ridges

Athens Ohio, 45701

\section{CONSOL Energy}

Research \& Development

400 Brownsville Road

South Park, PA 15129-9566

Advanced Technology Systems, Inc.

639 Alpha Drive-RIDC Park

Pittsburgh, PA 15238-2819

Atmospheric and Environmental Research, Inc.

131 Hartwell Avenue

Lexington, MA 02421-3126

\section{DISCLAIMER}

This report was prepared as an account of work sponsored by an agency of the United States Government. Neither the United States Government nor any agency thereof, nor any of their employees, makes warranty, express or implied, or assumes any legal liability or responsibility for the accuracy, completeness, or usefulness of any information, apparatus, product, or process disclosed, or represents that its use would not infringe privately owned rights. Reference herein to any specific commercial product process, or service by trade name, trademark, manufacturer, or otherwise does not necessarily constitute or imply its endorsement, recommendation, or favoring by the United States Government or any agency thereof. The views and opinions of authors expressed herein do not necessarily state or reflect those of the United States Government or any agency thereof. 


\section{TABLE OF CONTENTS}

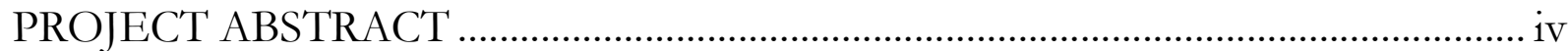

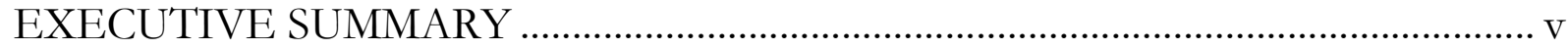

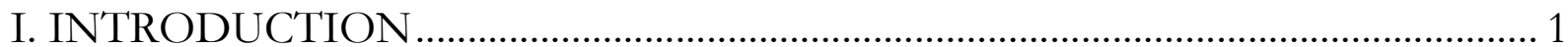

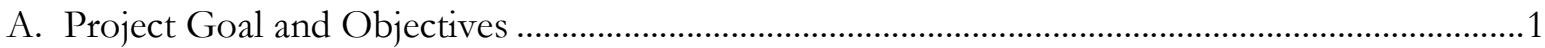

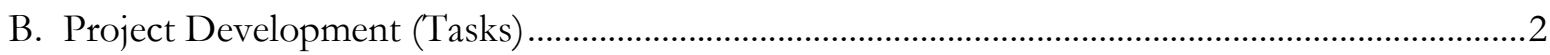

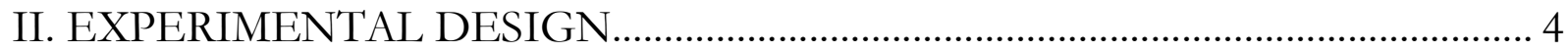

Task 1. Establish and operate a (SAM) station in Athens, Ohio ......................................................

Task 2. Refine and Update Emission Inventories (EIs) ....................................................................6

Task 2.1. Enhancing global emissions of mercury ............................................................................................

Task 3. Select and Evaluate a 3-D Regional-Scale Atmospheric Chemical Transport Model

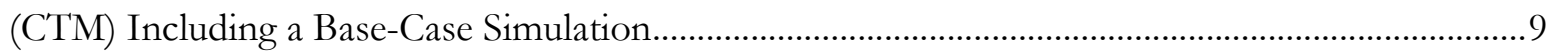

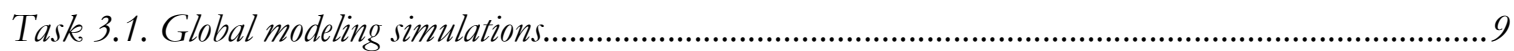

Task 3.2. Continental, regional and urban-scale modeling.......................................................................15

Task 4. Perform Short-Period Model Runs for Comparison with Field Data....................................26

Task 5. Seasonal Scale Simulations and Sensitivity Analysis.............................................................30

Task 6. Development of a Decision-Support Tool...............................................................................

Task 7. Project Management, Data Analysis, and Reporting ..........................................................39

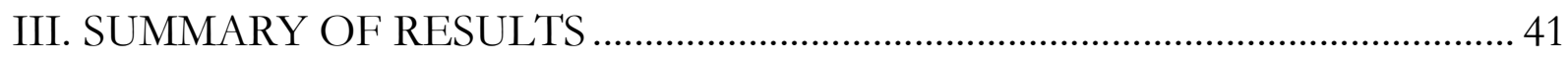

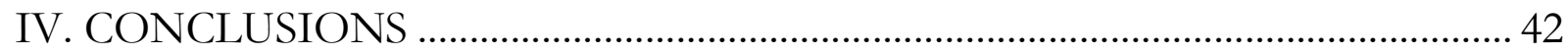

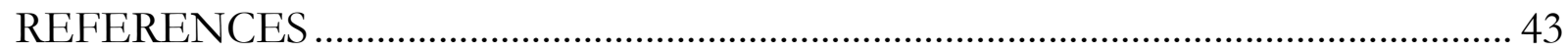

LIST OF ACRONYMNS AND ABBREVIATIONS............................................. 44

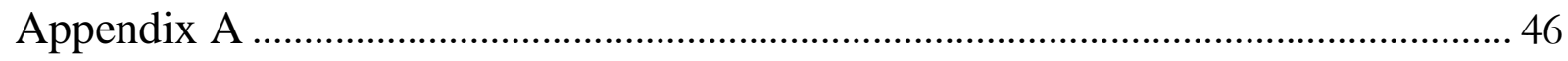

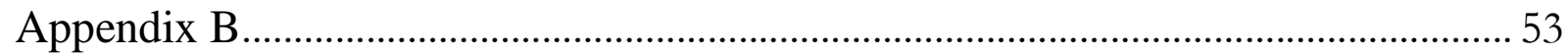

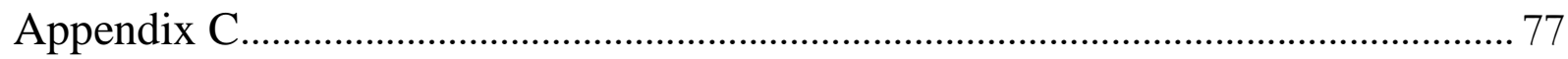




\section{LIST OF TABLES}

Table 1 Progress summary

Table 2. Seasonal mercury increase globally and within the United States based on comparisons between simulation outputs

Table 3. Summary Population (through 2004) in NEEDS 2006.

Table 4. Elemental mercury concentration range of Mozart output for CMAQ boundary conditions at surface level .18

Table 5. Deposition ( $\mathrm{\mu g} / \mathrm{m}^{2} / \mathrm{month}$ ) into the Ohio River Valley region in 2004 .18

Table 6. Seasonal model performance results for mercury wet deposition fluxes $\left(\mu \mathrm{g} / \mathrm{m}^{2}\right)$

Table 7. Percentage contribution of IPM utilities, China emissions and global background to mercury wet deposition over the Ohio Valley Region.

\section{LIST OF GRAPHICAL MATERIALS}

Figure 1. Topographical map of the Athens site: (a) regional and (b) local .. 5

Figure 2. Distribution of elemental mercury in tons/year (US 2002 HAP NEI) ................... 6

Figure 3. Distribution of RGM and $\mathrm{Hg}_{\mathrm{p}}$ in tons/year (US 2002 HAP NEI) ........................... 7

Figure 4. Total anthropogenic mercury emission with updated China emissions from Argonne.

Figure 5. Updated total mercury emission difference for all sources. (Total emission $\Delta$ $=$ Argonne - Pacyna)

Figure 6. Concentration time-series surface layer at the 24th and 28th hybrid levels for $\mathrm{Hg}^{0}$ with layer 28 being a surface level (blue and green lines are $\mathrm{KZ}$ filter curves).....11

Figure 7. Seasonal variation of $\mathrm{Hg}^{0}$ depicted using episodes in January 15, May 14, July 15 and October 5 to represent winter, spring, summer and autumn respectively......12

Figure 8. Percent difference in $\mathrm{Hg}^{0}$ concentrations between a simulation using the $\mathrm{Hg}^{0}$ emissions estimate of Streets et al. (2006) and a simulation with no emissions from China. Results for the Northern Hemisphere are shown at the model surface in winter (upper left), spring (upper right), summer (lower left), and autumn (lower right) (Taken from Drewniak et al, 2008).

Figure 9. Percent differences in RGM wet deposition in winter (upper left), spring (upper right), summer (lower left), and autumn (lower right) for the Streets and No China simulations. (Adapted from Drewniak et al, 2008). 
Figure 10. SMOKE emission results for point source emissions of IPM input data of elemental mercury $\left(\mathrm{Hg}^{0}\right)$ (left) and reactive gaseous mercury (RGM) (right) in $36 \mathrm{~km}$ grid resolution

Figure 11. SMOKE emission results for point source emissions of IPM input data of particulate mercury $\left(\mathrm{Hg}_{\mathrm{P}}\right)$ in $36 \mathrm{~km}$ grid resolution

Figure 12. MM5 and CMAQ $36 \mathrm{~km}$ model domain in Lambert Conformal Projection.

Figure 13. Comparison of MDN observations (left) and CMAQ modeling results (right) for mercury wet deposition during months of January, April, July and October in 2004

Figure 14. RGM wet, dry and total deposition of CMAQ results for January (left) and April (right) 2004.

Figure 15. RGM wet, dry and total deposition of CMAQ results for July (left) and October (right) 2004

Figure 16. Particulate mercury dry deposition of CMAQ results for January, April, July, and October 2004.

Figure 17. Scatter plot of CMAQ simulation results and observed MDN data for January (top left), April (top right), July (bottom left) and October (bottom right) 2004

Figure 18. Time series comparison of observations with modeled $\mathrm{Hg}_{0}$ for Oct. 2004 _.........27

Figure 19. Regression of observations with modeled $\mathrm{Hg}_{0}$ for Oct. 2004.

Figure 20. Spatial distribution of modeled PM2.5 concentration for short-term CTM runs. Upper-left is Jul. 22, 2004 with southeasterly winds predominant; upper-right is Aug. 15, 2004 westerly winds; Bottom-left Sept. 5, 2004 with southwesterly winds; and bottom-right Sept. 13, 2004, northeasterly winds.

Figure 21. Time series comparison of observations with modeled $\mathrm{PM}_{2.5} \ldots \ldots \ldots \ldots \ldots \ldots \ldots \ldots \ldots . . . .29$

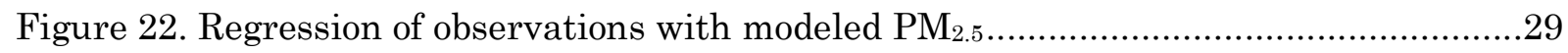

Figure 23. Total deposition \% difference with zero-out power generation utilities contributions

Figure 24. Total deposition \% difference with zero-out Global contributions.........................32

Figure 25. Total deposition \% difference with China zero-out. ............................................33

Figure 26. Schematic flowchart of web-based emission data management and mapping system

Figure 27. Spatial distribution of 4-km grid-based emission for area source category on Google Map.

Figure 28. Spatial distribution of county-based emissions on Google Map. .........................36

Figure 29. Online forecasting tool used for Cincinnati area forecasting.. ............................37

Figure 30. Structure of air quality mapping website and online forecasting tool. ................38 


\section{PROJECT ABSTRACT}

As stated in the proposal: Ohio University, in collaboration with CONSOL Energy, Advanced Technology Systems, Inc (ATS) and Atmospheric and Environmental Research, Inc. (AER) as subcontractors, evaluated the impact of emissions from coal-fired power plants in the Ohio River Valley region as they relate to the transport and deposition of mercury and associated fine particulate matter. This evaluation involved two interrelated areas of effort: ambient air monitoring and regional-scale modeling analysis.

The scope of work for the ambient air monitoring included the deployment of a surface air monitoring (SAM) station in southeastern Ohio. The SAM station contains sampling equipment to collect and measure mercury (including speciated forms of mercury and wet and dry deposited mercury), particulate matter (PM) mass, PM composition, and gaseous criteria pollutants $\left(\mathrm{CO}, \mathrm{NO}_{\mathrm{x}}, \mathrm{SO}_{2}, \mathrm{O}_{3}\right.$, etc.). Laboratory analyses of time-integrated samples were used to obtain chemical speciation of ambient PM composition and mercury in precipitation. Nearreal-time measurements were used to measure the ambient concentrations of PM mass and all gaseous species including $\mathrm{Hg}^{0}$ and RGM. Approximately 30 months of field data were collected at the SAM site to validate the proposed regional model simulations for episodic and seasonal model runs. The ambient air quality data provides mercury, and fine particulate matter data that can be used by Ohio Valley industries to assess performance on multi-pollutant control systems.

The scope of work for the modeling analysis includes (1) development of updated inventories of mercury emissions from coal plants and other important sources in the modeled domain; (2) adapting an existing 3-D atmospheric chemical transport model to incorporate recent advancements in the understanding of mercury transformations in the atmosphere; (3) analyses of the flux of $\mathrm{Hg}^{0}, \mathrm{RGM}$, and fine particulate matter in the different sectors of the study region to identify key transport mechanisms; (4) comparison of cross correlations between species from the model results to observations in order to evaluate characteristics of specific air masses associated with long-range transport from a specified source region; and (5) evaluation of the sensitivity of these correlations to emissions from regions along the transport path. This is accomplished by multiple model runs with emissions simulations switched on and off from the various source regions.

To the greatest extent possible, model results were compared to field data collected at other air monitoring sites in the Ohio Valley region, operated independently of this project. These sites may include (1) the DOE National Energy Technologies Laboratory's monitoring site at its suburban Pittsburgh, PA facility; (2) sites in Pittsburgh (Lawrenceville) PA and Holbrook, PA operated by ATS; (3) sites in Steubenville, OH and Pittsburgh, PA operated by the USEPA and/or its contractors; and (4) sites operated by State or local air regulatory agencies. Field verification of model results and predictions provides critical information for the development of cost effective air pollution control strategies by the coal-fired power plants in the Ohio River Valley region. 


\section{EXECUTIVE SUMMARY}

Ohio University performed a Cooperative Agreement with the U.S. Department of Energy's National Energy Technology Laboratory (DOE-NETL) to conduct regional-scale modeling analysis and ambient air monitoring that will provide critical information for the development of relevant and cost effective control strategies by the coal-fired power plants in the Ohio River Valley region.

Researchers developed a comprehensive budget of elemental mercury $\left(\mathrm{Hg}^{0}\right)$, reactive gaseous mercury (RGM), and fine particulate matter across the Ohio Valley region, including sources, sinks, atmospheric lifetimes, burdens, and advective fluxes using a regional scale model. In addition, updated global emissions inventories for mercury were utilized to support the regional modeling studies. A comprehensive surface air monitoring (SAM) site was developed and operated in southeastern Ohio. The SAM site has the capability of monitoring mercury speciation in ambient air and in precipitation, and it contains a full range of instrumentation for measuring the composition of fine particulate matter and co-pollutant gases. Short-term and seasonal simulations with the refined model were compared to field measurements from the monitoring site, and the results are being used to develop a decision-support tool. A supplemental objective of the analysis was to evaluate the impacts of long-range transport from regions outside the Ohio Valley on the measured and modeled reactive and total mercury concentration levels in the Ohio Valley region.

The effort has been broken down into the following seven separate tasks.

Task 1 consists of establishing and operating the SAM site in southeastern Ohio. Under this project, the SAM site has been set up; routine sampling was initiated on March 1, 2004; and data collection occurred through November of 2005. Consol Coal has completed analysis on the filter samples through November 2005. Additional sampling was extended through 2008 and the QA/QC data is supplied in the attached CD.

Task 2 involves the refinement and update of emission inventories (EIs) for sources of mercury within and upwind of the modeled domain. The Institute for Sustainable Energy and the Environment (ISEE) at Ohio University collected and processed that emissions information into the model structure throughout the modeling effort. In addition updated mercury emissions for China were obtained through an external partnership with Argonne National Laboratory.

Task 3 consists of the selection and evaluation of a 3-D regional-scale chemical transport model (CTM) for an application focused on the Ohio River Valley region. The Chemical Transport Model CMAQ (Community Multiscale Air Quality) model was used in this project.

Task 4 consists of short-period model simulations for comparison with field data. The summer of 2001 was used for initial comparisons because of the extensive field data on particulate matter and co-pollutants available from the DOE-sponsored Pittsburgh Air Quality Study. The ambient monitoring fine particulate data (PM sulfate and PM nitrate) from the Pittsburgh site and other USEPA-sponsored air quality sites was used to calibrate the short-term atmospheric chemistry model (refer to Semi-Annual Technical Report \# 3). Meteorological modeling, which supported the short-period runs, was completed and evaluated against ground based meteorological monitoring stations throughout the model domain. During this project 
period, the chemical transport model evaluations on the $4 \mathrm{~km}$ grid domain were completed for $\mathrm{PM}_{2.5}$ concentrations. In addition, box model evaluations (evaluate gas phase and liquid phase mercury schemes) were performed using gas phase mercury monitoring data from the Athens monitoring site. Argonne National Laboratory completed global model runs which were used to generate boundary conditions for the regional CMAQ model Using these boundary conditions, short term simulations for mercury were completed and then evaluated against gas phase monitoring and wet deposition sampling data.

Task 5 involves seasonal-scale simulations focusing on the identification of significant sources and source regions contributing to the deposition of mercury. The project team completed seasonal photochemical modeling simulations for the summer of 2004. This is the time period during which the SAM at Athens became operational. The quality and availability of these data are important in the decision-making processes and for confidence in the results arising from the air quality modeling applications. One of the significant components of this task is meteorological modeling simulations since the simulated meteorological variables are an essential input to the photochemical model.

The research team completed the meteorological model runs for 2004. In addition the nested grid for the modeling system was completed. Once the researchers from Argonne national lab finalize the global model runs the seasonal scale model runs will be completed. The modeling will examine the efficacy of emission reduction strategies specifically for coal-fired power plants. In addition, researchers conducted an analysis of long-range transport from regions outside the Ohio Valley of elemental $\mathrm{Hg}$ on the measured and modeled reactive and total mercury in the Ohio Valley region.

Task 6 consists of the development of Web-based model interface technologies to provide industry and government agencies with a user-friendly to facilitate the evaluation of source-receptor relationships. Utilizing the data analysis, obtained from this study, a detailed web based forecasting tool was developed and is currently being utilized by Government agencies in Ohio.

Task 7 consists of project management, data analysis, and reporting functions. Specific accomplishments included the development of a series of journal articles on analysis of the data obtained from the monitoring site and modeling efforts. 


\section{INTRODUCTION}

From the proposal: Ohio University performed a Cooperative Agreement with the U.S. Department of Energy's National Energy Technology Laboratory (DOE-NETL) to conduct regional-scale modeling analysis and ambient air monitoring that will provide critical information for the development of relevant and cost effective control strategies by the coal-fired power plants in the Ohio River Valley Region.

Coal flue gas contains a variety of hazardous air pollutants (HAPs), including organic and inorganic chemical compounds. Among the latter, mercury is of particular concern because of their toxicity to humans and animals. An understanding of the chemistry should be the basis of proposed legislation to regulate mercury emissions since specific chemical species will account for differences in human toxicity, rate of transport through the ecosystem, and the design variations in possible emission control schemes.

Mercury matter can be transported over large distances due to their minimal rate of sedimentation. In particular, mercury transport must be considered a global problem. Elemental mercury is believed to have a half-life of approximately one year in the atmosphere, and little is known about its cyclic transport between land, water, and air. Biogenic transport and biogenic sources are even less well understood. Therefore, the ISEE will adopt a regional scale approach for adequate evaluation of source-receptor relationships for mercury. Our approach in evaluating the impact of mercury emissions from coal-fired power plants and other sources is to examine the source-receptor relationship through ambient monitoring and regional scale modeling.

\section{A. Project Goal and Objectives}

From the proposal: The overall objective of the project is to quantitatively evaluate the emission, transport, and deposition of mercury, and fine particulate matter (PM), in the Ohio River Valley region. This evaluation involves two interrelated areas of effort: regional-scale modeling analysis and ambient air monitoring.

The objective of the regional modeling studies was to develop a comprehensive budget of elemental mercury $\left(\mathrm{Hg}^{0}\right)$ and reactive gaseous mercury (RGM), and fine particulate matter including sources, sinks, atmospheric lifetimes, burdens, and advective fluxes across the Ohio Valley Region. To support this objective, project researchers developed and updated emissions inventories for mercury. The second objective was to develop an air-monitoring site in Athens, Ohio to provide the capability to monitor mercury in ambient air and in precipitation. Researchers compared the refined model's short-term and seasonal simulations to field measurements. A supplemental objective of the analysis was to evaluate the impacts of longrange transport from regions outside the Ohio Valley as well as electricity generation utilities source of $\mathrm{Hg}$ on the measured and modeled reactive and total mercury concentration levels in the region. 


\section{B. Project Development (Tasks)}

Seven separate tasks were completed for this project:

- Task 1 consists of establishing and operating a Stationary Ambient Monitoring (SAM) site in Athens, Ohio. Routine sampling was initiated on March 1, 2004 and continued through December, 2008.

- Task 2 involves the refinement and update of EIs for sources of mercury within and upwind of the modeled domain. The project team collected Mexico and Canada mercury emissions and processed into the model structure throughout the modeling effort. In addition, researchers updated the EI for mercury with new China emissions data developed by David Streets of Argonne National Laboratory.

- Task 3 consists of the selection and evaluation of a 3-D regional-scale chemical transport model (CTM) using CMAQ (Byun and Ching, 1999) for an application focused on the Ohio River Valley region. A $36 \times 36 \mathrm{~km}$ grid system was used for mercury and $36 \mathrm{~km}$ coarse domain and $12-\mathrm{km}$ and $4-\mathrm{km}$ nested domains were employed for $\mathrm{PM}_{2.5}$. The project team completed short-term and seasonal base-case simulations for North America for the year 2004.

- Task 4 consists of conducting short-period base case model runs for comparison with field data. A short-term modeling run has been completed for July 2001 for the eastern United States for mercury and $\mathrm{PM}_{2.5}$. The simulations for mercury and $\mathrm{PM}_{2.5}$ were conducted with the photochemical model CMAQ. For initial comparisons, the project team used Athens SAM mercury species and wet deposition measurements for mercury observation and particulate sulfate and nitrate data collected during the summer of 2004 from the DOE-funded Pittsburgh Air Quality Study for $\mathrm{PM}_{2.5}$ observation. Model evaluations were performed using statistical evaluation tools. In addition, box model (chemistry only) evaluations were performed using data from the Athens Supersite.

- Task 5 involves seasonal-scale simulations that focus on the identification of significant sources and source regions contributing to the deposition and ambient concentrations of mercury over periods of seasonal months. The project team completed base case for the seasonal months (January, April, July, and October) which represent winter, spring, summer, and autumn. After the base case and model verification process, we performed three scenarios that indicated zero-out runs for electrical generation utilities, global background concentration, and China emissions to evaluate source contribution from each source to mercury wet/dry deposition over the Ohio River Valley region.

- Task 6 consists of the development of Web-based model interface technologies to provide industry and government agencies with a user-friendly decision-support tool 
to facilitate the evaluation of source-receptor relationships that led to the development of a detailed forecasting tool.

- Task 7 consists of project management, data analysis, and reporting functions.

Below is a progress summary for each task.

Table 1 Progress summary

\begin{tabular}{|c|l|c|c|}
\hline Task \# & \multicolumn{1}{|c|}{ Description } & $\begin{array}{c}\text { Planned \% } \\
\text { Completed }\end{array}$ & $\begin{array}{c}\text { Actual \% } \\
\text { Completed }\end{array}$ \\
\hline 1 & SAM & 100 & 100 \\
\hline 2 & Emission Inventories & 100 & 100 \\
\hline 3 & Base Case CTM Simulation & 100 & 100 \\
\hline 4 & Short Term Model Evaluation & 100 & 100 \\
\hline 5 & Seasonal Scale Simulations & 100 & 100 \\
\hline 6 & Development of Support Tool & 100 & 100 \\
\hline 7 & Project Management & 100 & 100 \\
\hline
\end{tabular}




\section{EXPERIMENTAL DESIGN}

In this section, the description of each task is presented as it was proposed in the funding application. Following the description is a discussion of the progress made toward completing the task.

\section{Task 1. Establish and operate a (SAM) station in Athens, Ohio}

The proposal for this project designated that the ISEE would establish a SAM station in Steubenville, Ohio. However, prior to April 3, 2003 the Environmental Protection Agency set up a SAM station in Steubenville that has the capacity to monitor for mercury. Consequently, the ISEE was able to select another site for the SAM station proposed for this project. The project staff located an optimal site south of Athens, Ohio in the heart of the Ohio River Valley. At an elevation of 950 feet, the site is the highest point within a 100-mile radius to the east, south, and west (Figure 1). It is an excellent site from which to capture the transport of pollutants into and out of the valley.

The Athens site utilizes air-monitoring equipment from the Steubenville Comprehensive Air Monitoring Project (SCAMP), sponsored by DOE-NETL under Cooperative Agreement DEFC26-00NT40771. In addition, the site includes sampling equipment for collecting and measuring mercury, including total, elemental, reactive, particulate, and wet/dry deposition.

\section{Accomplishments:}

Two primary objectives during this period were to

- Enhance data QA/QC recovery and continue analysis

- Disseminate preliminary data by attending conferences and preparing publications

Under the DOE contract the ambient monitoring was concluded in November 2005. The site has been expanded under an USEPA contract to include the installation of a $\mathrm{NO}_{\mathrm{y}}$, low level $\mathrm{CO}$, and additional equipment to support regional haze evaluations. Consol Energy R\&D has finalized the analysis of the filter samples generated over the 18 month sampling period. Also the operation of the real time monitors was extended through 2008 under an USEPA grant. Researchers at the ISEE, analyzed all the sampling data and have numerous papers submitted and under development based on the analysis (refer to task 7). In addition, the QA/QC data set from the monitoring site was submitted with this report in an attached $\mathrm{CD}$. The $\mathrm{CD}$ also contains summary of instrumentation and basic data analyses of gaseous pollutants, meteorological data and fine particulate matter $\left(\mathrm{PM}_{2.5}\right)$ collected through the period of 2004 to 2008. Key findings and analyses of the monitoring data at Athens were published in Yatavelli et al. (2006). Sourceapportionment modeling was also executed to identify the sources of $\mathrm{PM}_{2.5}$, retrieved at the site and can be found in a peer reviewed publication (Kim et al., 2007). 


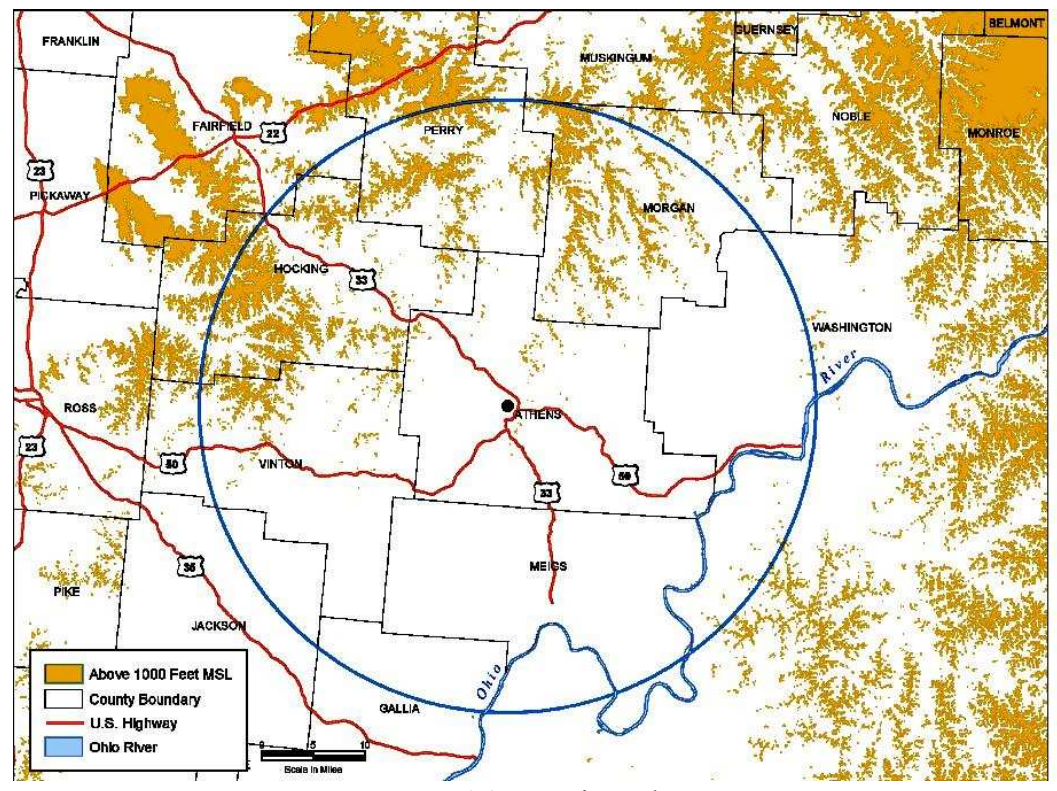

(a) Regional

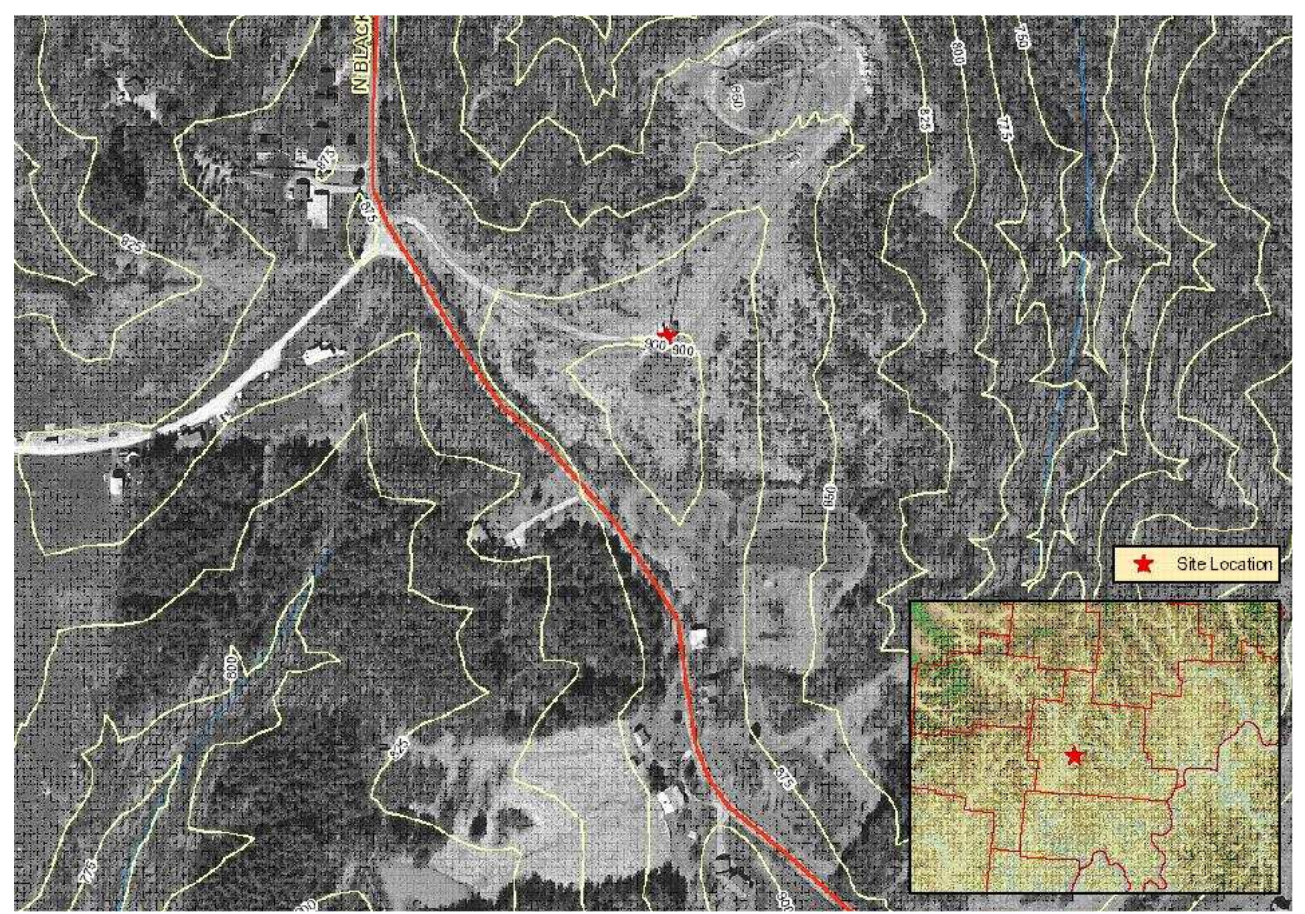

(b) Local

Figure 1. Topographical map of the Athens site: (a) regional and (b) local 


\section{Task 2. Refine and Update Emission Inventories (EIs)}

\section{Accomplishments:}

Regional mercury emission inventories as well as global estimates of mercury emissions were evaluated. The detailed analysis and results are documented in Appendix A. Emission inventories evaluated in this task were used to provide inputs for the regional and global modeling.

The USEPA 2002 National Emissions Inventory (NEI) and 2000 Canadian inventory were investigated for mercury species. The 2002 NEI including category air pollutants (CAP) and hazardous air pollutants (HAP) has been downloaded. As compared to 1999 NEI, the 2002 HAP NEI contained aggregated mercury emissions for source classification codes (SCC) as well as individual mercury species that have substantially different fate and transport characteristics which strongly affect the mercury modeling results. Figures 2 to 3 show spatial distributions of the three mercury species $\left(\mathrm{Hg}^{0}, \mathrm{RGM}\right.$, and $\left.\mathrm{Hg}_{\mathrm{p}}\right)$ within the $4 \mathrm{~km}$ grid domain that encompasses the Ohio River Valley (ORV) region. The research team set up the Sparse Matrix Operator Kernel Emissions Model (SMOKE) to process these emissions for input to CMAQ-Hg chemical transport modeling framework.

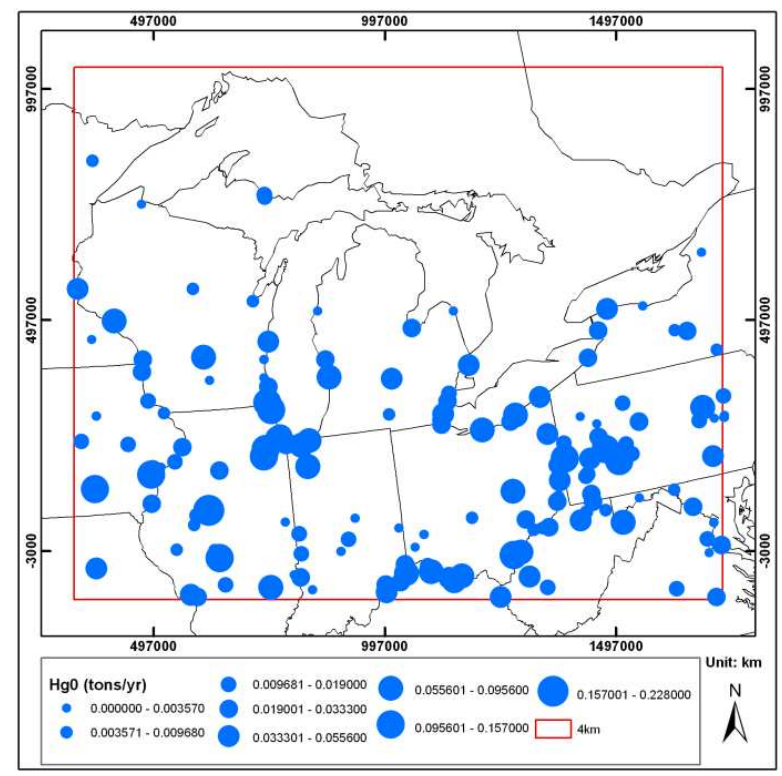

Figure 2. Distribution of elemental mercury in tons/year (US 2002 HAP NEI) 

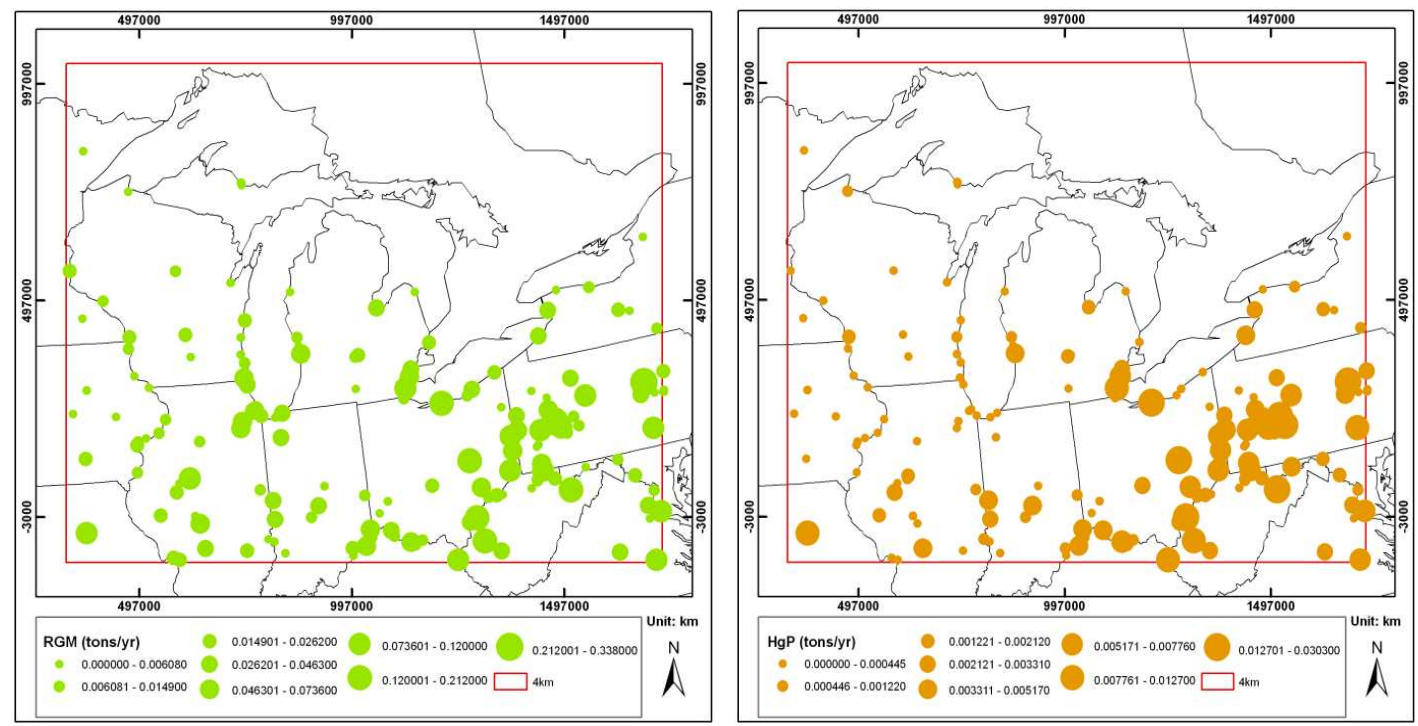

Figure 3. Distribution of RGM and $\mathrm{Hg}_{\mathrm{p}}$ in tons/year (US $2002 \mathrm{HAP}$ NEI)

\section{Task 2.1. Enhancing global emissions of mercury}

For better understanding of the transport and fate of mercury at the regional and urban scale, it is of critical importance to investigate the global background mercury since mercury transports and transforms in the atmosphere from very short (Schroeder \& Munthe, 1998) to very large temporal and spatial scales (1-2 years lifetime of elemental Hg) (Fitzgerald, 1989). Pacyna and Pacyna (2002) investigated global mercury emissions and estimated that China's emissions from coal combustion contributed more than $25 \%$ to total global emissions. Argonne National Laboratory has been actively engaged in developing a new emissions inventory of mercury for China (Streets et al., 2005), which is considered to be a high emitter of mercury.

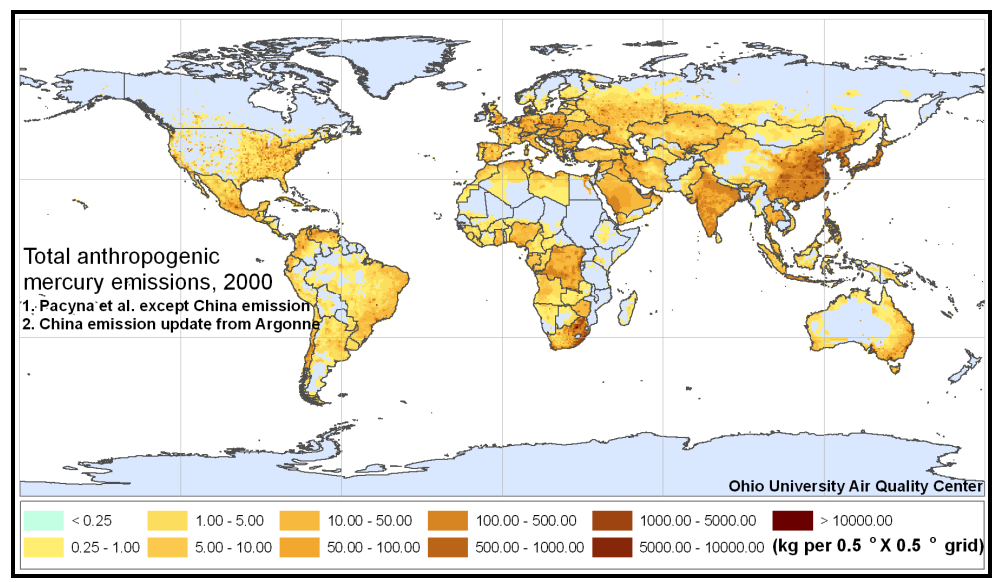

Figure 4. Total anthropogenic mercury emission with updated China emissions from Argonne.

The OU ISEE cooperated with Argonne, in order to employ the updated China emissions for use in global chemical transport simulation and thus provide better-estimated global background concentrations and their temporal variations for the regional CTM for the Ohio 
River Valley area. In this task, Ohio University ISEE investigated the difference between the China emissions estimated by Pacyna and Argonne as depicted in Figure 5.

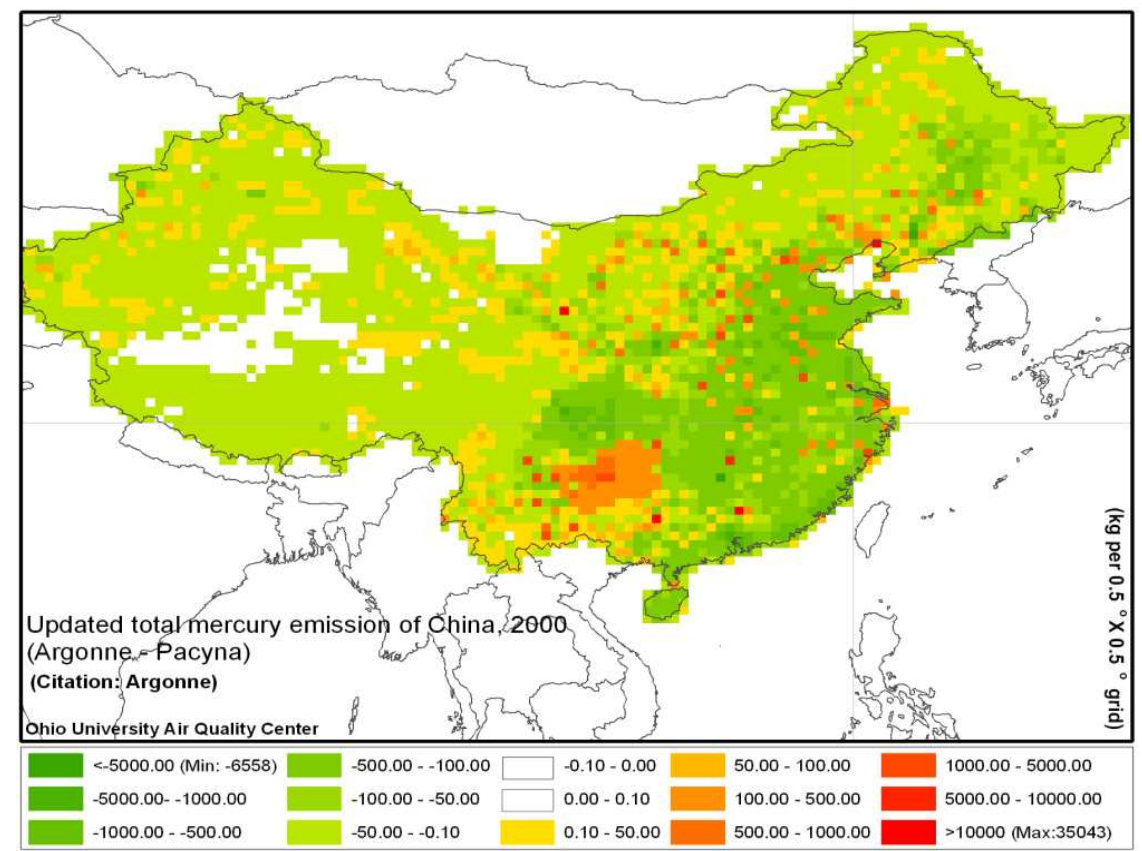

Figure 5. Updated total mercury emission difference for all sources. (Total emission $\Delta=$ Argonne - Pacyna)

The major differences between the two estimates of China emissions are noted below:

- All sources (Point source + distributed source): Argonne's mercury emission estimation for all sources was less than Pacyna's estimation by $16.5 \%, 18.9 \%, 20.1 \%$, for total mercury, elemental mercury $\left(\mathrm{Hg}^{0}\right)$ and reactive gaseous mercury (RGM), respectively. In contrast, particulate mercury $\left(\mathrm{Hg}_{\mathrm{p}}\right)$ estimated by Argonne increased by $14.4 \%$.

- Point sources: Significantly higher point source emission estimations were observed for Argonne which revealed enhancements by $135.4 \%, 90.6 \%, 386.8 \%$, and $98.4 \%$ for total mercury, $\mathrm{Hg}^{0}, \mathrm{RGM}$, and $\mathrm{Hg}_{\mathrm{p}}$, respectively relative to Pacyna's results.

- Distributed sources (area sources): Unlike the point sources results, Pacyna's emission estimates superseded Argonne's for the distributed source category. The breakdown shows an enhancement of $38.8 \%, 42.4 \%$, and $45.0 \%$, for total mercury, $\mathrm{Hg}^{0}$, and RGM, respectively. $\mathrm{Hg}_{\mathrm{p}}$ estimation for Argonne displayed a 7.6\% elevation relative to Pacyna's estimation.

These emission inventories with revised China emissions were used for MOZART 3D (Horowitz et al., 2003) global modeling to provide temporal variability of initial and background concentration for regional mercury transport modeling. Further, the research team performed sensitivity analyses to evaluate the impact of the revised China emissions on the ambient mercury species and wet deposition level in the ORV region. 


\section{Task 3. Select and Evaluate a 3-D Regional-Scale Atmospheric Chemical Transport Model (CTM) Including a Base-Case Simulation}

\section{Accomplishments:}

Global simulation of mercury species was executed to comprehend the mercury fate and transport at the global scale as well as to provide mercury background concentrations for input to regional modeling system. The detailed analyses of the global simulation results are documented in a published manuscript (Drewniak et al., 2008) and attached in Appendix B. The regional modeling was performed using CMAQ which is a chemical transport model implemented in this study to evaluate the impact of urban and regional sources of mercury on the Ohio River Valley region.

\section{Task 3.1. Global modeling simulations}

Increase in mercury concentrations in the Ohio River Valley and its surrounding areas is a major concern now and have piqued much interest. As such regulatory bodies and researchers have initiated studies to identify likely emission sources of $\mathrm{Hg}$ and consequently reduction of the toxic substance entering the water bodies. Cohen et al (2004) examined the atmospheric transport and deposition of $\mathrm{Hg}$ emitted from regional direct anthropogenic sources and concluded that coal combustion is a major contributor of $\mathrm{Hg}$ to water bodies. However global modelling studies have shown that long-range trans-continental transport of elemental $\mathrm{Hg}$ influences domestic $\mathrm{Hg}$ levels within the United States as well as regions that contains no significant emissions sources of $\mathrm{Hg}$ (Drewniak et al., 2008 \& Seigneur et al., 2004). Selin et al (2008) concurred, suggesting that most of the RGM deposited within the United States originated from the global $\mathrm{Hg}$ pool.

In this task, Model for Ozone and Related Chemical Tracers (MOZART) was employed by Argonne to evaluate the fate of long-range inter-continental transport of mercury and thus estimate its impact on North America by comparing simulations on the following emission scenerios:

- Global emissions obtained from Pacyna et al. (2002)

- China emissions in Pacyna et al. (2002) was substituted using Streets et al. (2005) estimates

- Zero -out China emissions in Pacyna et al. (2002)

In addition, the global mercury simulation can provide temporal variations of background and initial conditions for regional mercury transport model whereas typical chemical transport models have used a predetermined constant value (e.g. $1.56 \mathrm{ng} / \mathrm{m}^{3}$ for the surface layer) for the background and initial concentrations.

OU ISEE and Argonne investigated the temporal and spatial characteristics of the influence of global mercury on North America. These analyses were published in Drewniak et al. (2008) and are attached in Appendix B. The followings are the model configuration and results. 


\section{MOZART Model Setup}

- Resolution: $128 \times 64$ grid boxes and 28 hybrid vertical levels with a resolution of $2.8^{\circ}$ latitude $\times 2.8^{\circ}$ longitude

- Mercury emission estimates: Global emissions estimated by Pacyna et al. (2002), Sensitivity simulations in Pacyna's estimates with zero-out China emissions and Streets's estimates for China

- Meteorological database: Anthropogenic species emission fluxes were based on the Emission Database for Global Atmospheric Research (EDGAR).

- Platform: MOZART-2

- Chemical Module:

- MOZART Chemical Transport Model with CB-IV (Carbon bond-4)

- Mercury chemistry was factored into CB-IV

The emissions were gridded to conform to the MOZART horizontal resolution of T42 and converted to NetCDF format for use in the model. Dynamic forcing for the year 2004 obtained from National Centers for Environmental Prediction (NCEP) reanalysis was used to drive the model. The model initial conditions for elemental mercury and reactive gaseous mercury were set to zero for an initialization run. A full year simulation was completed on the Argonne Jazz computing cluster using 16 nodes. The model output on the last day of simulation (December 31, 2004) was then used to initialize a separate run for the year 2004.

\section{MOZART Mercury Chemistry}

Two mercury species are incorporated into the model; $\mathrm{Hg}^{0}$ and RGM. Atmospheric chemistry for $\mathrm{Hg}$ is included in MOZART for $\mathrm{Hg}^{0}$. The following reactions of $\mathrm{Hg}^{0}$ with $\mathrm{O}_{3}, \mathrm{HCl}$, $\mathrm{Cl}_{2}, \mathrm{H}_{2} \mathrm{O}_{2}$, and $\mathrm{OH}$ are included:

$$
\begin{aligned}
& \mathrm{Hg}^{0}+\mathrm{O}_{3} \rightarrow \mathrm{Hg}(\mathrm{II})+\mathrm{O}_{2} \ldots \\
& \mathrm{Hg}^{0}+\mathrm{H}_{2} \mathrm{O}_{2} \rightarrow \mathrm{Hg}(\mathrm{OH})_{2} . \\
& \mathrm{Hg}^{0}+\mathrm{OH} \rightarrow \mathrm{Hg}(\mathrm{II}) \ldots \ldots \ldots \ldots
\end{aligned}
$$

The mercury considered was modeled as $\mathrm{Hg}^{0}$ emitted from the surface. Both dry and wet deposition for $\mathrm{Hg}^{0}$ were set to zero in the model since dry deposition of $\mathrm{Hg}^{0}$ is relatively small and it is sparingly soluble in water. For wet and dry deposition of RGM however, the model incorporated nitric acid model parameters. Hall (1995) and Drewniak et al. (2008) suggested a reaction rate of $3 \times 10^{-20}$ molec $\mathrm{cm}^{-3} \mathrm{~s}^{-1}$ for the reaction of $\mathrm{Hg}^{0}$ with ozone. The rate constant for the reaction in Equation 2 was set to $8.5 \times 10^{-19}$ molec $\mathrm{cm}^{-3} \mathrm{~s}^{-1}$ (Drewniak et al., 2008). Sommer et al. (2001) \& Drewniak et al. (2008) recommended a reaction rate of $8 \times 10^{-14}$ molec cm $\mathrm{cm}^{-3} \mathrm{~s}^{-1}$ for the reaction in Equation 3. 


\section{$\underline{\text { MOZART Simulation Results }}$}

\section{Elemental Mercury}

The time-series of the MOZART simulated daily $\mathrm{Hg}^{0}$ concentration for the surface layer (based on Pacyna's global emissions modified with Streets's estimates for China) is depicted in Figure 6. For layers closest to the surface, a lowering of the concentrations of $\mathrm{Hg}^{0}$ in summer to a minimum of $1.5 \mathrm{ng} / \mathrm{m}^{3}$ was noted along with increase in the winter to a maximum of $3.2 \mathrm{ng} / \mathrm{m}^{3}$. This results from the dynamics that occurs within the mixing layer which observes a heightening of convective mixing during the warmer months due to thermal forcing. Consequently, the mixing layer extends to the lower troposphere (average global mercury concentration is approximately $1.5 \mathrm{ng} / \mathrm{m}^{3}$ ) where the turbulence within the mixing layer enhances dispersion of $\mathrm{Hg}^{0}$ and causes subsidence of $\mathrm{Hg}^{0}$ from the global pool. A decrease in the mixing height during the colder months results in reduced dispersion of air and hence, there is an elevated level of $\mathrm{Hg}^{0}$, which is a possible combination of local, regional and global contributions.

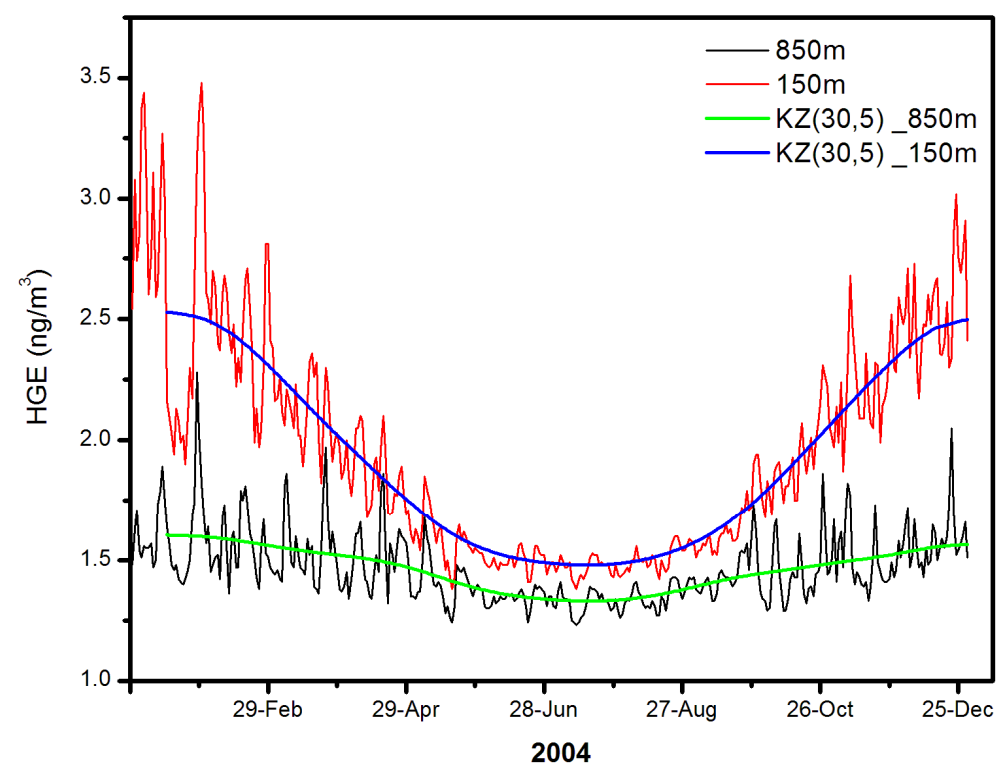

Figure 6. Concentration time-series surface layer at the 24th and 28th hybrid levels for $\mathrm{Hg}^{0}$ with layer 28 being a surface level (blue and green lines are $\mathrm{KZ}$ filter curves).

Figure 7 shows $\mathrm{Hg}^{0}$ seasonality in volume mixing ratio (VMR) globally. Four days: January 15, May 14, July 15 and October 5 were chosen to represent winter, spring, summer and autumn respectively. These days were selected to emphasize the seasonality of $\mathrm{Hg}^{0}$ with prominent trends noticeable over Asia. Significantly higher activity was simulated in July when compared to May which showed the least movement. 

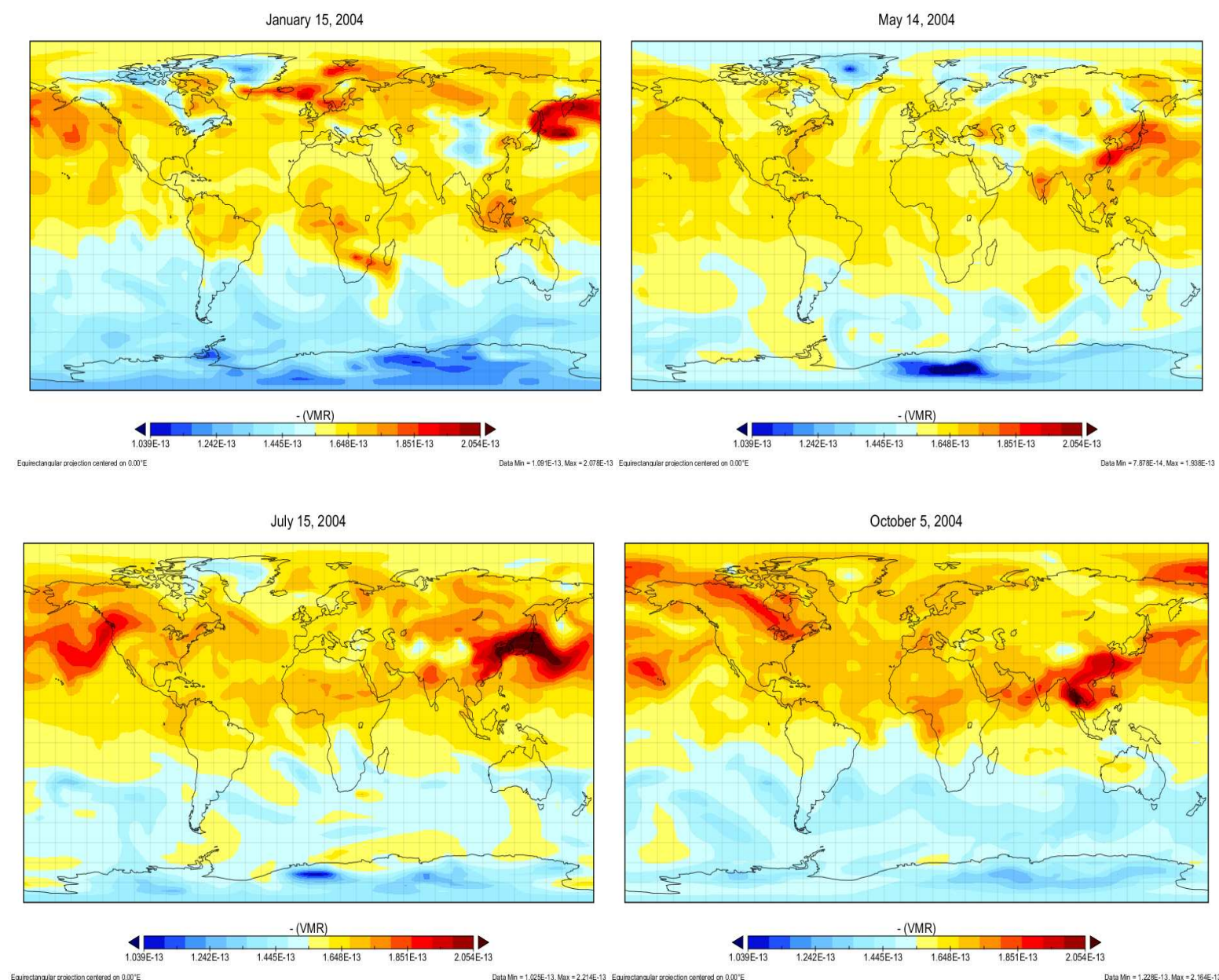

\section{(1)}

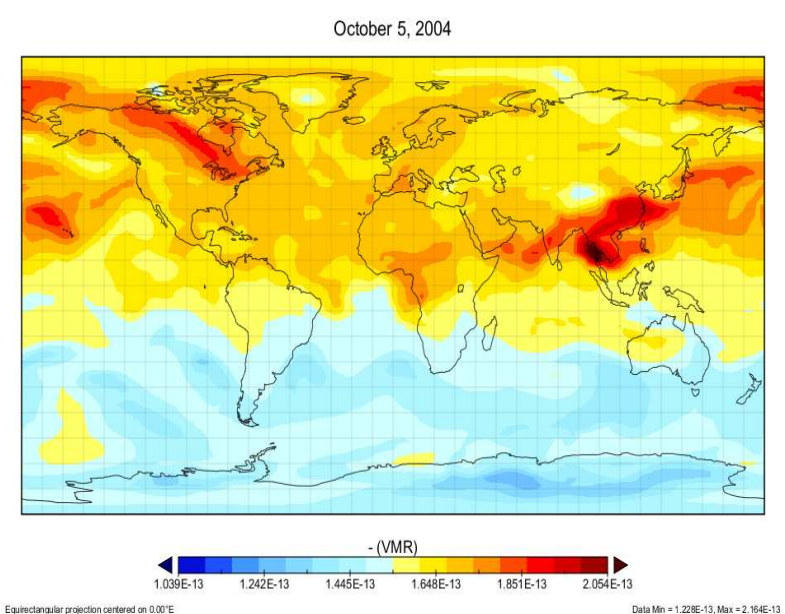

Figure 7. Seasonal variation of $\mathrm{Hg}^{0}$ depicted using episodes in January 15, May 14, July 15 and October 5 to represent winter, spring, summer and autumn respectively.

MOZART simulated seasonal averaged $\mathrm{Hg}^{0}$ concentrations at surface grid levels in the Northern Hemisphere for Pacyna's anthropogenic emission estimates showed seasonal mercury concentrations for China of upto and greater than $4 \mathrm{ng} \mathrm{m}^{-3}$ which are the highest values recorded for the surface levels.

Comparison of the simulation results for the Streets's estimates and net zero China emissions (Figure 8) at the surface levels indicated that the greatest difference was centered near China. The prevailing increase of $\mathrm{Hg}^{0}$ in the Northern Hemisphere suggests transport of the sparingly soluble substance to the United States, with elevated concentrations up to $7 \%$ in the west and 3-5\% in the East of the nation. This increase is experienced globally with an average of 3-4\%. An assessment of Pacyna and Streets simulation output also showed an increase even though the difference was smaller (Drewniak, 2008). 


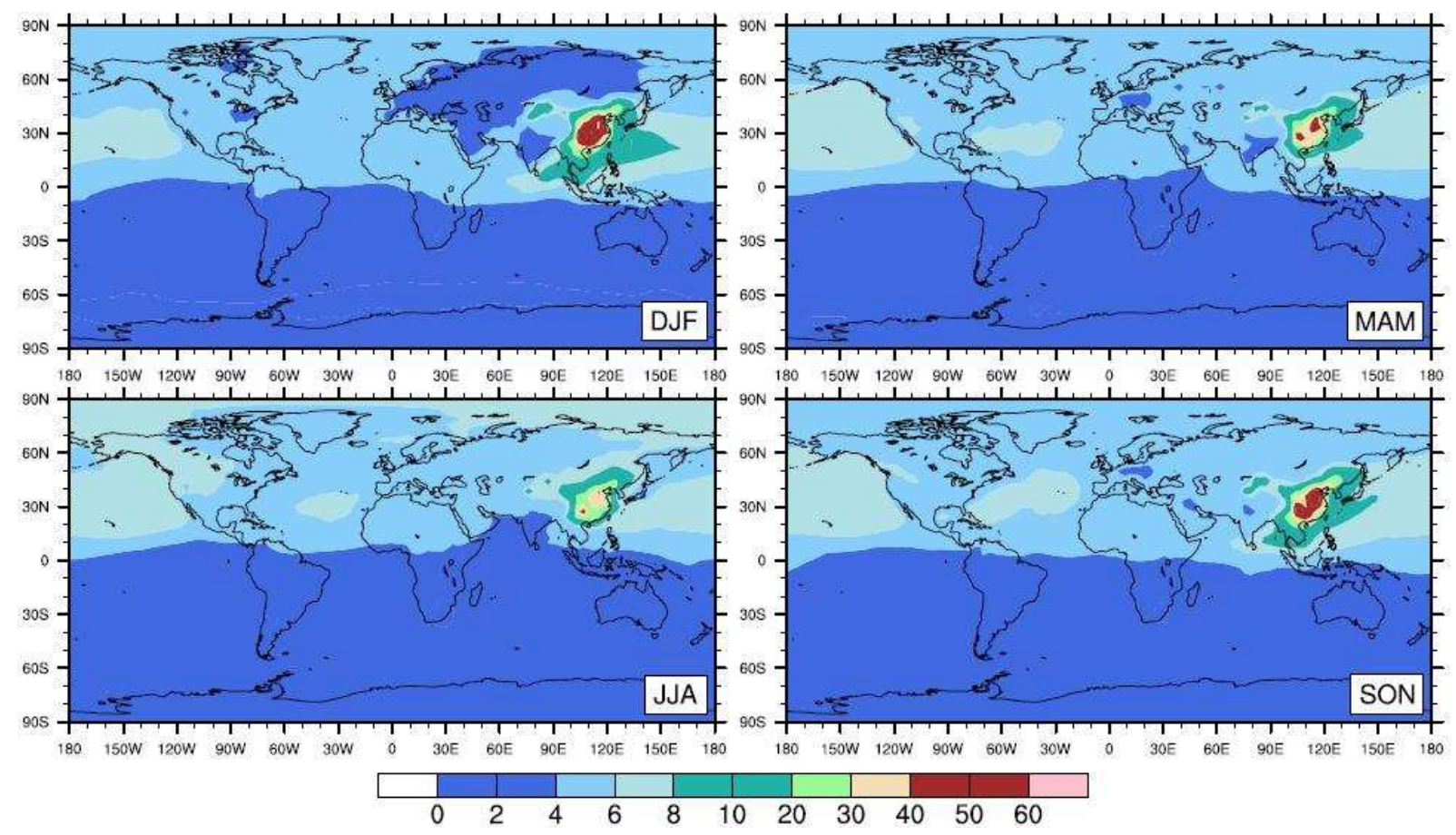

Figure 8. Percent difference in $\mathrm{Hg}^{0}$ concentrations between a simulation using the $\mathrm{Hg}^{\mathbf{0}}$ emissions estimate of Streets et al. (2006) and a simulation with no emissions from China. Results for the Northern Hemisphere are shown at the model surface in winter (upper left), spring (upper right), summer (lower left), and autumn (lower right) (Taken from Drewniak et al, 2008).

\section{$\underline{\text { Reactive Mercury }}$}

Wet and dry deposition fluxes were used to assess the MOZART simulation results for RGM. Figure 9 shows the seasonal difference in wet deposition for Streets and zero China simulations, indicating that, like $\mathrm{Hg}^{0}$, the differences were conglomerated over China (Drewniak et al, 2008). High deposition, specifically during the spring and summer, in the Northern Hemisphere were primarily due to strong winds, that caused the mercury to traverse the Pacific Ocean (Drewniak et al, 2008). Within sections of the United States, increases of 7-8\% occurred, while globally an average of $2 \%$ was recorded.

Similar results of high wet deposited mercury in Northern hemisphere during spring were noted from a comparison between simulations for estimates of Pacyna and Streets data. However, the differences over China were less. From the Pacyna-Streets evaluation, the eastern and western United States showed a 6-7\% increase while the South had a 5\% rise. Similar observations were made for dry deposition with the greatest difference in dry deposition occurring over China during winter and autumn. However, noticeable global elevations of dry deposited mercury were observed, especially in the spring. The western United States showed a rise of $7-8 \%$ during the spring and 6-7\% in the east. However, the summer observed slightly higher increases, ranging from 7-9\% in the western United States and greater than $9 \%$ in the far northwestern part of the United States. Table 2 summarizes the increases observed globally and within North America. 


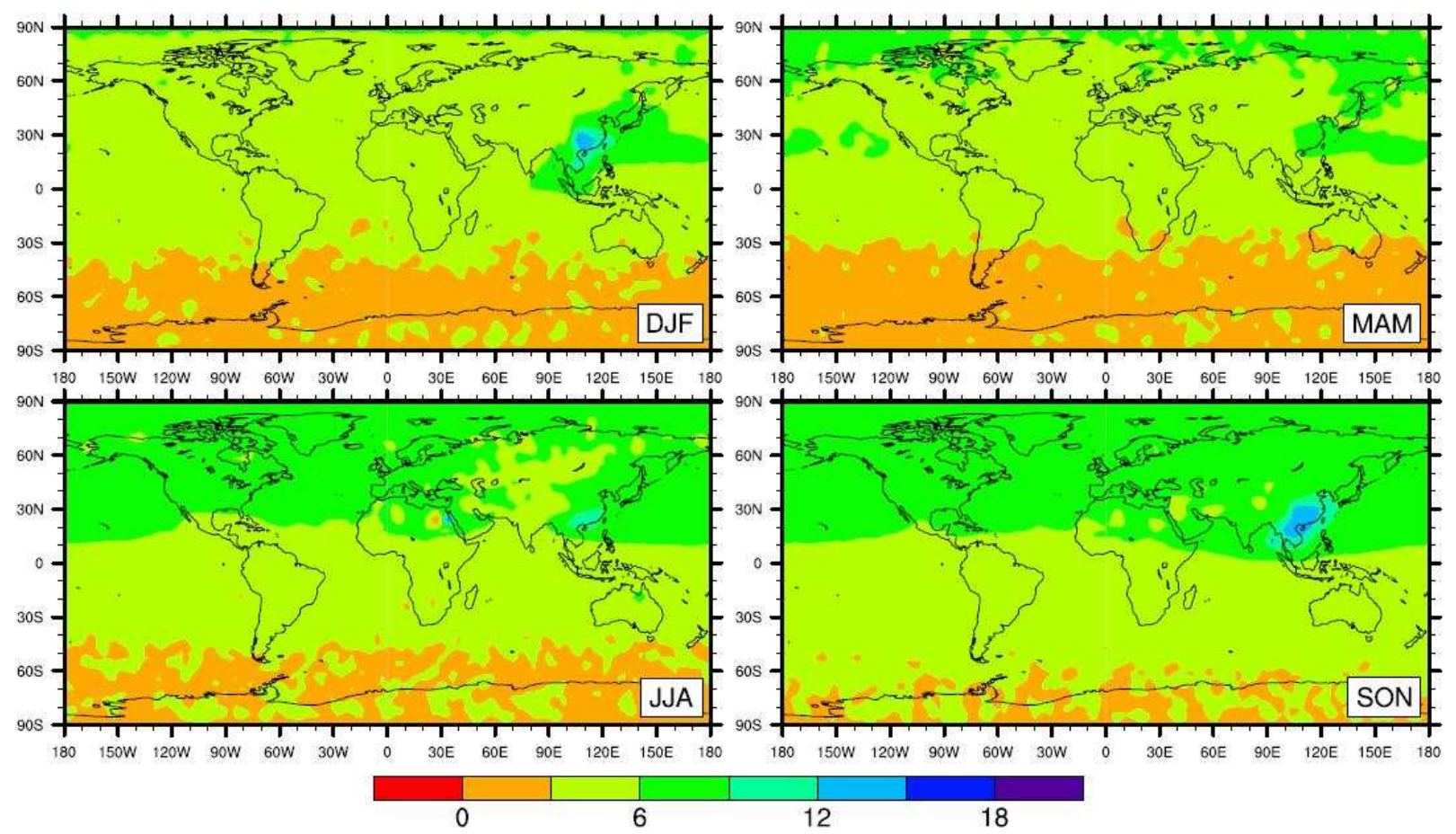

Figure 9. Percent differences in RGM wet deposition in winter (upper left), spring (upper right), summer (lower left), and autumn (lower right) for the Streets and No China simulations. (Adapted from Drewniak et al, 2008).

Table 2. Seasonal mercury increase globally and within the United States based on comparisons between simulation outputs

\begin{tabular}{|c|c|c|c|c|c|c|}
\hline Data set & Seasons & Eastern & Western & Northern & Southern & Global $\mathbf{H g}^{0}$ \\
\hline & & $\mathrm{US} \mathrm{Hg}^{0}$ & & & & \\
\hline Streets - Pacyna with No China & Spring & 7 & $3-5$ & & & $3-4$ \\
\hline & & \multicolumn{5}{|c|}{ US RGM (Wet Deposition) } \\
\hline \multirow[t]{2}{*}{ Streets - Pacyna with No China } & Spring & $7-8$ & $7-8$ & & & 2 \\
\hline & Summer & $7-8$ & $7-8$ & & & 2 \\
\hline \multirow[t]{2}{*}{ Pacyna - Streets } & Spring & $6-7$ & $6-7$ & & 5 & \\
\hline & & US RGM & Dry Depos & on) & & \\
\hline \multirow[t]{2}{*}{ Streets - No China } & Spring & $6-7$ & $3-5$ & & $<1$ & $3-4$ \\
\hline & Summer & $5-6$ & $7-9$ & & & \\
\hline \multirow[t]{2}{*}{ Pacyna - Streets } & Spring & $4-6$ & $7-9$ & & & \\
\hline & Summer & $2-6$ & & $7-10$ & & \\
\hline
\end{tabular}

Note: All the values are expressed as percentage increase of mercury during the study period

Adapted from (Drewniak et al, 2008) 


\section{Task 3.2. Continental, regional and urban-scale modeling}

Emissions Inventory

Mercury emissions inventory used in the CMAQ model was downloaded from the following sources included in the CAP and HAP 2002-Base case modeling Platform, version 3:

- National Air Toxics Assessment National Emission Inventory (NATA/NEI) version 3, draft for 2002

- North American Emissions Inventories - Canada for 2000

- Mexico National Emissions Inventory (NEI) for 1999

\section{MM5 Modeling}

The ISEE performed MM5 v3.7.0 modeling using Redhat Enterprise Linux and PGI FORTRAN compiler. This simulation was completed for the $36 \times 36 \mathrm{~km}$ grid system covering the North America for 2004. Detailed methodology is documented in the previous report.

\section{$\underline{\text { SMOKE }}$}

Meteorological and emission modeling outputs from SMOKE were used as input for CMAQ-Hg photochemical modeling. Comprehensive details of analyses and results are provided in Appendix C. Figures 10 to 11 illustrate the SMOKE processed point source emissions, at 36 $\mathrm{km}$ grid resolution for surface layer, obtained from the national emissions inventory (NEI) excluding the Integrated Planning Model (IPM) input data for $\mathrm{Hg}^{0}, \mathrm{RGM}$, and $\mathrm{Hg}_{\mathrm{p}}$. The IPM is a multi-regional, linear programming model with primary application in the power generation sector to assess long-term capacity expansion and production costing. Table 3 exhibits the list of utilities population in the IPM data. The units listed in Table 3 were treated as point sources and were used in the sensitivity analysis to exam their relative contributions to RGM deposition over North America with a focus on the Ohio River Valley region.

Table 3. Summary Population (through 2004) in NEEDS 2006

\begin{tabular}{lcc}
\hline \multicolumn{1}{c}{ Plant Type } & Number of Units & Capacity (MW) \\
\hline \hline Biomass & 130 & 2,142 \\
Coal Steam & 1,292 & 309,309 \\
Combined Cycle & 1,467 & 162,784 \\
Combustion Turbine & 5,400 & 131,369 \\
Fossil Waste & 29 & 502 \\
Geothermal & 204 & 2,103 \\
Hydro & 3,686 & 78,107 \\
IGCC & 4 & 515 \\
Landfill Gas & 609 & 950 \\
Municipal Solid Waste & 173 & 2,116 \\
Non-Fossil Waste & 74 & 521 \\
Nuclear & 104 & 100,824 \\
O/G Steam & 743 & 119,454 \\
Pumped Storage & 146 & 20,493 \\
Solar & 39 & 406 \\
Tires & 4 & 99 \\
Wind & 261 & 6,420 \\
\hline Total & 14,365 & 938,114 \\
\hline
\end{tabular}


Figures 10 and 11 reflect emission data at 19:00:00 on July 13, 2004. Elevated levels of $\mathrm{Hg}^{0}$ were observed in eastern U.S. and along western coastal regions. Similar trends can be observed in the spatial distribution of $\mathrm{RGM}$ and $\mathrm{Hg}_{\mathrm{p}}$ point source emissions excluding IPM input data.

Layer 1 HGNRVAh

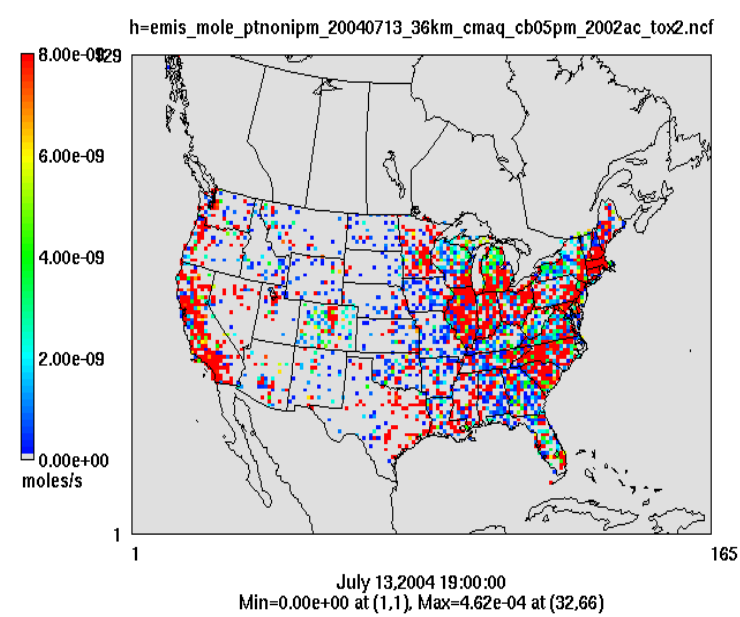

Layer 1 HGIIGASh

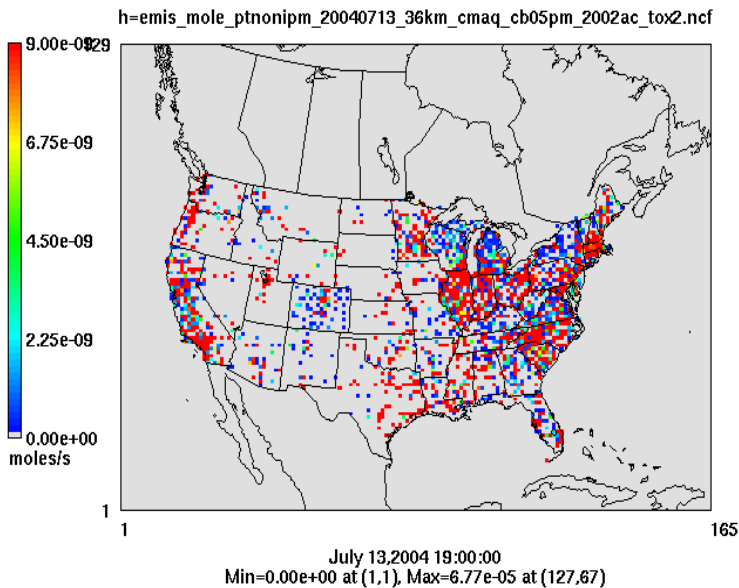

Figure 10. SMOKE emission results for point source emissions of IPM input data of elemental mercury $\left(\mathrm{Hg}^{0}\right)$ (left) and reactive gaseous mercury (RGM) (right) in 36km grid resolution

\section{Layer 1 PHGIh}

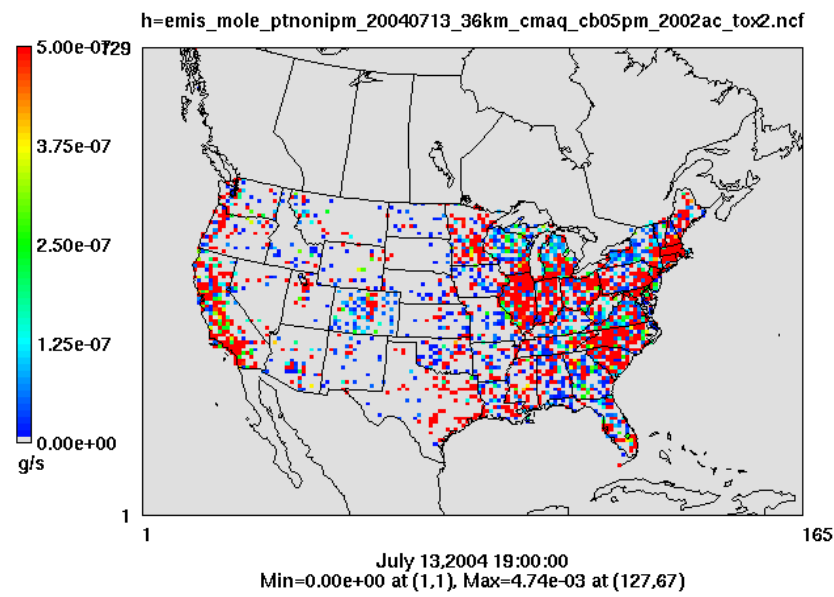

Figure 11. SMOKE emission results for point source emissions of IPM input data of particulate mercury $\left(\mathrm{Hg}_{\mathrm{P}}\right)$ in $36 \mathrm{~km}$ grid resolution. 


\section{Model Domain}

As shown Figure 12, the model domain was subdivided into $152 \times 116$ grid system. The grid was defined in a Lambert Conformal Projection (LCP) with the origin at $(97.0 \mathrm{~W} 40.0 \mathrm{~N})$, parallels 1 and 2 at $33.0 \mathrm{~N}$ and $45.0 \mathrm{~N}$ respectively and southwest corner point situated at $(-2,736 \mathrm{~km}, 2,088$ $\mathrm{km})$. CMAQ was configured with 23 vertical layers ranging from 1000 to $100 \mathrm{mb}$.

\section{$\underline{\text { Boundary Conditions }}$}

MOZART global modeling results, framing the United States, were used to provide boundary conditions for the CMAQ modeling. Results from the global model provided monthly average 3D concentrations mercury species for winter, spring, summer and autumn. The mercury concentrations across all global grid cells corresponding to each CMAQ boundary were averaged to ascertain seasonal variation of mercury boundary conditions for each layer. Table 4 gives the specified range (minimum to maximum) for the boundary conditions used in the CMAQ model.

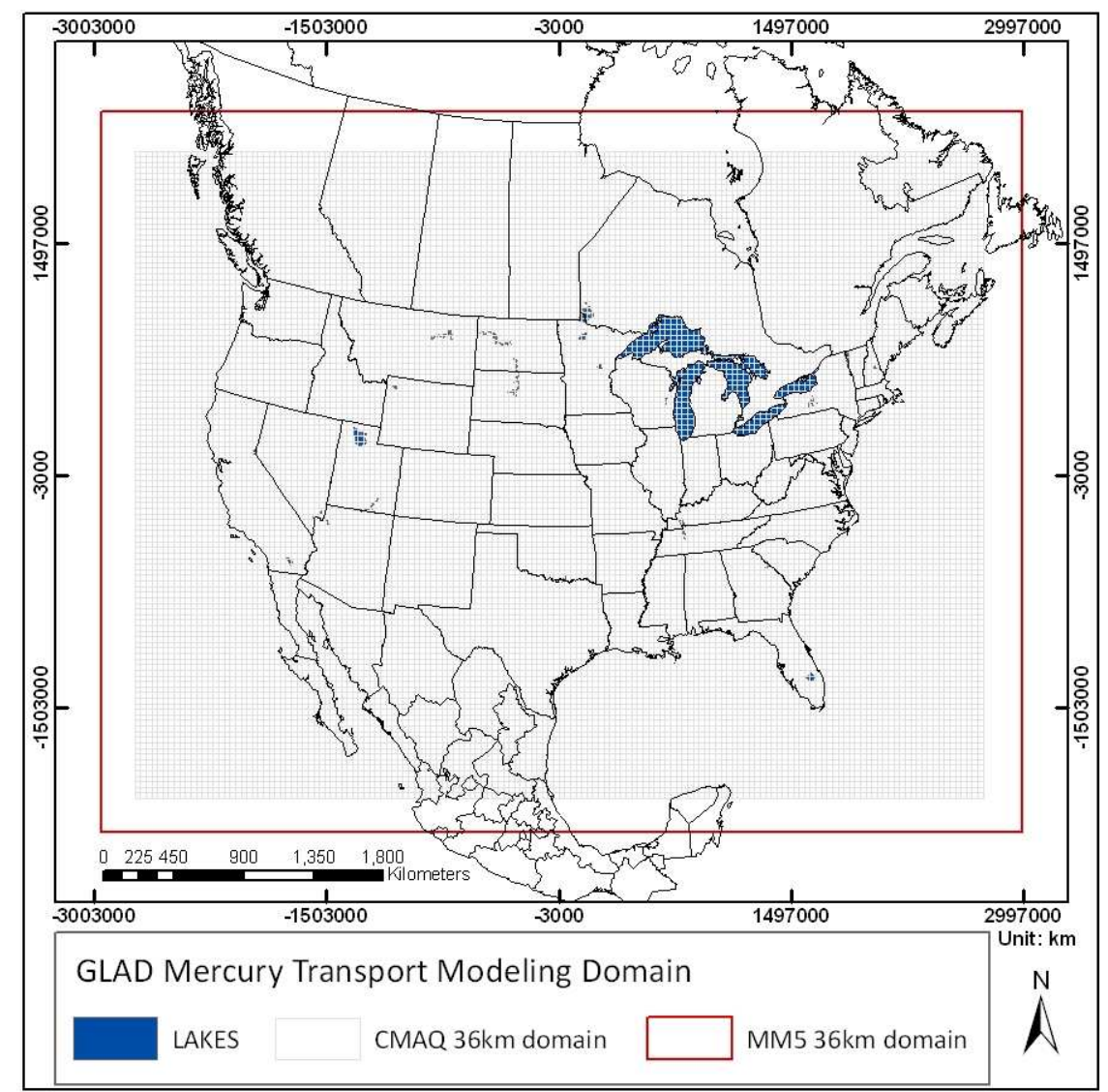

Figure 12. MM5 and CMAQ $36 \mathrm{~km}$ model domain in Lambert Conformal Projection. 
Table 4. Elemental mercury concentration range of Mozart output for CMAQ boundary conditions at surface level

\begin{tabular}{lllll}
\hline & West & East & South & North \\
\hline Winter & $1.5 \mathrm{e}-07$ to $2.0 \mathrm{e}-07$ & $1.6 \mathrm{e}-07$ to $2.1 \mathrm{e}-07$ & $1.5 \mathrm{e}-07$ to $2.0 \mathrm{e}-07$ & $1.6 \mathrm{e}-07$ to $1.9 \mathrm{e}-07$ \\
Spring & $1.6 \mathrm{e}-07$ to $2.0 \mathrm{e}-07$ & $1.6 \mathrm{e}-07$ to $2.1 \mathrm{e}-07$ & $1.5 \mathrm{e}-07$ to $2.0 \mathrm{e}-07$ & $1.6 \mathrm{e}-07$ to $1.9 \mathrm{e}-07$ \\
Summer & $1.4 \mathrm{e}-07$ to $2.1 \mathrm{e}-07$ & $1.5 \mathrm{e}-07$ to $2.0 \mathrm{e}-07$ & $1.5 \mathrm{e}-07$ to $2.1 \mathrm{e}-07$ & $1.5 \mathrm{e}-07$ to $2.0 \mathrm{e}-07$ \\
Autumn & $1.5 \mathrm{e}-07$ to $2.0 \mathrm{e}-07$ & $1.5 \mathrm{e}-07$ to $2.0 \mathrm{e}-07$ & $1.5 \mathrm{e}-07$ to $2.0 \mathrm{e}-07$ & $1.5 \mathrm{e}-07$ to $1.9 \mathrm{e}-07$ \\
\hline
\end{tabular}

$\underline{\text { Model Results - Base case }}$

Figure 13 shows a comparison between the MDN observations (obtained from the National Acid Deposition Program's Mercury Deposition Network (NADP/MDN) website) and CMAQ model simulated results. The MDN data are given in $\mathrm{ng} / \mathrm{m}^{2}$ and are scaled based on availability of data and as such each map will have a different scale. The modeled results are all mapped on the same scale and are displayed in $\mu \mathrm{g} / \mathrm{m}^{2}$. January, April, July and October were chosen to represent the seasons, winter, spring, summer and autumn respectively.

In January the MDN observations showed that the eastern United States had a higher deposition flux relative to the west except for the coastal states. This trend was also evident in the modeled result which showed similar spatial distribution to the MDN data. The trends in April were also well correlated with the exception of the Michigan area which was not fully captured by the model. For July, in the upper Ohio River Valley and western Pennsylvania, CMAQ simulation showed high deposition, however this was not observed in the MDN data. This is most likely due to the lack of an MDN site in this area in 2004. July had the highest wet deposition when compared to the other months which is primarily due to increased precipitation during this time. The highest values were seen in the southeastern section of the country. The mercury wet deposition observed in October, was most dominant over the south central states and was modeled accordingly. By and large for all the seasons, the highest concentration spans the Atlantic and Gulf coasts, eastern Ohio and western Pennsylvania, with July observing the highest deposition. January had the lowest of the four months.

Though the spatial distributions had comparatively similar trends between the MDN and the CMAQ results, the model showed a bias in terms of the magnitude of the deposition. This, as explained by the scatter plot in the model validation results, form an overestimation of precipitation used in the simulation.

Table 5. Deposition $\left(\mu \mathrm{g} / \mathrm{m}^{2} / \mathrm{month}\right)$ into the Ohio River Valley region in 2004

\begin{tabular}{c|ccc|ccc}
\hline \multirow{4}{*}{ RGM $\left(\mathrm{Hg}_{\mathrm{p}}\right)$} & \multicolumn{3}{|c|}{ Winter (January) } & \multicolumn{3}{c}{ Spring (April) } \\
\cline { 2 - 7 } & Wet & Dry & Total & Wet & Dry & Total \\
\cline { 2 - 7 } & 3.81 & 2.18 & 5.99 & 1.75 & 6.79 & 8.54 \\
& 0.170 & 0.023 & 0.193 & 0.160 & 0.062 & 0.222 \\
\hline \multirow{3}{*}{$\mathrm{RGM}\left(\mathrm{Hg}_{\mathrm{p}}\right)$} & \multicolumn{3}{|c|}{ Summer (July) } & \multicolumn{3}{c}{ Autumn (October) } \\
\cline { 2 - 7 } & Wet & Dry & Total & Wet & Dry & Total \\
\cline { 2 - 7 } & 7.52 & 6.55 & 14.7 & 4.23 & 6.28 & 10.51 \\
& 0.217 & 0.072 & 0.289 & 0.239 & 0.041 & 0.28 \\
\hline
\end{tabular}





HGIIGAS WET DEP

Jul

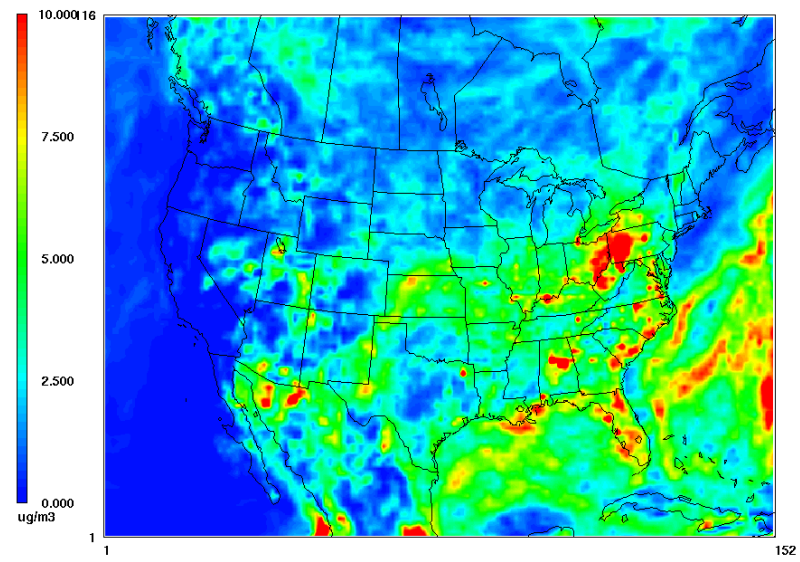


Oct
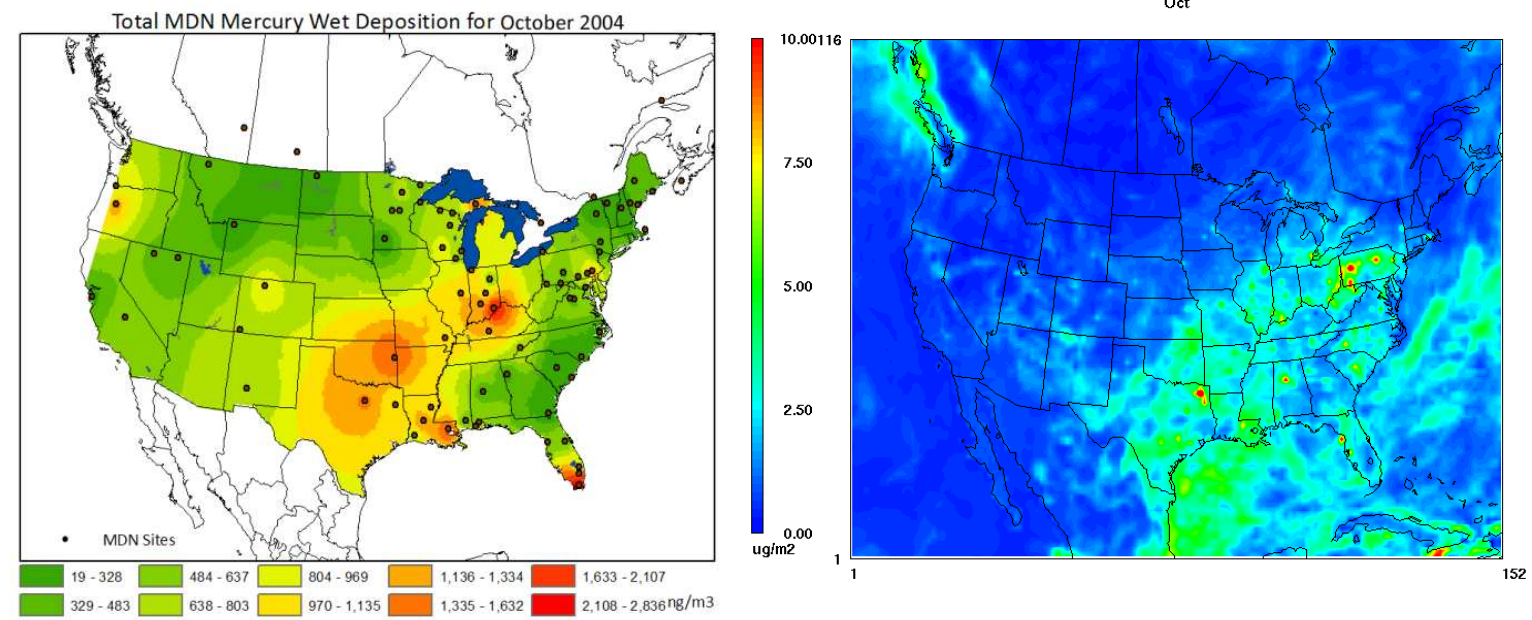

Figure 13. Comparison of MDN observations (left) and CMAQ modeling results (right) for mercury wet deposition during months of January, April, July and October in 2004

Figures 14, 15 and 16 show the seasonal variation for dry and wet mercury deposition in North America simulated by CMAQ. Seasonally, the spatial distribution shifted from the south coast in winter where deposition flux was highest and moved gradually into the mid west where it peaked in July. The highest levels of mercury deposition were observed over the eastern section of the United States which has a higher density of local sources relative to the west. Consistently higher levels of wet deposition of RGM were observed in comparison to dry deposition, except in April, where depositions peaked over upper Ohio River valley region and in major urban areas in the region. While the wet deposition is the direct result of precipitation amounts, the meteorological dynamics (i.e. mixing depths, inversion) and atmospheric chemistry during this time account for the higher levels of mercury dry deposition. For both dry and wet deposition, the warmer months (April and July) had higher deposition and winter observed less total deposition over North America. Convective mixing and increased oxidation during the warmer months account for the increased activity, especially in July. 
HGIIGAS WET DEP

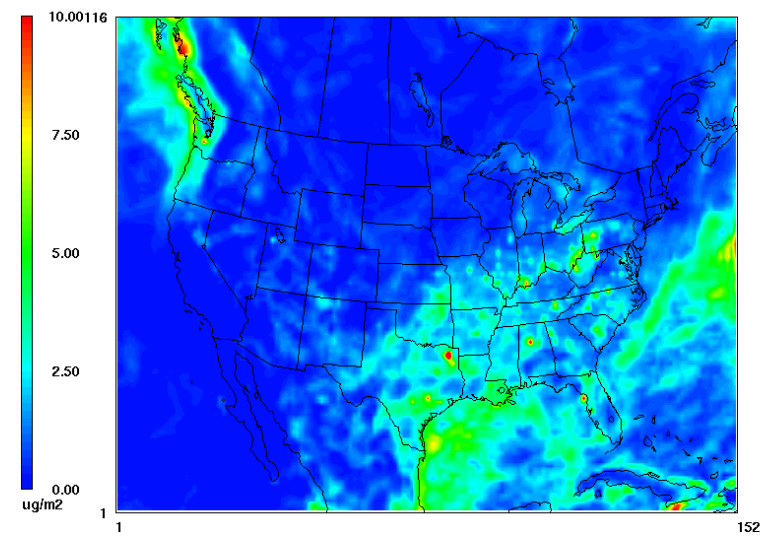

HGIIGAS DRY DEP

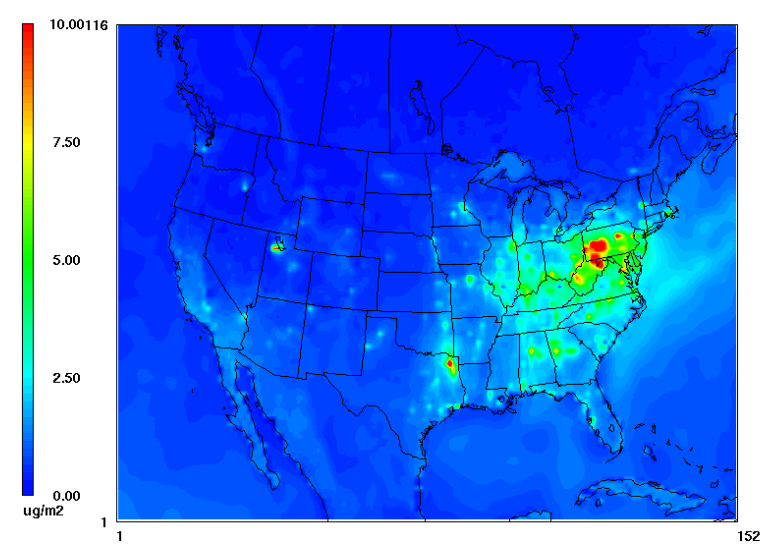

HGIIGAS TOTAL DEP

Jan

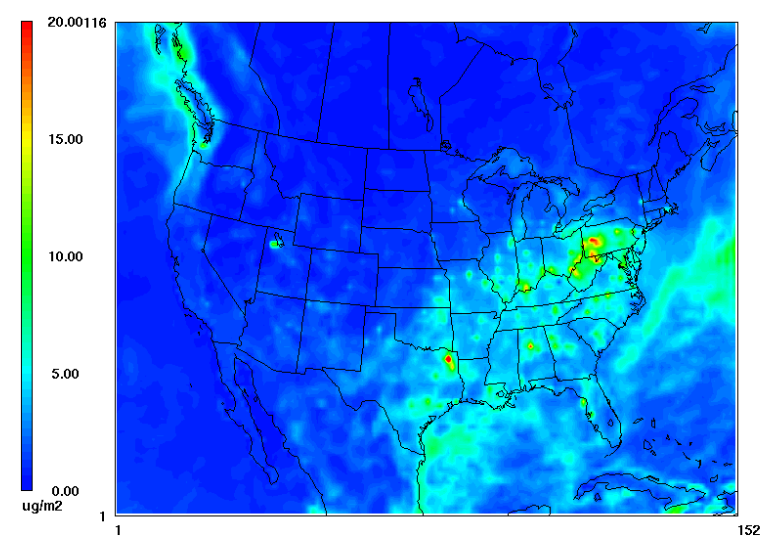

HGIIGAS WET DEP

Apr

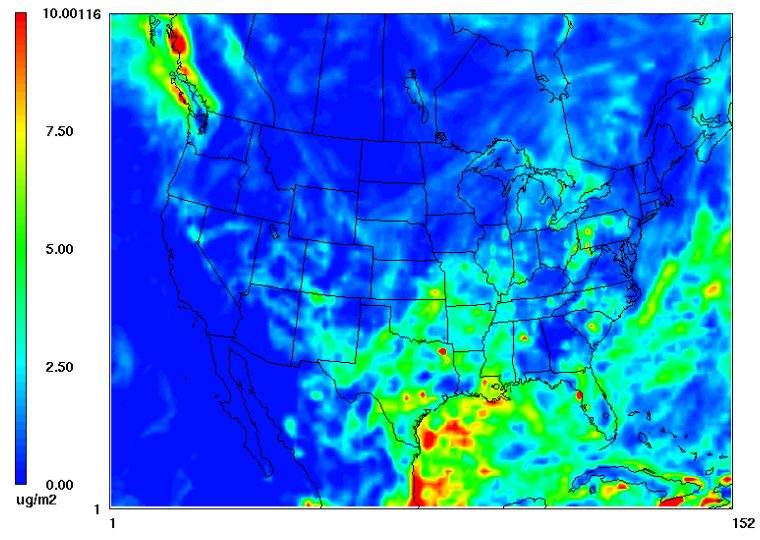

HGIIGAS DRY DEP

April

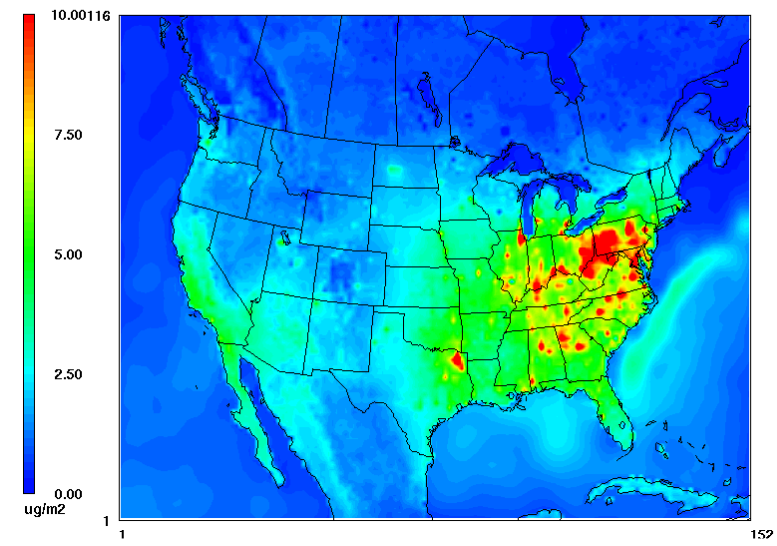

HGIIGAS TOTAL DEP

Apr

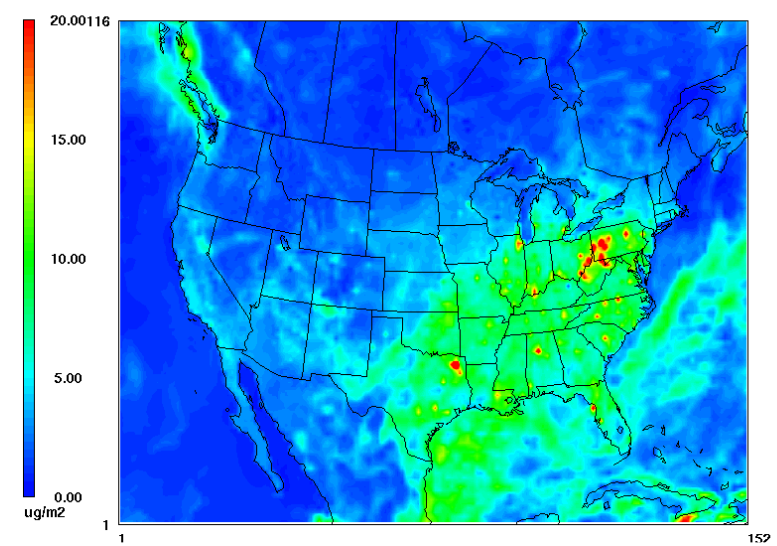

Figure 14. RGM wet, dry and total deposition of CMAQ results for January (left) and April (right) 2004 
HGIIGAS WET DEP

Jul

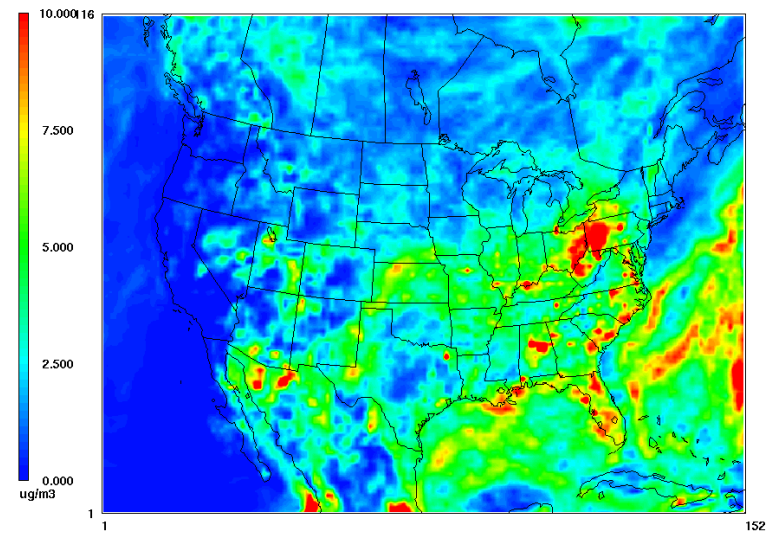

HGIIGAS DRY DEP

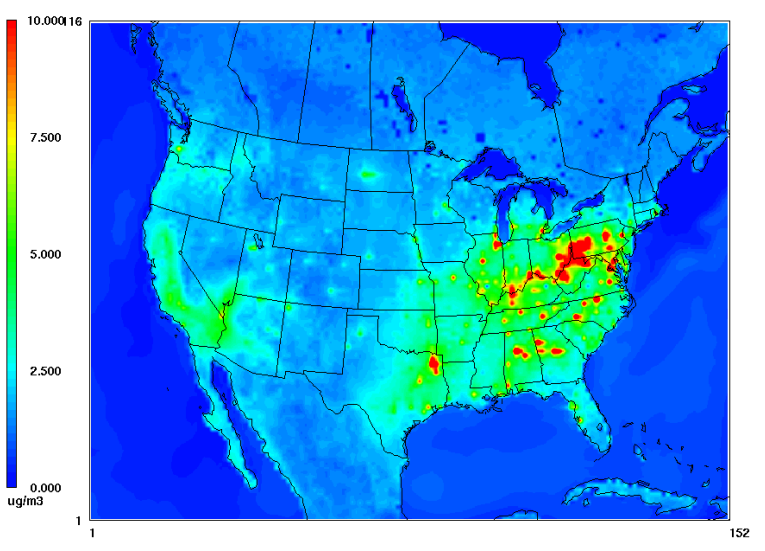

HGIIGAS TOTAL DEP

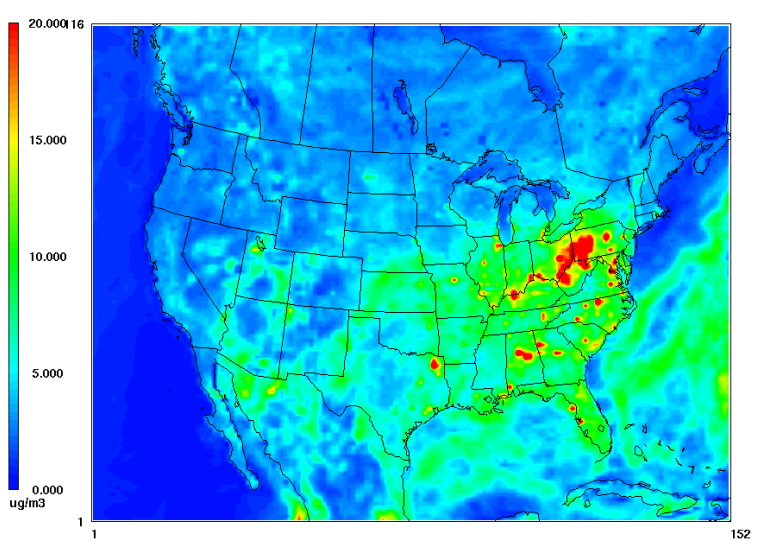

HGIIGAS WET DEP

Oct

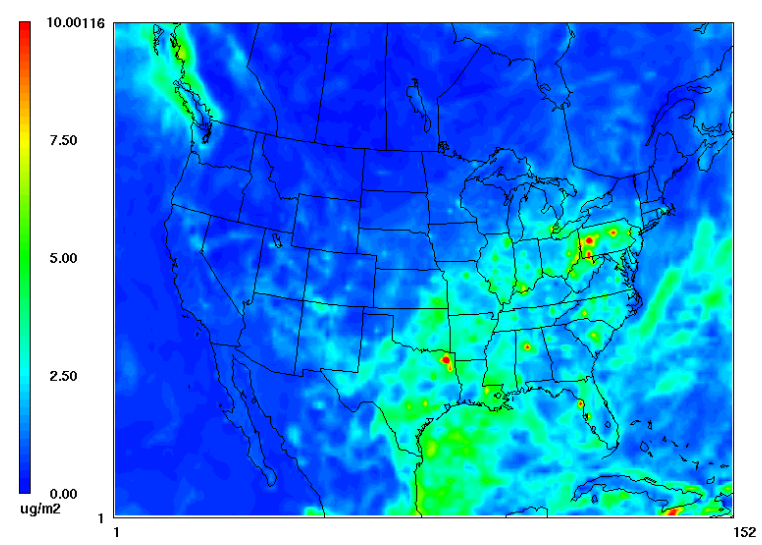

HGIIGAS DRY DEP

Oct

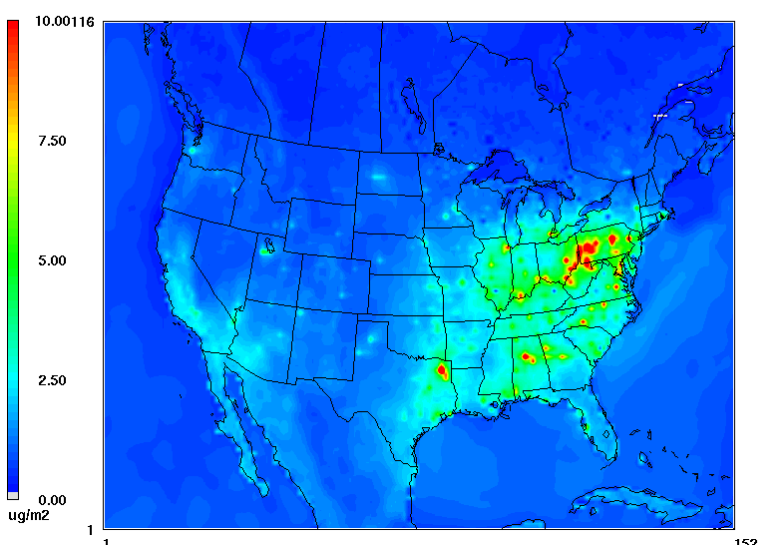

HGIIGAS TOTAL DEP

Oct

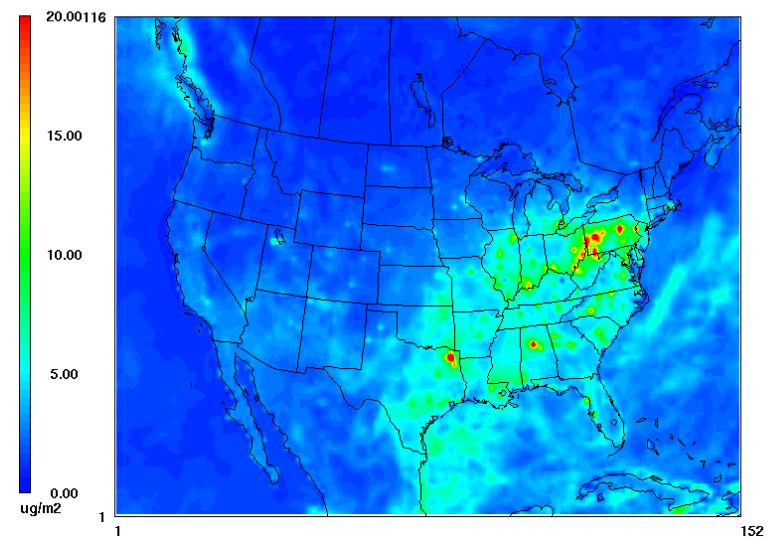

Figure 15. RGM wet, dry and total deposition of CMAQ results for July (left) and October (right) 2004 

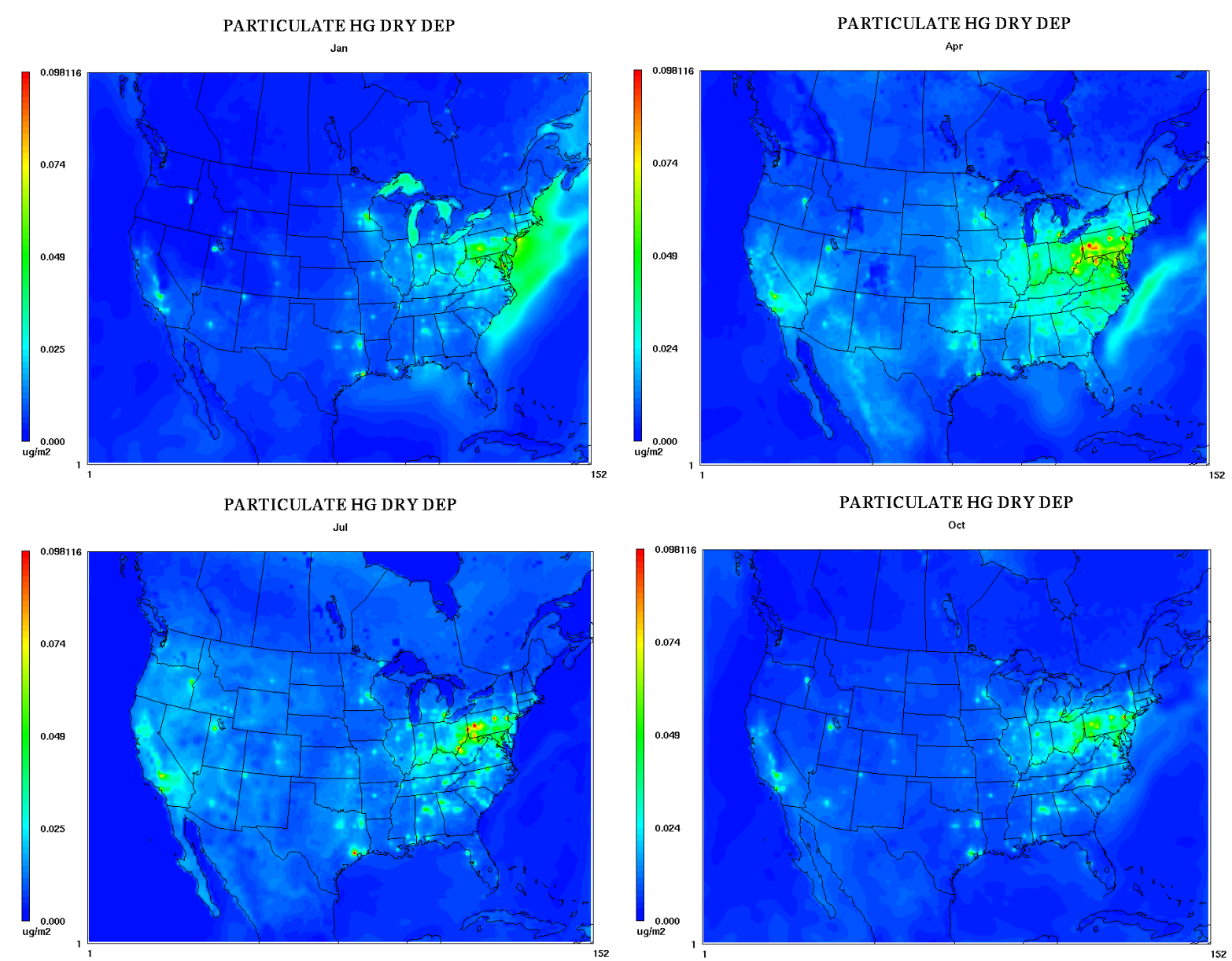

Figure 16. Particulate mercury dry deposition of CMAQ results for January, April, July, and October 2004. 


\section{$\underline{\text { Model validation }}$}

Scatter-plots comparing MDN observed data with CMAQ results for January, April, July and October are presented in Figure 17. This plot shows a relatively good fit with a coefficient of determination $\left(\mathrm{R}^{2}\right)$ value of $0.30-0.36$, except for April. Most of the points fall to the left of the 45 degree line which indicates over prediction by the CMAQ model. This is a consequence of the MM5 over-estimation of precipitation and likely the drawback of RGM reduction mechanism in CMAQ.
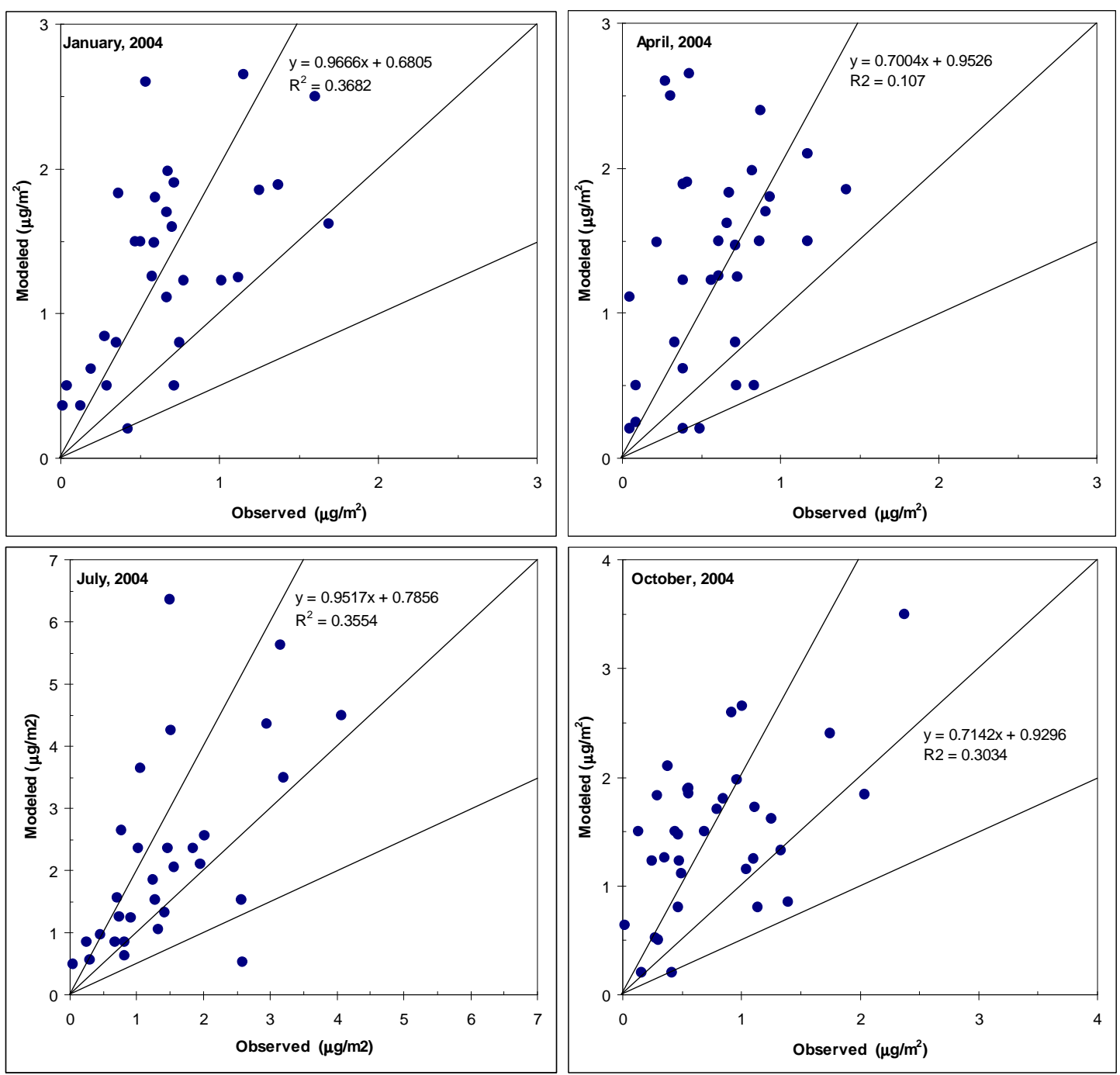

Figure 17. Scatter plot of CMAQ simulation results and observed MDN data for January (top left), April (top right), July (bottom left) and October (bottom right) 2004 


\section{Performance Evaluation Metrics}

The following metrics was used for the mercury wet deposition comparisons:

1. Normalized Bias (NB)

$B_{N}=\frac{1}{N} \sum_{i=1}^{N}\left(\frac{P_{i}-o_{i}}{O_{i}}\right)$

where:

$N$ - total number of measurement sites with non-missing values

$\mathrm{P}_{\mathrm{i}}$ - Predicted value at site ' $\mathrm{i}$ '

$\mathrm{O}_{\mathrm{i}}$ - Observed value at site ' $\mathrm{i}$ '

2. Fractional Bias (FB)

$B_{F}=\frac{1}{N} \sum_{i=1}^{N}\left(2 \cdot \frac{P_{i}-o_{i}}{P_{i}+o_{i}}\right)$

3. Normalized Gross Error (NGE)

$E_{N}=\frac{1}{N} \sum_{i=1}^{N}\left|\frac{P_{i}-O_{i}}{O_{i}}\right|$

4. Fractional Gross Error (FGE)

$E_{F}=\frac{1}{N} \sum_{i=1}^{N}\left|2 \cdot \frac{P_{i}-o_{i}}{P_{i}+o_{i}}\right|$

Table 6. Seasonal model performance results for mercury wet deposition fluxes $\left(\mu \mathrm{g} / \mathrm{m}^{2}\right)$

\begin{tabular}{lcccc}
\hline Performance Measure & Spring (Apr) & Summer (Jul.) & Autumn (Oct.) & Winter (Jan.) \\
\hline \hline Average observation & 0.65 & 1.48 & 0.82 & 0.67 \\
Average prediction & 1.35 & 2.19 & 1.48 & 1.33 \\
Normalized bias & $177 \%$ & $138 \%$ & $154 \%$ & $178 \%$ \\
Fractional bias & 0.87 & 0.85 & 0.84 & 0.87 \\
Normalized error & $174 \%$ & $136 \%$ & $154 \%$ & $177 \%$ \\
Fractional error & 0.87 & 0.89 & 0.87 & 0.85 \\
$\mathrm{r}^{2}$ & 0.37 & 0.36 & 0.30 & 0.11 \\
\hline
\end{tabular}




\section{Task 4. Perform Short-Period Model Runs for Comparison with Field Data}

Proposed: ISEE will conduct a series of model runs to evaluate the system against field observations. The model run will correspond to the NETL-sponsored intensive sampling campaigns centered in Pittsburgh, Pennsylvania. Researchers will combine the extensive datasets collected during this campaign with other relevant datasets in this region. Meteorological input data for these simulations will be derived diagnostically using MM5 V3. The model evaluations involve short-time-period runs for the field-intensive periods, storing hourly averaged fluxes and production-and-loss rates for ozone, hydrocarbons, $\mathrm{Hg}^{0}$, and RGM for direct comparison with field data. In addition, long-range transport events will be identified from the short-term CTM runs and evaluated with the observational data set.

\section{Accomplishments}

In addition to the model evaluations conducted against field observations obtained from the 2001 NETL-sponsored sampling campaigns, the model was also evaluated against the observational data sets, including the speciated mercury, collected at the Athens SAM for the 2004 sampling period. These simulations are vital for model verification because the Athens SAM is one of the few sites providing measurements on individual mercury species. The model evaluations involved short-time-period runs for the field-intensive periods, simulating hourly averaged fluxes and production-and-loss rates for ozone, hydrocarbons, $\mathrm{Hg}^{0}, \mathrm{RGM}$ and particulate matter for direct comparison with field data. In addition, long-range transport events were identified from the short-term CTM runs and evaluated with the observational data set.

- During elevated mercury events at the Athens Monitoring site, a consistent pattern of elemental mercury (GEM) depletion with a simultaneous increase in reactive gaseous mercury (RGM) was observed. In order to characterize the chemical transformation between mercury species, a two phase photochemical box model was established for the Athens region. Specifically the box model was used to evaluate the impact of atmospheric mercury oxidation on RGM concentrations and to subsequently update the mercury chemistry in the chemical transport model. The box modeling results were documented in the previous progress report.

- The research team completed CMAQ base cases for Hg dry and wet deposition. Modeled $\mathrm{Hg}$ species in gas phase and wet deposition were compared with observations to verify the model performance and investigate atmospheric chemical transformation. Figure 18 and Figure 19 depict the time series comparison and regression, respectively, for elemental mercury during October, 2004. The modeled $\mathrm{Hg}^{0}$ concentrations were relatively in a good agreement with observed $\mathrm{Hg}^{0}$. However, RGM modeled concentrations were significantly over-estimated and there was no significant correlation between modeled values and observations in terms of temporal trends, indicating that a possible reason could be the reduction of RGM chemistry in CMAQ.

- The research team completed $\mathrm{PM}_{2.5}$ runs for the short-term episodes that were associated with plume events. There were 18 plume events from Jul. to Dec. 2004. Figure 20 presents spatial distribution of modeled $\mathrm{PM}_{2.5}$ concentration from short-term CTM runs for episodes of Jul. 22, Aug. 15, Sept. 5, and Sept. 13, 2004. During these events, high levels of RGM 
were observed. Figures 21 and 22 show the time series comparison and regression between modeled $\mathrm{PM}_{2.5}$ concentrations and observations during Sept 4 to 6, 2004.

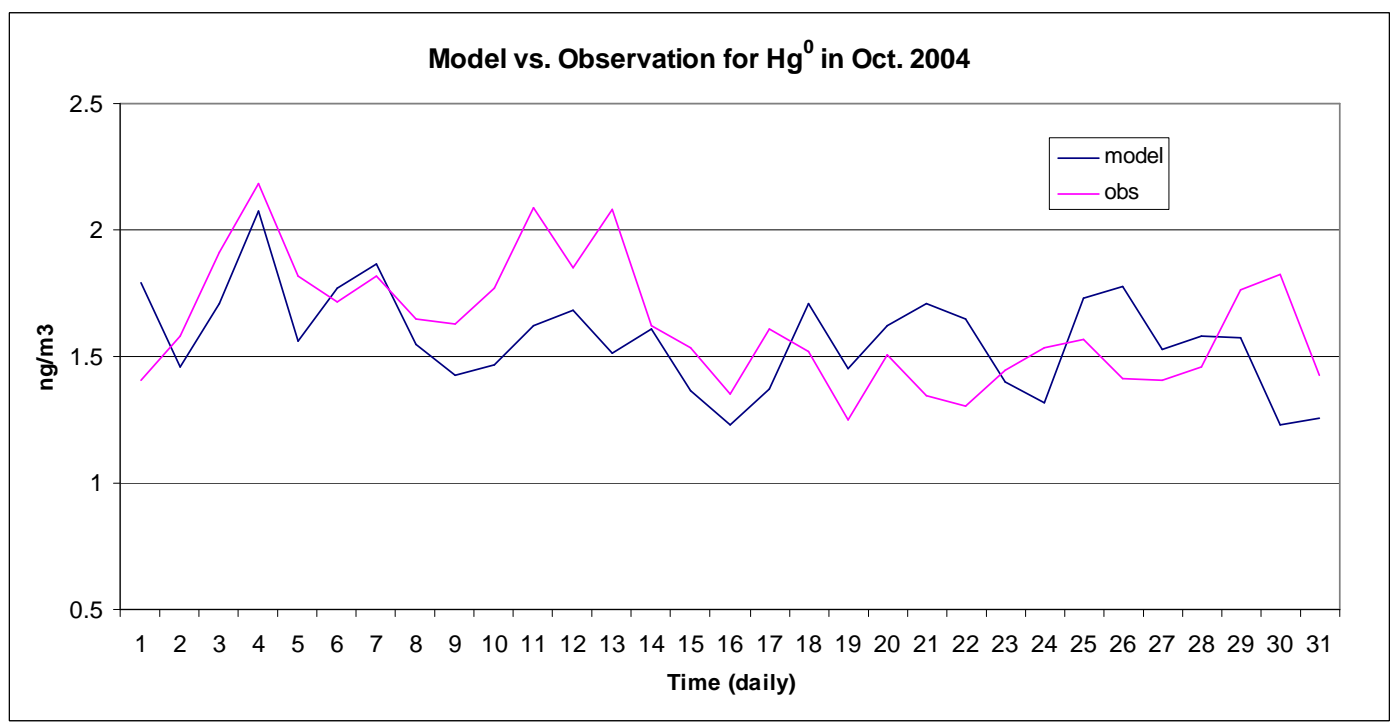

Figure 18. Time series comparison of observations with modeled $\mathrm{Hg}_{0}$ for Oct. 2004

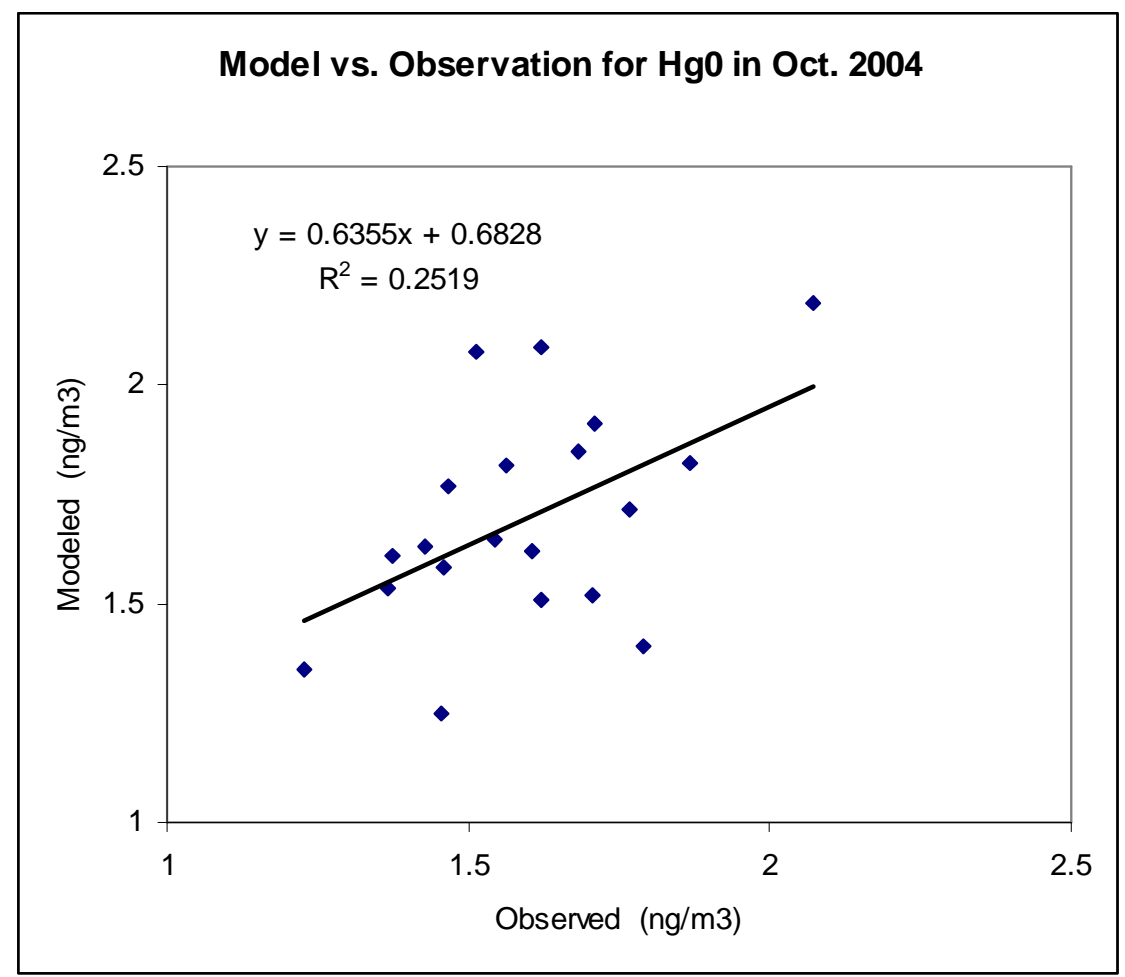

Figure 19. Regression of observations with modeled $\mathrm{Hg}_{0}$ for Oct. 2004 

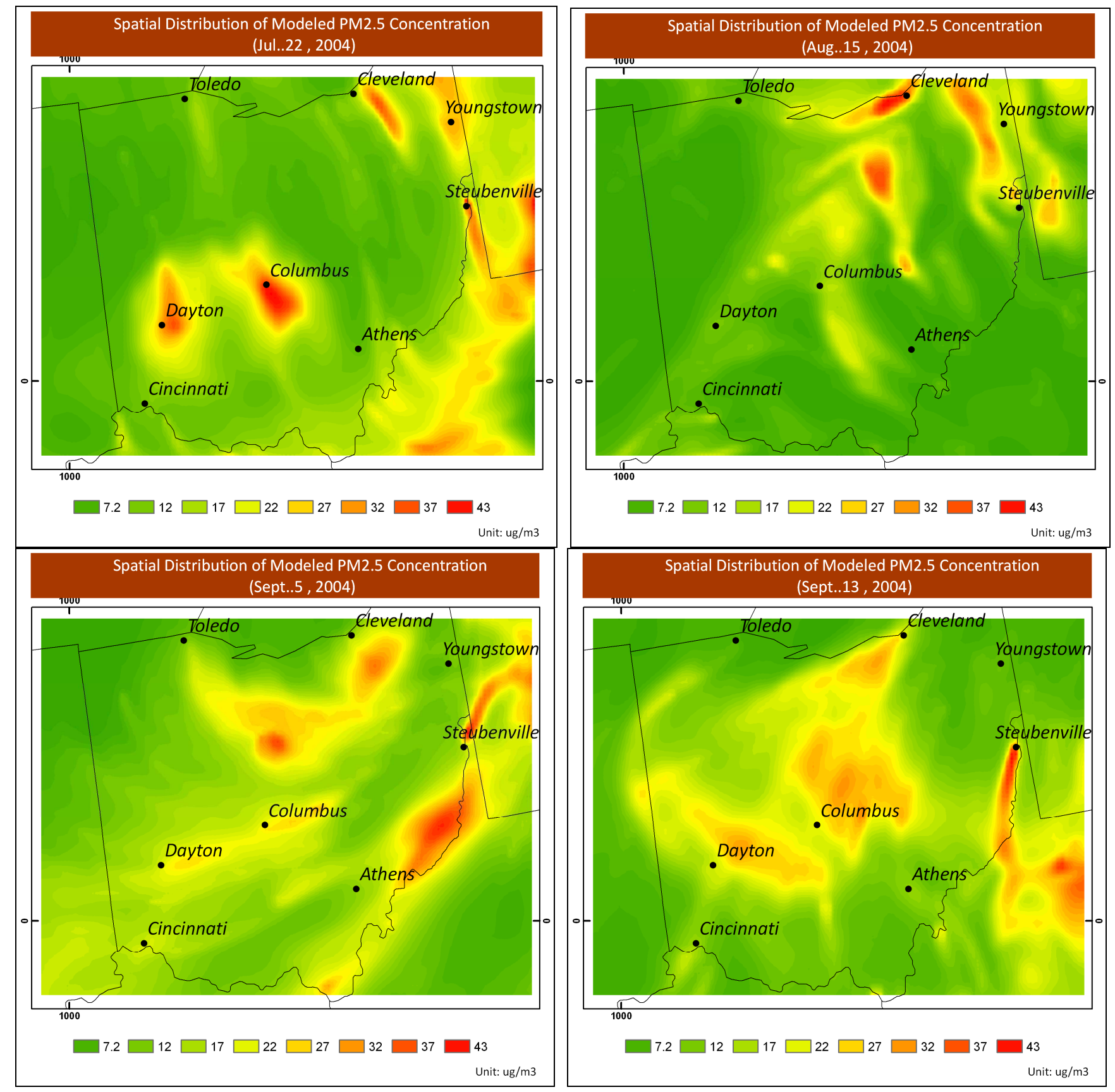

Figure 20. Spatial distribution of modeled PM2.5 concentration for short-term CTM runs. Upperleft is Jul. 22, 2004 with southeasterly winds predominant; upper-right is Aug. 15, 2004 westerly winds; Bottom-left Sept. 5, 2004 with southwesterly winds; and bottom-right Sept. 13, 2004, northeasterly winds. 


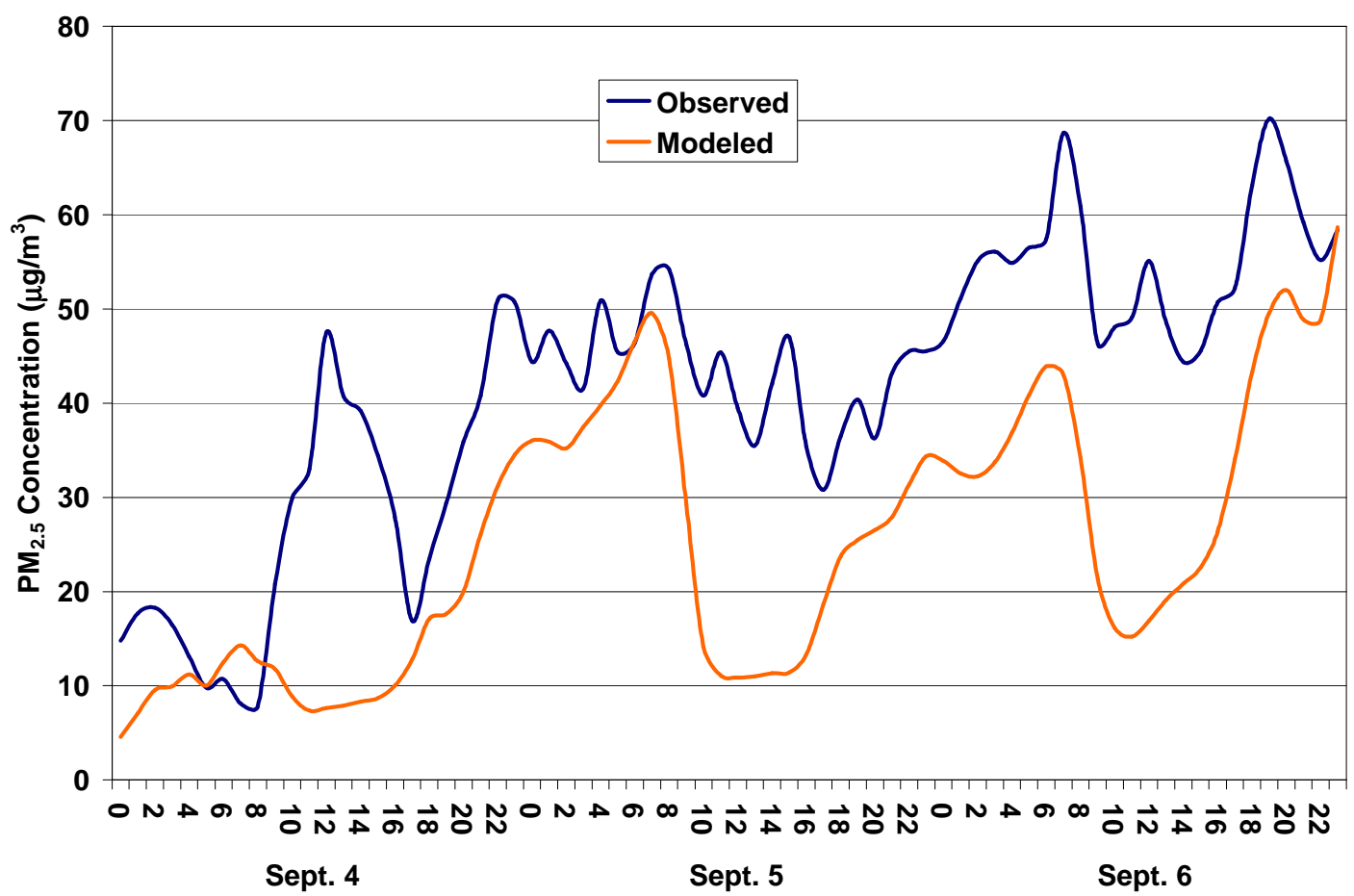

Figure 21. Time series comparison of observations with modeled $\mathbf{P M}_{2.5}$



Figure 22. Regression of observations with modeled $\mathbf{P M}_{2.5}$ 


\section{Task 5. Seasonal Scale Simulations and Sensitivity Analysis}

Proposed: A major focus of the modeling effort is to identify significant sources and source regions contributing to the deposition of mercury and ambient concentrations of fine particulate matter. The modeling will also examine the efficacy of reduction strategies specifically for coal-fired power plants. In addition, researchers will conduct an analysis of the long-range transport of mercury from regions outside the Ohio Valley.

\section{Accomplishments}

OU researchers completed a seasonal scale simulation for the entire North American continent on a $36 \mathrm{~km} \times 36 \mathrm{~km}$ grid system. They used the NCEP-4D assimilation data set to drive the regional-scale meteorology model (MM5 V3) to develop dynamic inputs for the CTM. The model analysis was completed for the seasonal run to establish a 'base-case' simulation or the most likely current-day simulation for the season. Uncertainty ranges were developed for critical parameters in the model, such as emissions and deposition rates. Additional seasonal scale simulations were performed to develop an 'uncertainty envelope' of the model-generated estimates of deposition rates and fluxes.

The analysis was performed to assess mercury contributions from major sources regionally and globally. Percentage differences between the wet deposition base cases and zeroout simulations of IPM utilities and global contribution were examined and are shown in Figures 23 and 24 respectively. For the IPM zero-out case, the highest total point source percentage contribution was observed in January and the lowest contributions occurred in April, as illustrated in Figure 23. Figure 24 highlights, that the impact of global percentage contributions was lowest in the regions that had the highest point source influences. The largest differences were noted on the south eastern coast of the United States, Gulf of Mexico and Canada. 

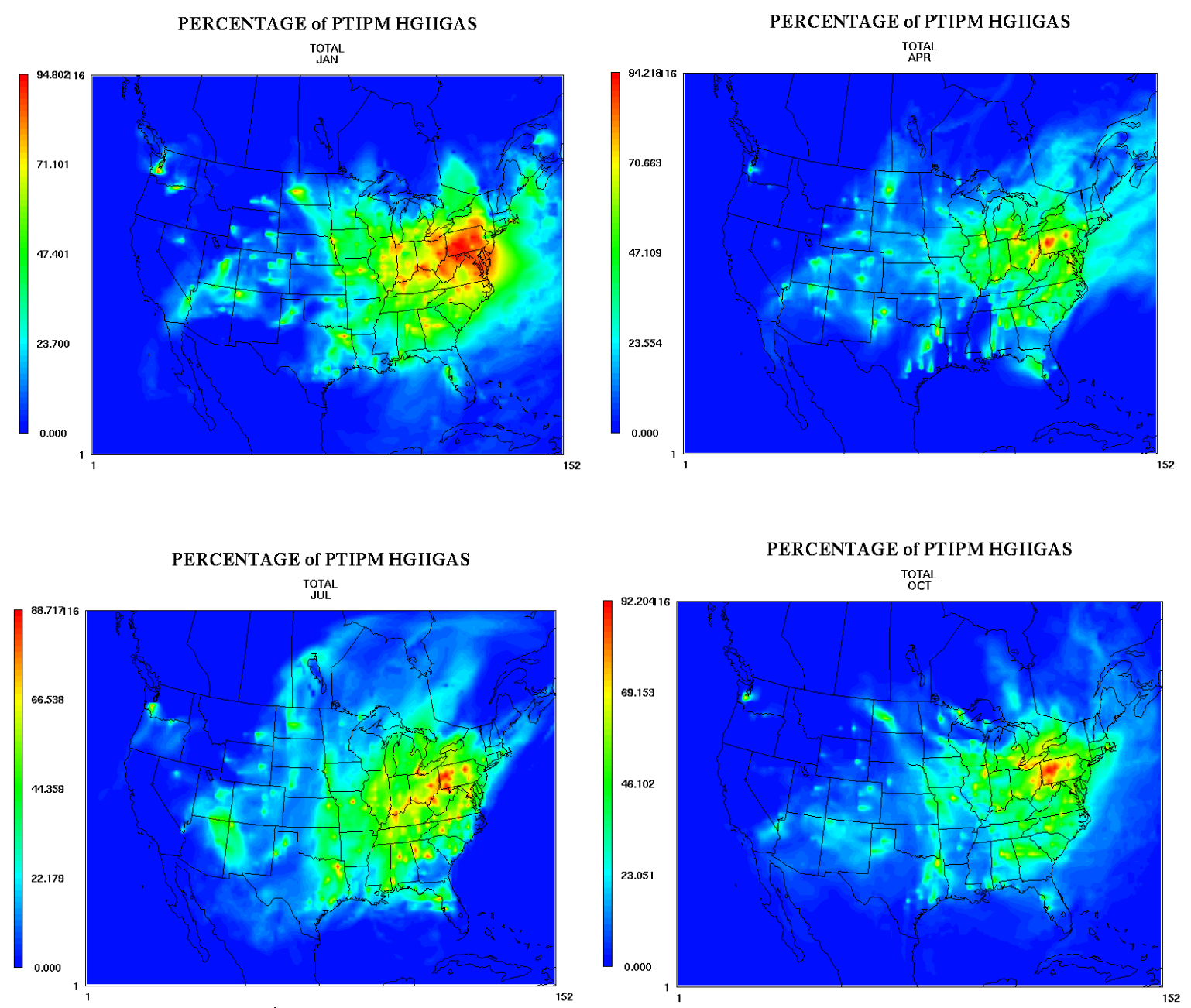

Figure 23. Total deposition \% difference with zero-out power generation utilities contributions 


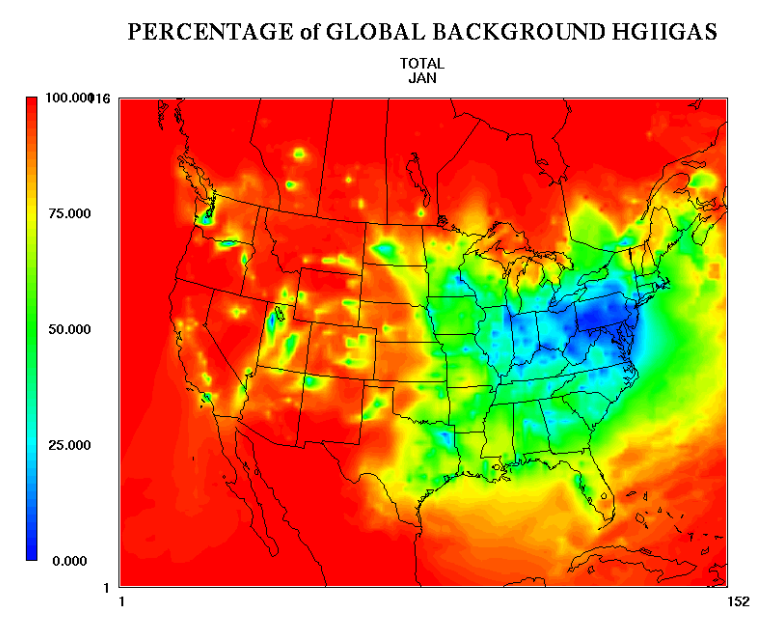

PERCENTAGE of GLOBAL BACKGROUND HGIIGAS TOTAL

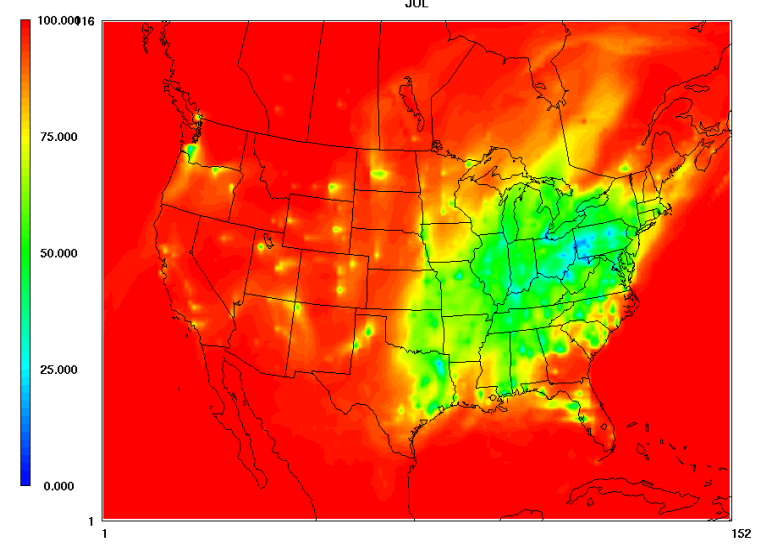

PERCENTAGE of GLOBAL BACKGROUND HGIIGAS

TOTAL

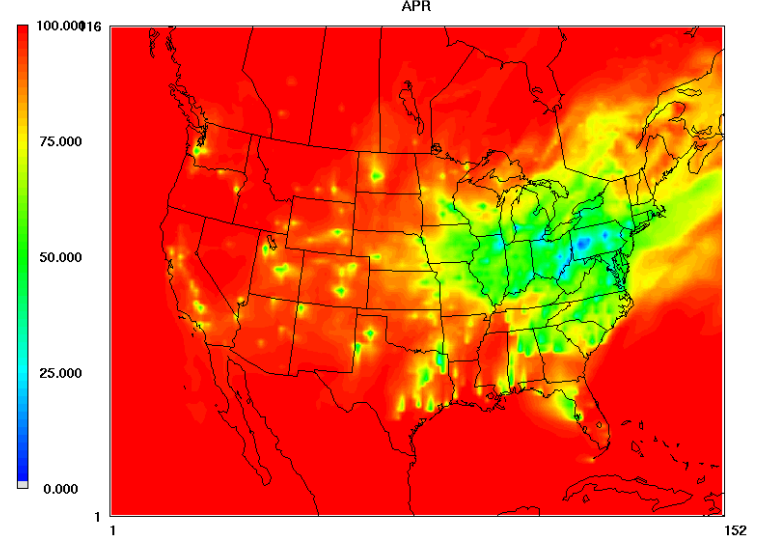

PERCENTAGE of GLOBAL BACKGROUND HGIIGAS DRYDEP
OCT

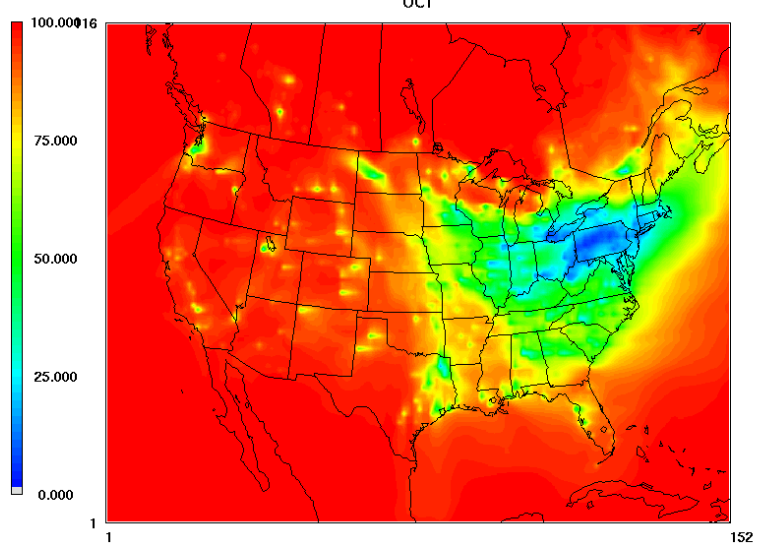

Figure 24. Total deposition \% difference with zero-out Global contributions.

The net-zero China emissions modeling results are displayed in Figure 25. The relative average percentage contributions to North America due to China, ranges from 5 to $7 \%$. Drewniak et al (2008), in a recent study supported this claim, suggesting that China's mercury emissions contribute to about $7 \%$ rise in mercury deposition over North America. The plots in Figure 25 show that this impact is promulgated across the entire North America. According to the model results, in April and October the west coast observed greater influences due to China contributions to the global pool.

From Table 7, the electrical generation utilities exhibited 42 to $71 \%$ of contribution to mercury wet deposition in the Ohio River Valley region, global background 28 to $50 \%$, and China emissions 5 to $6 \%$ contributions. The electrical generation utilities illustrated highest impact $(71 \%)$ on Ohio River Valley region in January while global background concentration contributed maximum in October. 

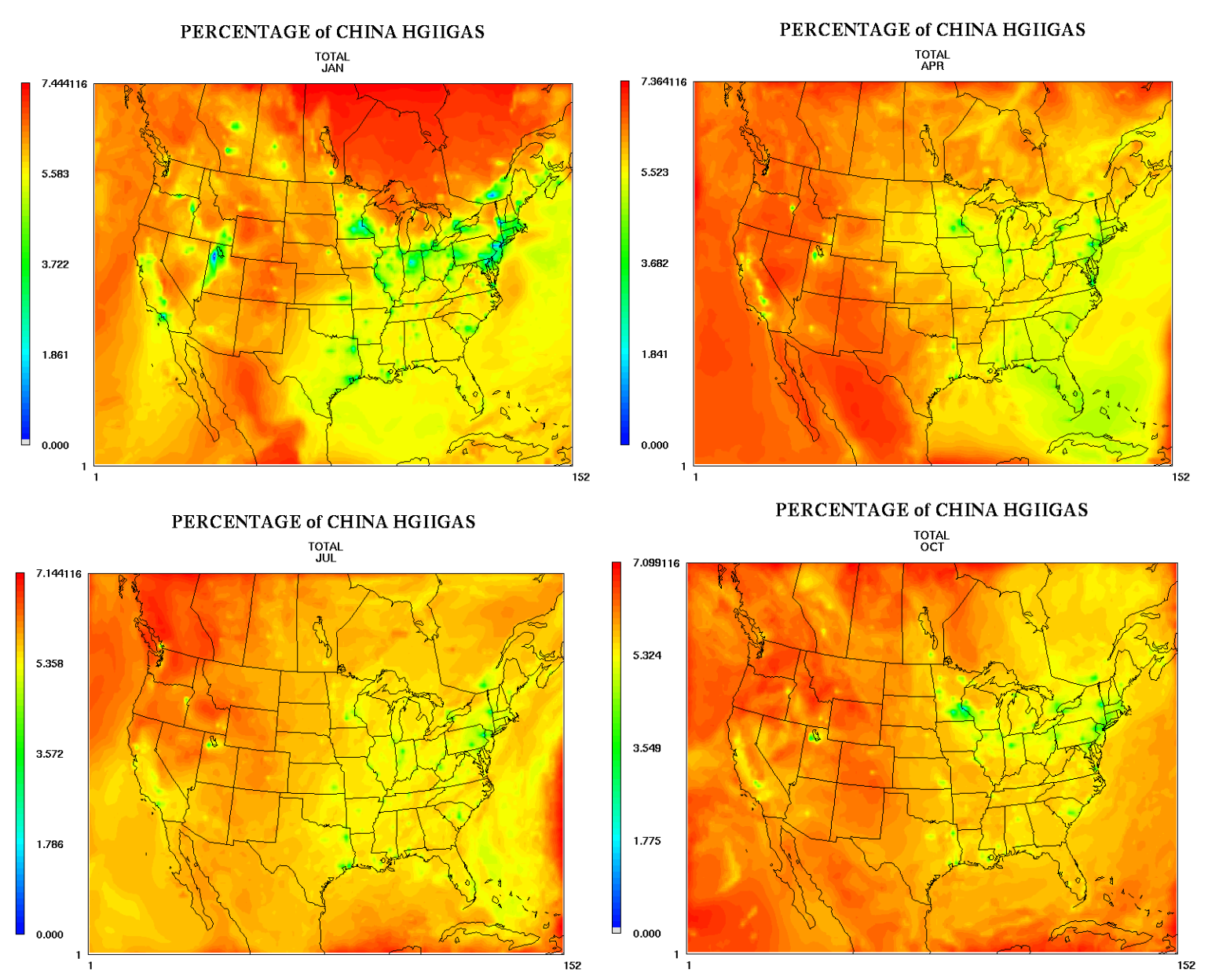

Figure 25. Total deposition \% difference with China zero-out.

Table 7. Percentage contribution of IPM utilities, China emissions and global background to mercury wet deposition over the Ohio Valley Region.

\begin{tabular}{llcccc}
\hline & Sensitivity & Winter (Jan.) & Spring (Apr.) & Summer (Jul.) & Autumn (Oct.) \\
\hline \hline \multirow{3}{*}{ Ohio River Valley } & IPM & 71.3 & 54.2 & 64.2 & 42.6 \\
& China Emissions & 4.7 & 5.2 & 5.8 & 5.6 \\
& Global Background & 27.8 & 45.3 & 35.0 & 50.2 \\
\hline
\end{tabular}




\section{Task 6. Development of a Decision-Support Tool}

Proposed: ISEE will conduct a series of model runs to perform a matrix analysis of the sensitivity of point sources to deposition patterns in the region. The analysis will also include selective emission reduction scenarios for these point sources. The team will couple this matrix with a GIS and the emission pre-processor to provide a detailed spatial analysis of the sourcereceptor relationships. In addition, this entire system will be supported by Web-based technologies to provide industry and government agencies with a user-friendly decision-support tool that will evaluate source-receptor relationships and the efficacy of emission reduction strategies.

\section{Accomplishments:}

- Researchers have completed the framework for the web-based support tool. They developed an interactive Web based GIS interface linking sources with a database that contains the results from the matrix analysis. The web-based system provides a user-friendly interface linking specified source reductions with the associated impact on receptor sites.

- The research team has developed web-based emissions inventory for each source category. This requires the support of Google maps API, .asp and MS SQL. With its dynamic and userfriendly interface, users can zoom to different areas on the maps to check current conditions for ozone and $\mathrm{PM}_{2.5}$. Various places of interest and daily places can be better viewed with the assistance of Google maps. The user can also overlay other Google maps such as school sites and hospitals to check conditions for at-risk populations. 


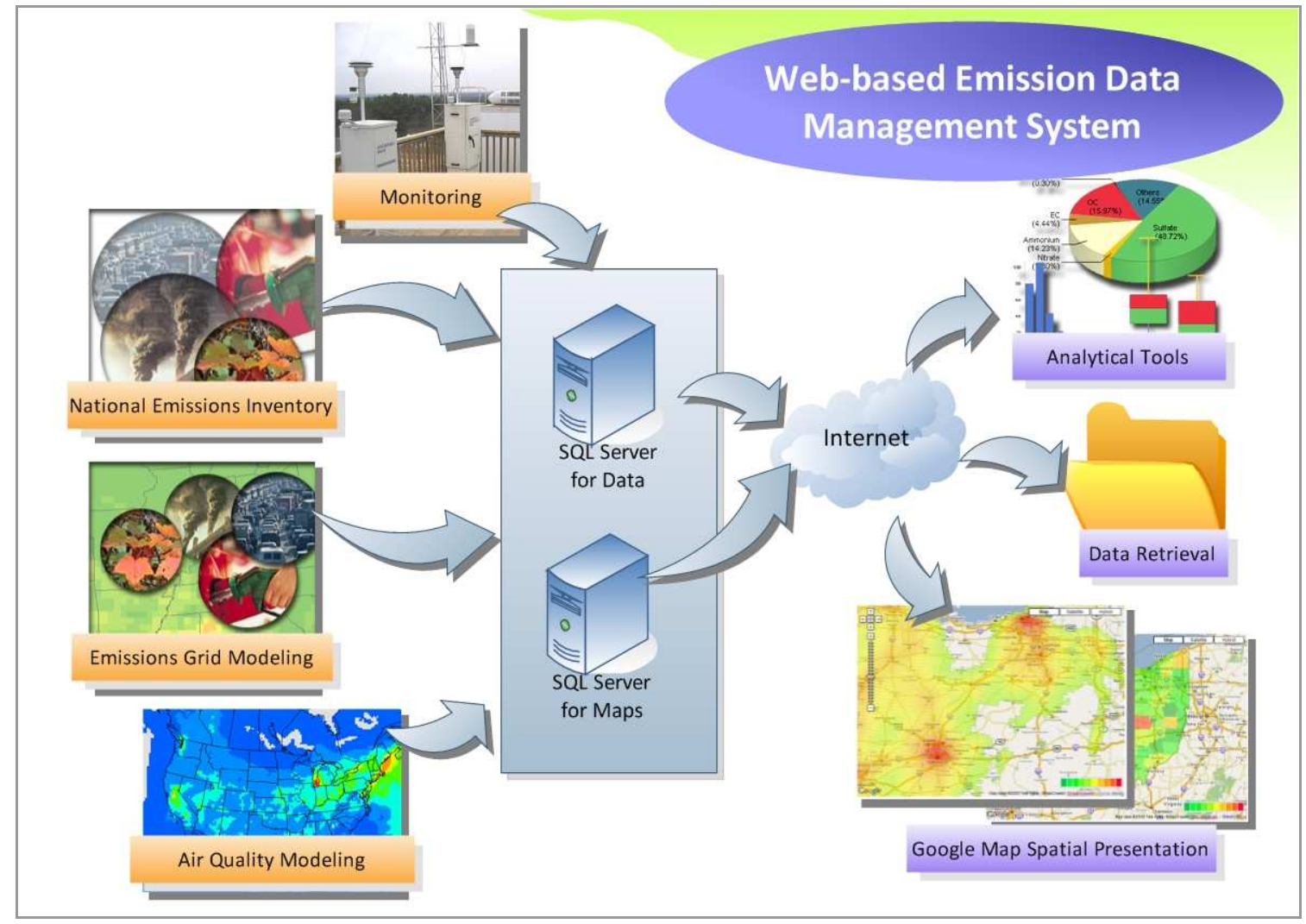

Figure 26. Schematic flowchart of web-based emission data management and mapping system

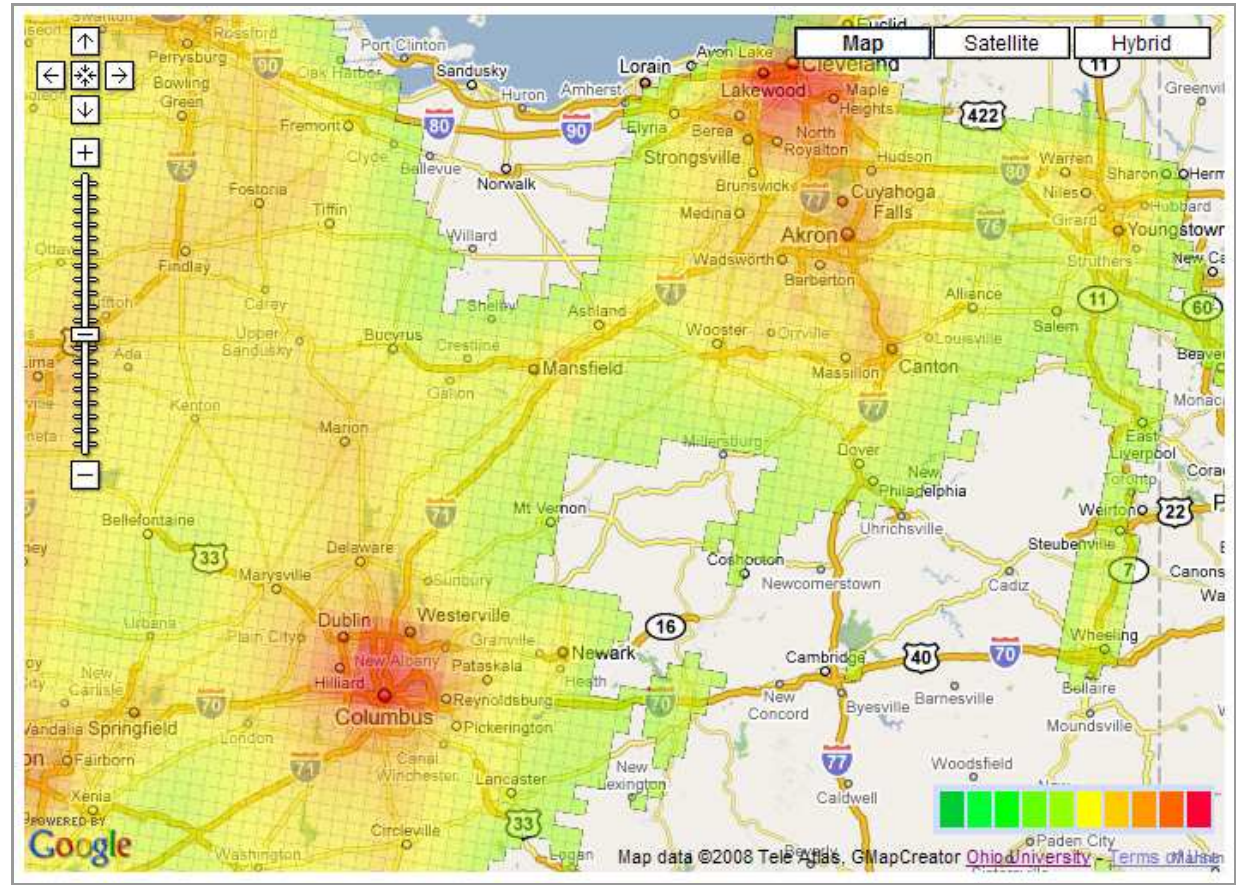

Figure 27. Spatial distribution of 4-km grid-based emission for area source category on Google Map. 


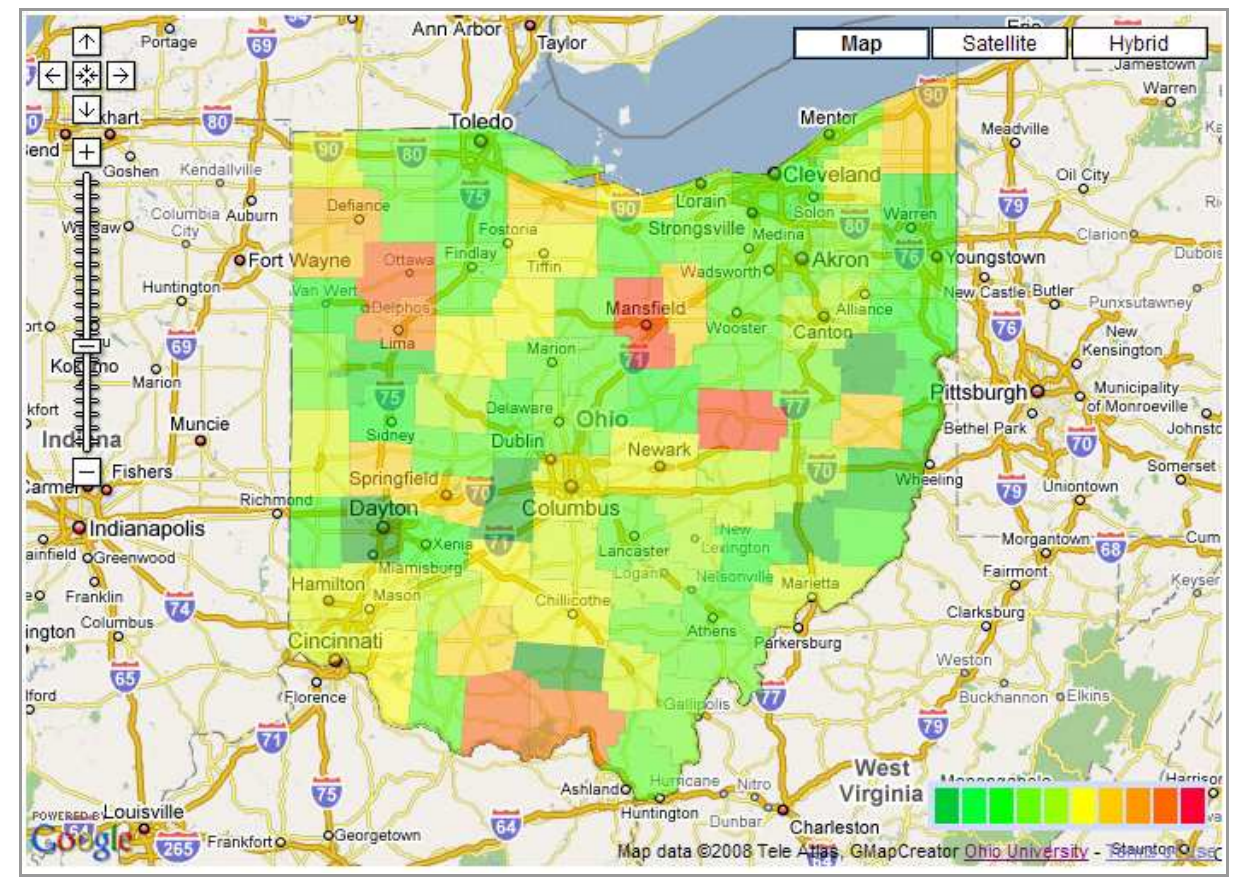

Figure 28. Spatial distribution of county-based emissions on Google Map.

- The ISEE at Ohio University has developed a forecasting model capable of incorporating these site-specific determinants into a Classification and Decision Tree (CDT) model for forecasting 24-hour averaged $\mathrm{PM}_{2.5}$ concentrations for metropolitan areas in Ohio. The CDT model provides avenues to continually enhance $\mathrm{PM}_{2.5}$ forecasting capability resulting in greater accuracy of the predicted 24-hour averaged concentration values as compared to those projected by conventional models. The CDT forecasting model was incorporated into a web-based air quality forecasting system to provide a user-friendly and efficient forecasting tool for air quality forecasters. Figure 13 presents online forecasting tool for Cincinnati area.

- The online forecasting tool automatically draws model parameter values such as surface meteorology and the previous day's pollutant levels from the designated national weather forecast websites and pollutant databases. The input section is designed to accept these values as inputs to the model. The output/results section displays the forecasted $\mathrm{PM}_{2.5}$ results post-model execution as well as uncertainty/error range. During a model execution, model inputs as well as the results are stored in a database for statistical evaluation of the model performance. Figure 14 demonstrates structure of air quality mapping website and online forecasting tool. The update section allows forecasters to transfer the forecasted air quality indices from the online forecasting tool to the corresponding sections of mapping and forecasting websites. 


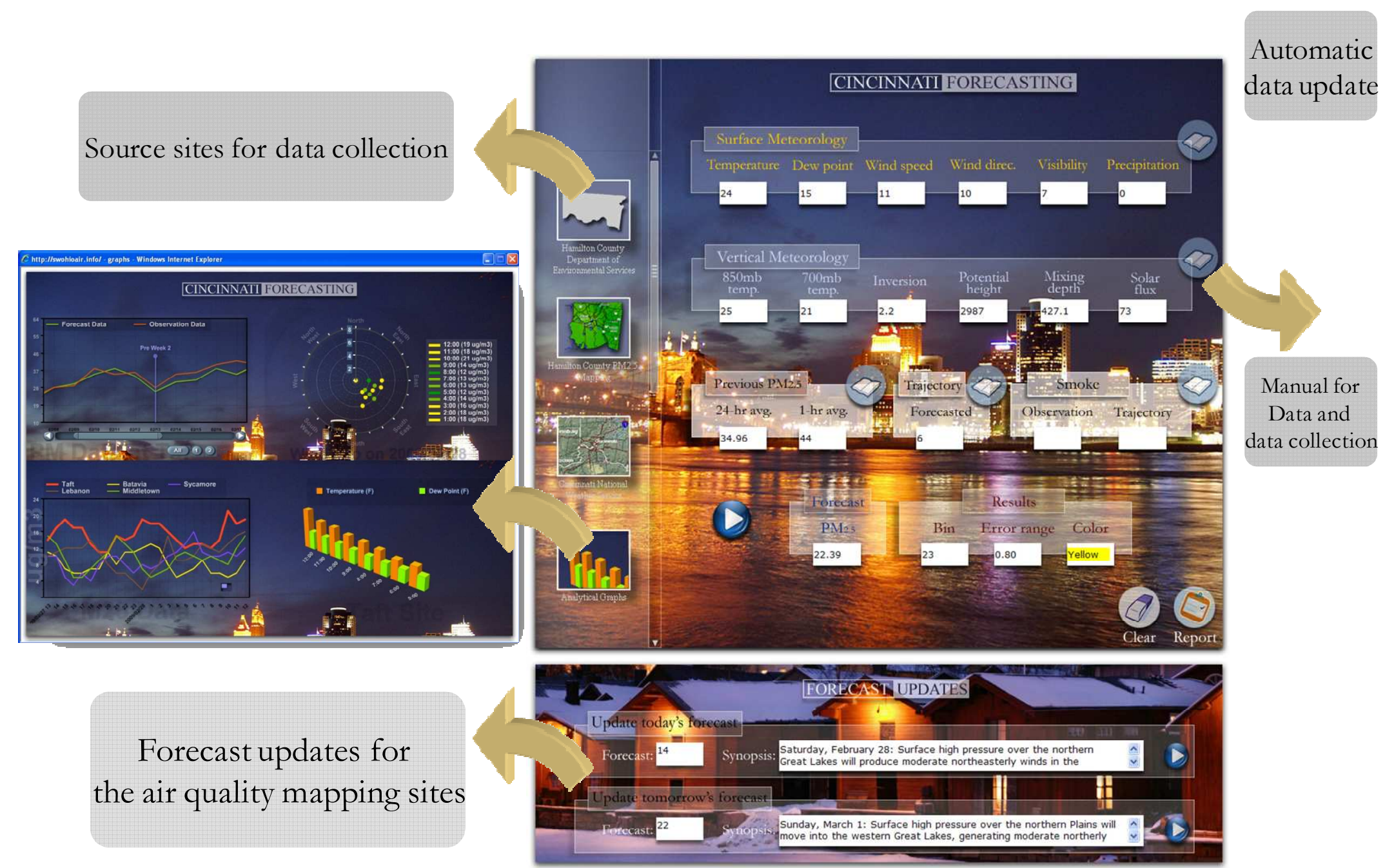

Figure 29. Online forecasting tool used for Cincinnati area forecasting.. 


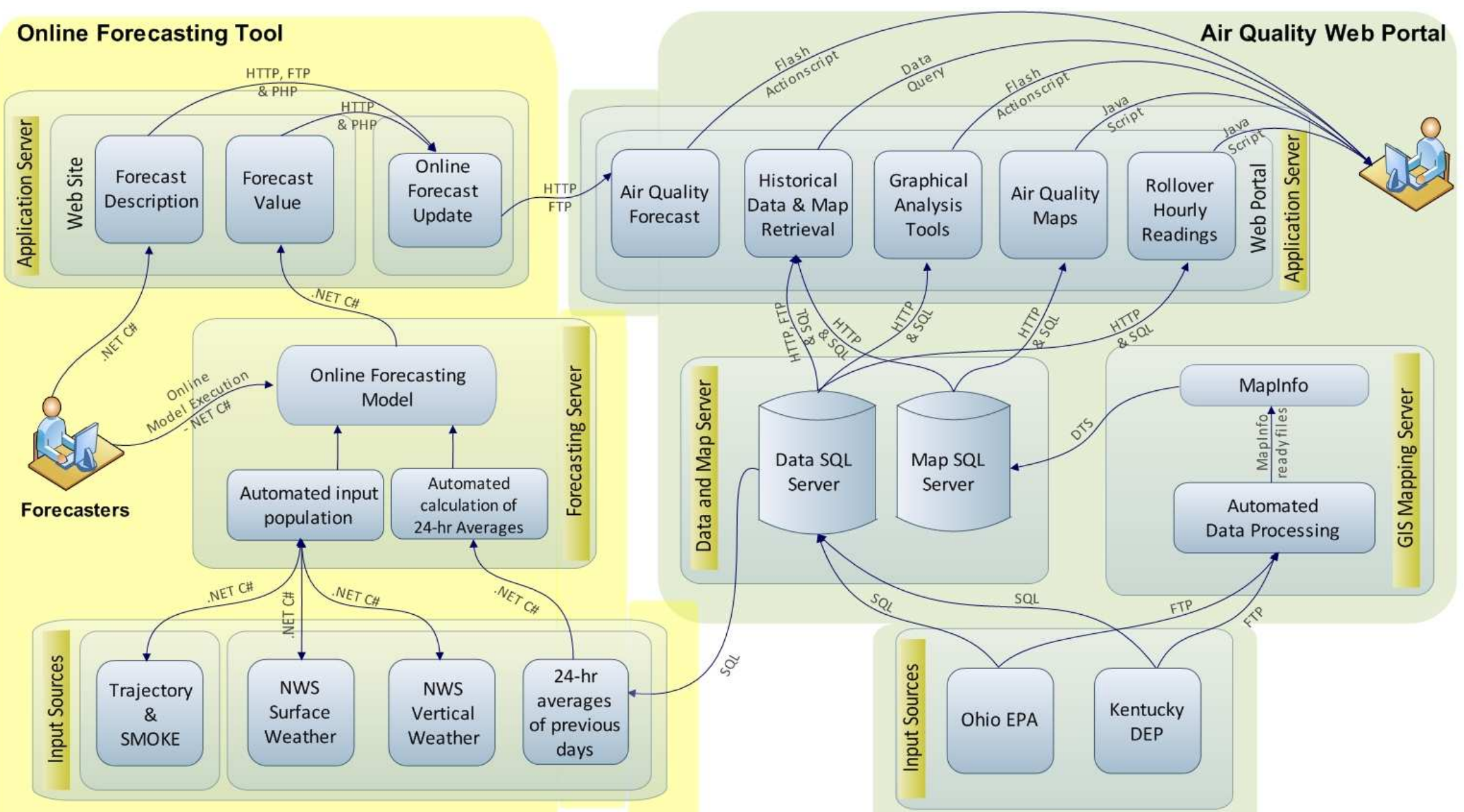

Figure 30. Structure of air quality mapping website and online forecasting tool. 


\section{Task 7. Project Management, Data Analysis, and Reporting}

Proposed: This task involves all communication between the project team members, DOE-NETL, and external collaborating parties and includes all meetings, presentations, and DOE-required reports pertaining to the project. To facilitate data analysis, the data from the SAM and the results of the model runs will be archived into a user-friendly database that will provide functionality to help calculate final mercury and fine particulate matter mass and composition concentrations. It will also allow the delineation of basic trends and the evaluation of variables. To the greatest extent possible, the data from the SAM site will be incorporated into the ambient air quality database being compiled for DOE-NETL by ATS and Ohio University under project DEFC26-02NT41476. However, the primary function of the database will be to reduce data efficiently for evaluation of the proposed model simulations. At the conclusion of the project, Ohio University will submit the database containing the SAM information, results of model runs, and comparison statistics to DOE-NETL along with a comprehensive final report.

\section{Accomplishments:}

- Researchers completed the monitoring campaign at the Athens Supersite under this contract. The site is currently supported under a separate USEPA contract. OU research team completed the analysis of the speciation samples. Listed below are the papers that have been published and are currently under development that highlight the data and analysis and modeling associated with this project.

\section{Published Papers:}

1. Drewniak, B.A., Kotamarthi, V.R., Streets, D., Kim, M., and Crist, K. Estimates of mercury flux into the United States from non-local and global sources: results from a 3-D CTM simulation. Atmospheric Chemistry and Physics, 8, 19861-19890, 2008

2. Kim, M., Deshpande, S.R., and Crist, K. Source Apportionment of Fine Particulate Matter (PM2.5) at a Rural Ohio River Valley Site. Atmospheric Environment, 41, 9231-9243, 2007

3. Yetavelli, R.L.N., Fahrni, J.K., Kim, M., Crist, K., Vickers, C.D., Winter, S.E. and Connell, D.P. Mercury, $\mathrm{PM}_{2.5}$ and Gaseous Co-Pollutants in the Ohio River Valley Region: Preliminary Results from the Athens Supersite. Atmospheric Environment, 40, 6650-6665, 2006

\section{Paper under Development:}

\section{Mercury}

1. The Episodic Nature of Ambient Mercury At a Rural Ohio River Valley Supersite, prepared for Atmospheric Environment, 2007

2. Temporal Variability of Ambient Mercury at a Rural Site in the Ohio River valley area, prepared for Atmospheric Environment, 2007 
3. Analysis of Mixing Boundary Layer Dynamics Impact on Temporal Mercury Species Variability, prepared for Environmental Science \& Technology, 2007

4. Interaction of Mercury Species with Water Vapor Mixing Ratio and Ozone Concentration, prepared for Journal of Applied Meteorology, 2007

5. Evaluation of Mercury Wet Deposition At A Rural Ohio River Valley, prepared for Atmospheric Environment, 2007

6. Source Apportionment of Elemental Mercury in Ohio River Valley using Positive Matrix Factorization, prepared for Atmospheric Environment, 2007

7. Identification of source locations for mercury species using trajectory-based models, prepared for Atmospheric Environment, 2007

\section{$\mathbf{P M}_{2.5}$}

1. Analysis of Fine Particulate Matter at a Rural Site in the Ohio River Valley Part I: Chemical Composition and Temporal-Spatial Variation, prepared for Journal of Air \& Waste Management, 2007

2. Analysis of Fine Particulate Matter at a Rural Site in the Ohio River Valley Part II: Influence of Meteorological conditions, prepared for Journal of Air \& Waste Management, 2007

\section{Modeling}

1. Numerical Simulation of Precipitation for Ohio Using Observational Data Assimilation in a 4-km prognostic Meteorological Model, prepared for Atmospheric Research, 2007 


\section{SUMMARY OF RESULTS}

The monitoring campaign at the Athens SAM was concluded in November of 2005 under this contract. The site has been in operation under an USEPA contract and has been expanded to include $\mathrm{NO}_{\mathrm{y}}$, low level $\mathrm{CO}$ (used as co-pollutants for mercury source and transport analysis), and measurements for regional haze. Ohio University developed a series of papers around the analysis of the monitoring data.

Ohio University completed regional emissions inventory updates. The focus of their efforts was to develop a comprehensive and accurate emission inventory utilizing current research on emissions data from coal-fired power plants. Argonne National Laboratory improved global emission inventory, specifically for China emissions. The investigation suggested that the Argonne-revised China's point source emissions are greater than the previous other emissions while the area emissions of the other studies was greater than those of Argonne-updated China emissions. This revised China emissions resulted in an increase of $\mathrm{Hg}^{0}$ concentration transported into U.S. due to its elevated stack emissions.

Argonne National Laboratory completed MOZART 3-D CTM global modeling using an enhanced global emissions inventory for mercury. The global modeling results have been utilized as initial and boundary conditions for base cases simulations including the seasonal /short-term scale modeling. Due to the global modeling, we could provide finer temporal and spatial resolution.

The OU researchers chose the CMAQ model developed for air-pollution studies on a regional scale by the USEPA and its collaborators. The modeling framework for the 2004 base-case was completed for mercury with $36 x 36 \mathrm{~km}$ grid system and $\mathrm{PM}_{2.5}$ with $4 \mathrm{~km}$ grids. And an MM5 simulation was optimized for precipitation accuracy. Statistical model verification suggested that CMAQ model performed relatively well for elemental mercury (October, $\mathrm{R}^{2}=0.25$ ) and $\mathrm{PM}_{2.5}$ (high pollution episode, $\mathrm{R}^{2}=0.54$ ) as compared with observation data. However, RGM was overestimated. The proposed reason is reduction mechanism in CMAQ was still needed to improve. Wet deposition was in a good agreement (seasonal average, $\mathrm{R}^{2}=0.35$ ) but over-predicted. This could result from the over-predicted precipitation of meteorological modeling as well as over-estimated RGM in the chemistry model.

OU conducted the short-scale simulations of mercury for October 2004 and high $\mathrm{PM}_{2.5}$ episodes in 2004 and utilized a GIS interface for the decision support tool. These short-term high pollution episodes can be used for decision making process. In addition a two phase box model was established and the research team completed sensitivity analysis on the oxidation of elemental mercury and its impact on local RGM levels. This analysis suggested that Ohio River Valley area is most likely an oxidizing environment 
and that reduction of RGM most likely occurs during plume events. These findings can be used enhance the mercury chemistry schemes in the CTM system.

Three scenarios were selected to quantify source contribution of electricity generation utilities (IPM sources), global background concentration, and China emissions. The results indicated the electrical generation utilities exhibited 42 to $71 \%$ of contribution to mercury wet deposition in the Ohio River Valley region, global background 28 to $50 \%$, and China emissions 5 to $6 \%$ contributions.

Web-based data management system was developed to provide visualization and online mapping for emissions and modeling results that can be used as decision support tools. $\mathrm{PM}_{2.5}$ forecasting system was developed to provide online forecasting tools for local air quality forecasters. OU researchers published and submitted peer-reviewed journals highlight the data and analysis and modeling associated with this project.

\section{CONCLUSIONS}

The research team concluded the monitoring campaign, global modeling, regional photochemical modeling for gaseous mercury species, mercury wet/dry deposition, and $\mathrm{PM}_{2.5}$ for seasonal months for 2004 . The base-case simulations were in a good agreement with observations and sensitivity simulations identified 42 to $71 \%$ of contribution to mercury wet deposition in the Ohio River Valley region, global background 28 to 50\%, and China emissions 5 to $6 \%$ contributions. The research team also investigated mercury depletion events associated with oxidation of elemental mercury using box modeling and found that ORV region is an oxidizing environment. OU researchers developed online data and mapping support system that can serve as decision support tools. 


\section{REFERENCES}

Byun, D. and J. Ching, 1999. Introduction to the Models-3 framework and the Community Multiscale Air Quality Model (CMAQ). In Science Algorithms of the EPA Models-3 Community Multiscale Air Quality (CMAQ) Modeling System, EPA/600/R99/030, U.S. Environmental Protection Agency, Washington, D.C

Cohen, M., Artz, R., Draxler, R., Miller, P., Poissant, L., Niemi, D. Modeling the atmospheric transport and deposition of mercury to the Great Lakes. Environmental Research, 95(3), 247-265, 2004.

Drewniak, B.A., Kotamarthi, V.R., Streets, D., Kim, M., and Crist, K. Estimates of mercury flux into the United States from non-local and global sources: results from a 3-D CTM simulation. Atmospheric Chemistry and Physics, 8, 19861-19890, 2008

Hall, B. The gas-phase oxidation of elemental mercury by ozone. Water Air \& Soil Poll., 80, 235-250, 1995.

Horowitz, L.W., Walters, S., Mauzerall, D.L., Emmons, L.K., Rasch, P.J., Granier, C., Tie, X., Lamarque, J.F., Schultz, M.G., Tyndall, G.S., Orlando, J.J., and Brasseur, G.P. A global simulation of tropospheric ozone and related tracers: Description and evaluation of MOZART, version 2. J. Geophys. Res., 108, 4784, 2003

Fitzgerald, W.F. Atmospheric and Oceanic cycling of mercury. Chemical Oceanography, 10, 151-186, 1986

Kim, M., Deshpande, S.R., and Crist, K. Source Apportionment of Fine Particulate Matter (PM2.5) at a Rural Ohio River Valley Site. Atmospheric Environment, 41, 9231-9243, 2007

Pacyna, E.G., and Pacyna, J.M. Global emission of mercury from anthropogenic sources in 1995. Water, Air and Soil Pollution, 137, 149-165, 2002

Pacyna, E.G., Pacyna, J.M., Steenhuisen, F., and Wilson, S. Global anthropogenic mercury emission inventory for 2000. Atmos. Environ., 40, 4048-4063, 2006.

Yetavelli, R.L.N., Fahrni, J.K., Kim, M., Crist, K., Vickers, C.D., Winter, S.E. and Connell, D.P. Mercury, $\mathrm{PM}_{2.5}$ and Gaseous Co-Pollutants in the Ohio River Valley Region: Preliminary Results from the Athens Supersite. Atmospheric Environment, 40, 6650-6665, 2006

Schroeder, W.H., and Munthe, J. Atmospheric Mercury - An Overview. Atmospheric Environment, 32, 809-822, 1998.

Sommer, J., Gårdfeldt, K., Strömberg, D., and Feng, X. A kinetic study of the gas-phase reaction between the hydroxyl radical and atomic mercury. Atmospheric Environment, 35, 3049-3054, 2001.

Streets, D.G., Jiming, H., Wu, Y., Jiang, J., Chan, M., Tian, H., and Feng, X. Anthropogenic mercury emissions in China, Atmos. Environ., 39, 7789-7806, 2005. 


\section{LIST OF ACRONYMNS AND ABBREVIATIONS}

\begin{tabular}{|c|c|c|c|}
\hline${ }^{210} \mathrm{~Pb}$ & Rediactive Lead Isotope & $\mathrm{Hg}_{\mathrm{p}}$ & Particulate Mercury \\
\hline AER & $\begin{array}{l}\text { Atmospheric and Environmental } \\
\text { Research Inc }\end{array}$ & $\begin{array}{l}\mathrm{HNO}_{3} \\
\mathrm{IPM}\end{array}$ & $\begin{array}{l}\text { Nitric Acid } \\
\text { Integrated Planning Model }\end{array}$ \\
\hline ALM & $\begin{array}{l}\text { Aircraft Locomotive and Marine } \\
\text { Vessel }\end{array}$ & ISEE & $\begin{array}{l}\text { Institute for Sustainable Energy } \\
\text { and the Environment }\end{array}$ \\
\hline ANL & Argonne National Laboratory & LCP & Lambert Conformal Projection \\
\hline API & Application Programming Interface & MDN & Mercury Depostion Network \\
\hline ATS & Advanced Technology Systems Inc & MM5 & PSU/NCAR mesoscale model \\
\hline CAP & Criteria Air Pollutants & MOZART & Model for Ozone and Related \\
\hline CB-IV & Carbon Bond -4 chemistry & & Chemical Tracers \\
\hline CCM3 & Community Climate Model ve & MSSQL & Microsoft Sequel Query Language \\
\hline & & MW & Mega Watt \\
\hline & C & $\mathrm{N}_{2} \mathrm{O}$ & Nitrous Oxide \\
\hline $\mathrm{CH}_{2} \mathrm{C}$ & dehyde & $\mathrm{N}_{2} \mathrm{O}_{5}$ & Dinitrogen Pentoxide \\
\hline $\mathrm{CH}_{4}$ & Methane & NADP & National Acid Deposition Program \\
\hline $\mathrm{Cl}_{2}$ & Chlorine gas & NATA & National Air Toxics Assessment \\
\hline CMAQ & Community Multiscale Air & NB & Normalized Bias \\
\hline $\mathrm{CO}$ & & NCEP & National Center for Environmental \\
\hline CTM & Chemical Iransport Mo & & Prediction \\
\hline DOE & Department Of Energy & NEEDS & National Electric Energy Data \\
\hline EDGAR & $\begin{array}{l}\text { Emission Database for Global } \\
\text { Atmospheric Research }\end{array}$ & NEI & $\begin{array}{l}\text { System } \\
\text { National Emission Inventory }\end{array}$ \\
\hline EGU & Electric Generating Unit & NEI & National Emission Inventory \\
\hline EI & Emission Inventory & NetCDF & Network Common Data Form \\
\hline FB & Fractional Bias & NETL & National Energy \\
\hline FFSL & Flux Form Semi Lagrangian & & Labc \\
\hline FGE & Fractional Gross Error & NGE & Normalized Gross Error \\
\hline GEM & Gaseous Elemental Mercury & NMHC & Non-Methane Hydrocarbons \\
\hline GIS & Geographical Information System & $\mathrm{NO}_{3}$ & Nitrate Ion \\
\hline $\mathrm{H}_{2} \mathrm{O}_{2}$ & Hydrogen Peroxide & $\mathrm{NO}_{\mathrm{x}}$ & Mono Nitrogen \\
\hline HAP & Hazardous Air Pollutants & & 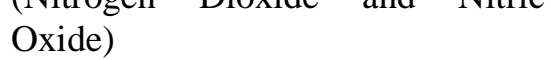 \\
\hline $\mathrm{HCL}$ & Hydrocloric Acid & $\mathrm{NO}_{\mathrm{y}}$ & $\mathrm{NO}_{\mathrm{x}}$ and their oxidation products \\
\hline $\mathrm{Hg}$ & Mercury & NRC & National Research Council \\
\hline $\mathrm{Hg}(\mathrm{II})$ & Oxidized Mercury & $\mathrm{O}_{3}$ & Ozone \\
\hline $\mathrm{Hg}^{0}$ & Elemental Mercury & $\mathrm{OH}$ & Ohio \\
\hline HGE & Elemental Mercury & $\mathrm{OH}$ & Hydroxyl Radical \\
\hline HGO & Oxidized Mercury & ORV & Ohio River Valley \\
\hline
\end{tabular}




\begin{tabular}{|c|c|c|c|}
\hline $\begin{array}{l}\mathrm{OU} \\
\mathrm{PA}\end{array}$ & $\begin{array}{l}\text { Ohio University } \\
\text { Pennsvlvania }\end{array}$ & SCAMP & $\begin{array}{l}\text { Steubenville Comprehensive Air } \\
\text { Monitoring Project }\end{array}$ \\
\hline PAN & PeroxyAcetylNitrate & SCC & Source Classification Codes \\
\hline PM & Particulate Matter & SMOKE & Sparse Matrix Operator Kernel \\
\hline $\mathrm{PM}_{2.5}$ & Fine Particulate Matter & & Emissions \\
\hline QA/QC & Quality Analysis/Quality Control & $\mathrm{SO}_{2}$ & Sulfur Dioxide \\
\hline$R \& D$ & Research And Development & USEPA & United States \\
\hline $\mathrm{R}^{2}$ & Coefficient of Determination & & Protection Agency \\
\hline RGM & Reactive Gaseous Mercury & VMR & Volume Mixing Ratio \\
\hline SAM & Surface Air Monitoring & & \\
\hline
\end{tabular}




\section{Appendix A}

\section{Summary of 2000 Global Mercury Emissions}

Comparison between two emission estimates, Pacyna et al. vs. Argonne National Laboratory

Ohio University Air Quality Center 


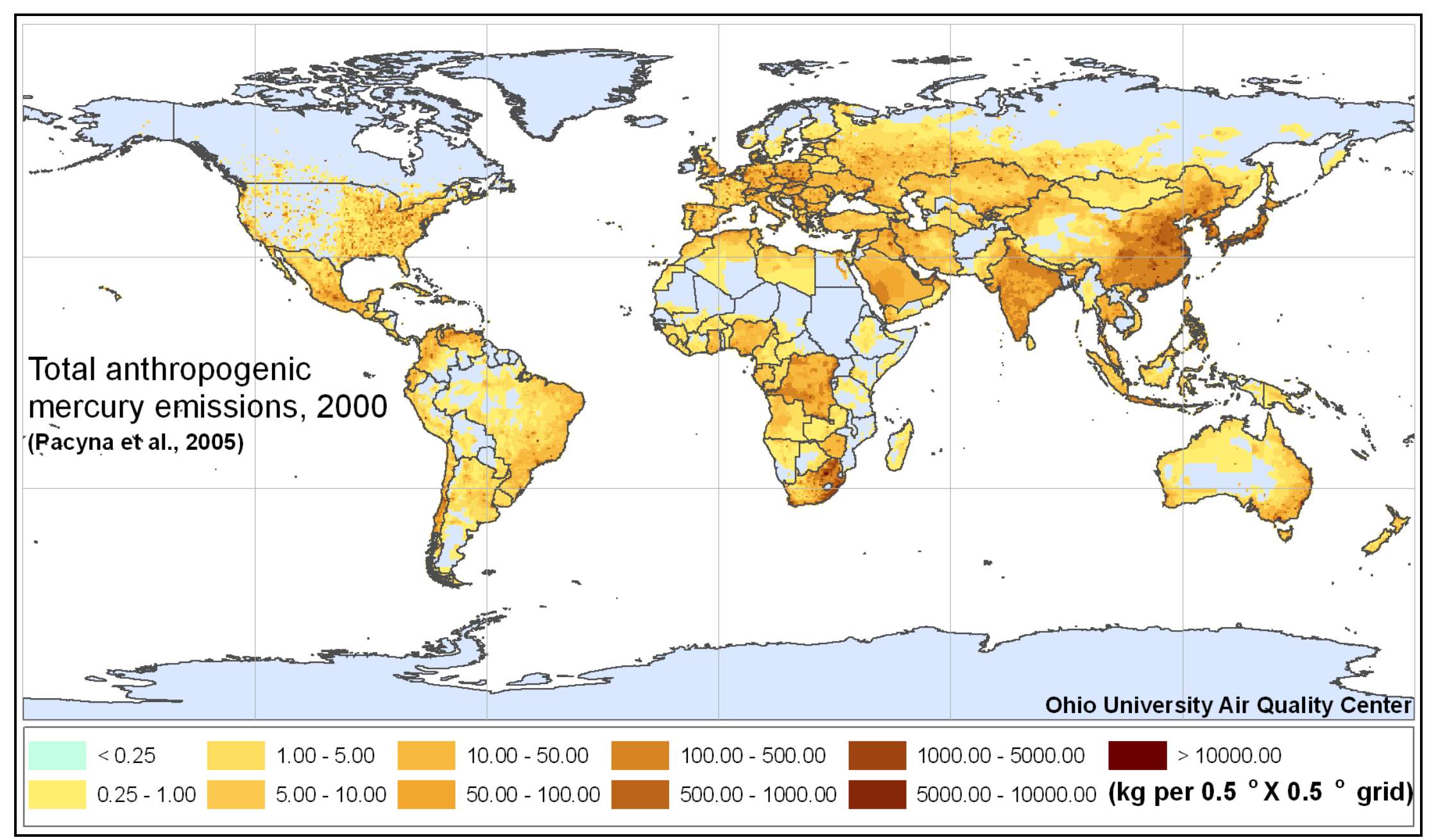

Figure 1. Total anthropogenic mercury emissions (distributed + point source) (Pacyna et al., 2005) 
Total anthropogenic mercury emission with updated China emissions from Argonne

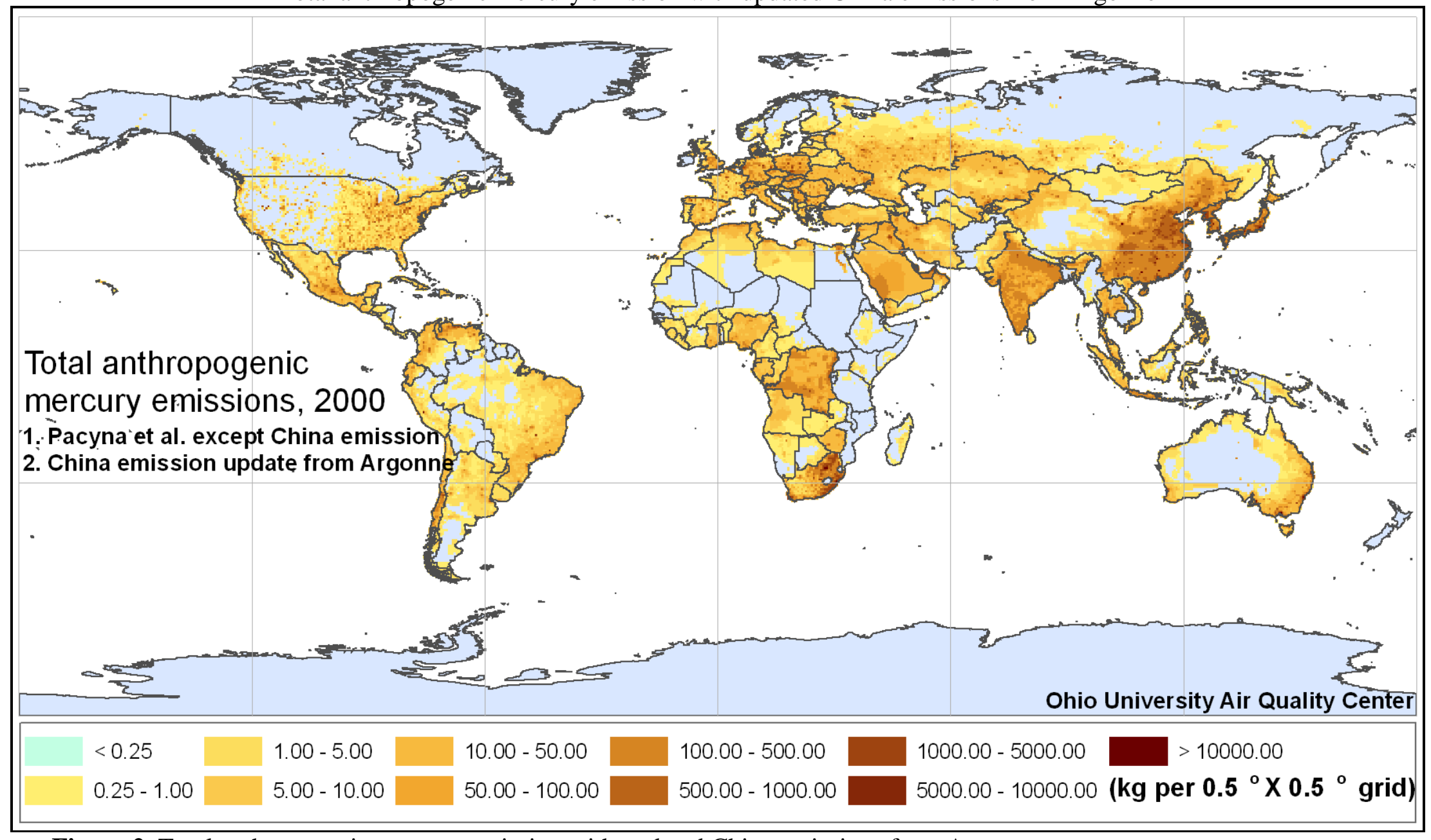

Figure 2. Total anthropogenic mercury emission with updated China emissions from Argonne 
Figure 3. Updated total mercury emission difference for all sources. (Total emission $\Delta=$ Argonne - Pacyna)

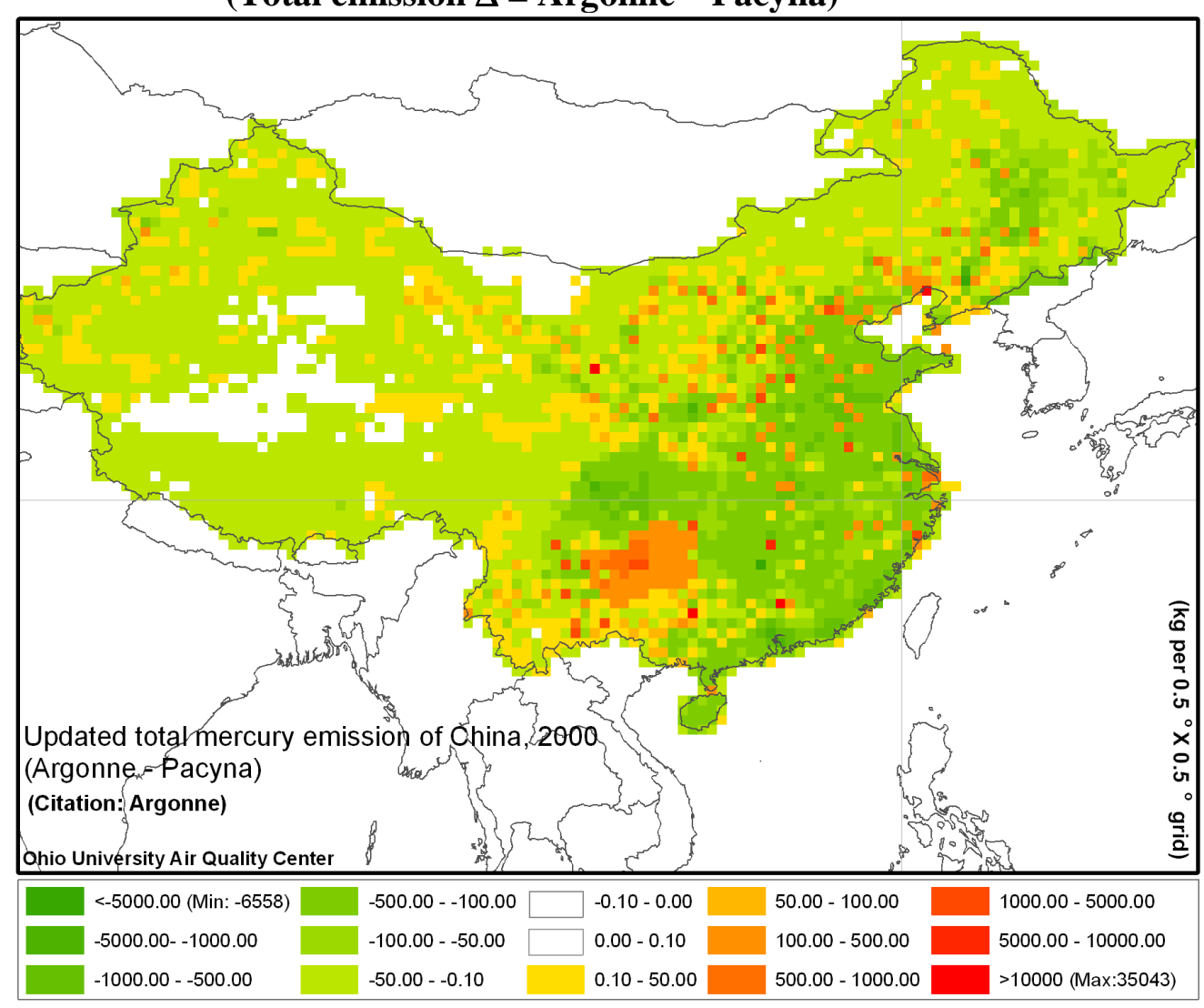

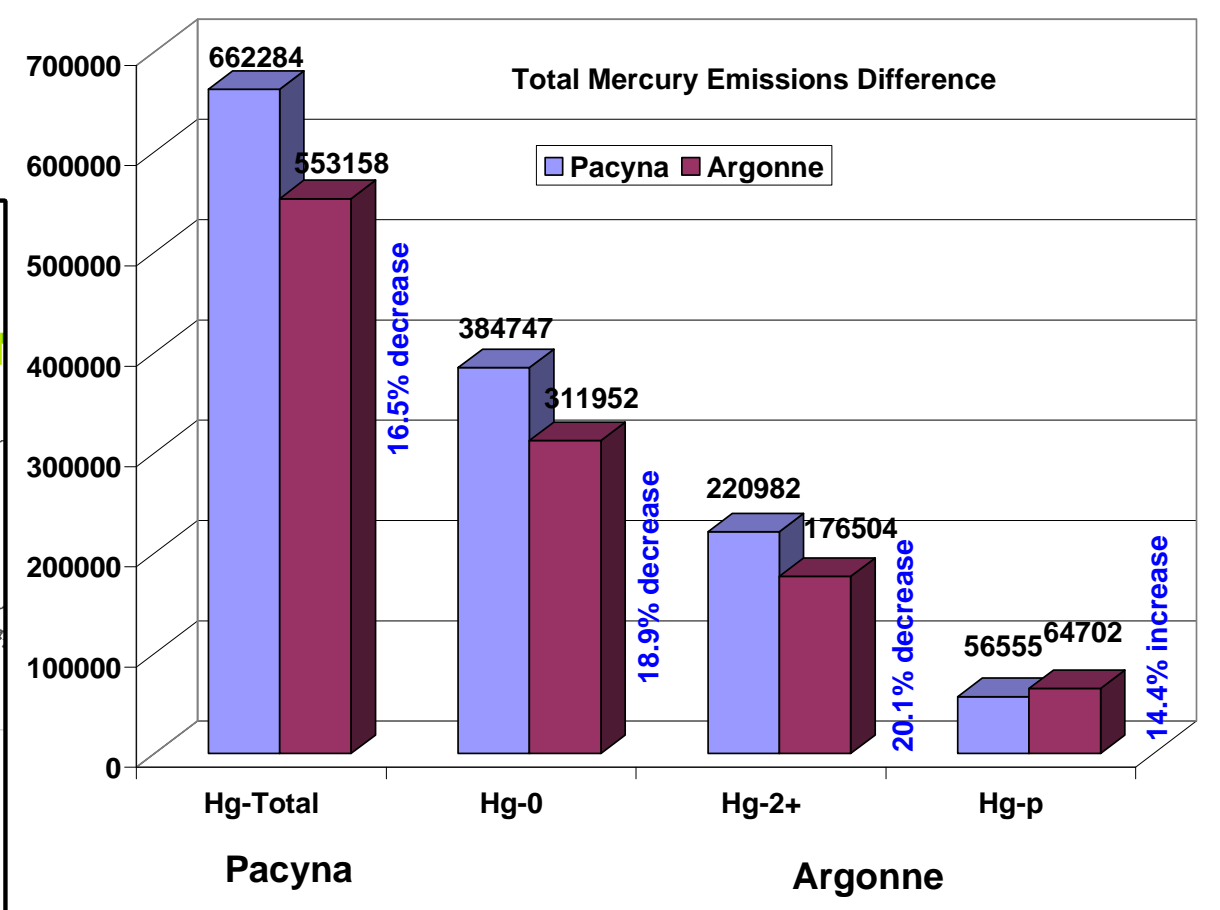
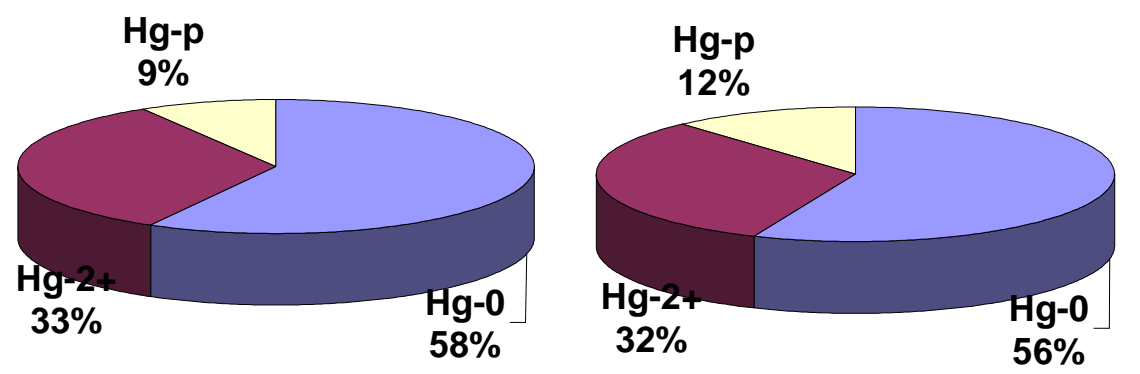
Figure 4. Point source mercury emission difference.

(Point source emission $\Delta=$ Argonne - Pacyna)

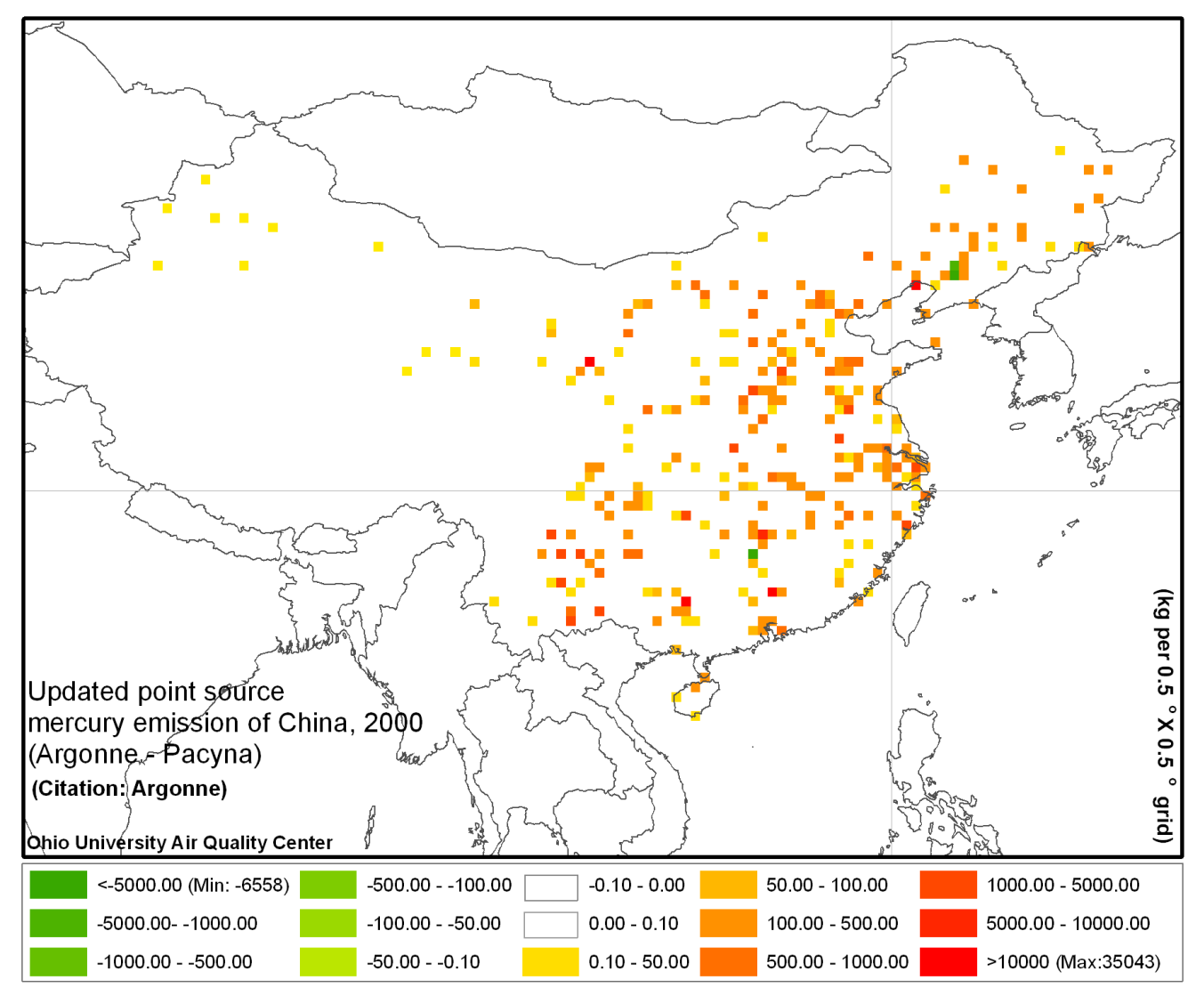

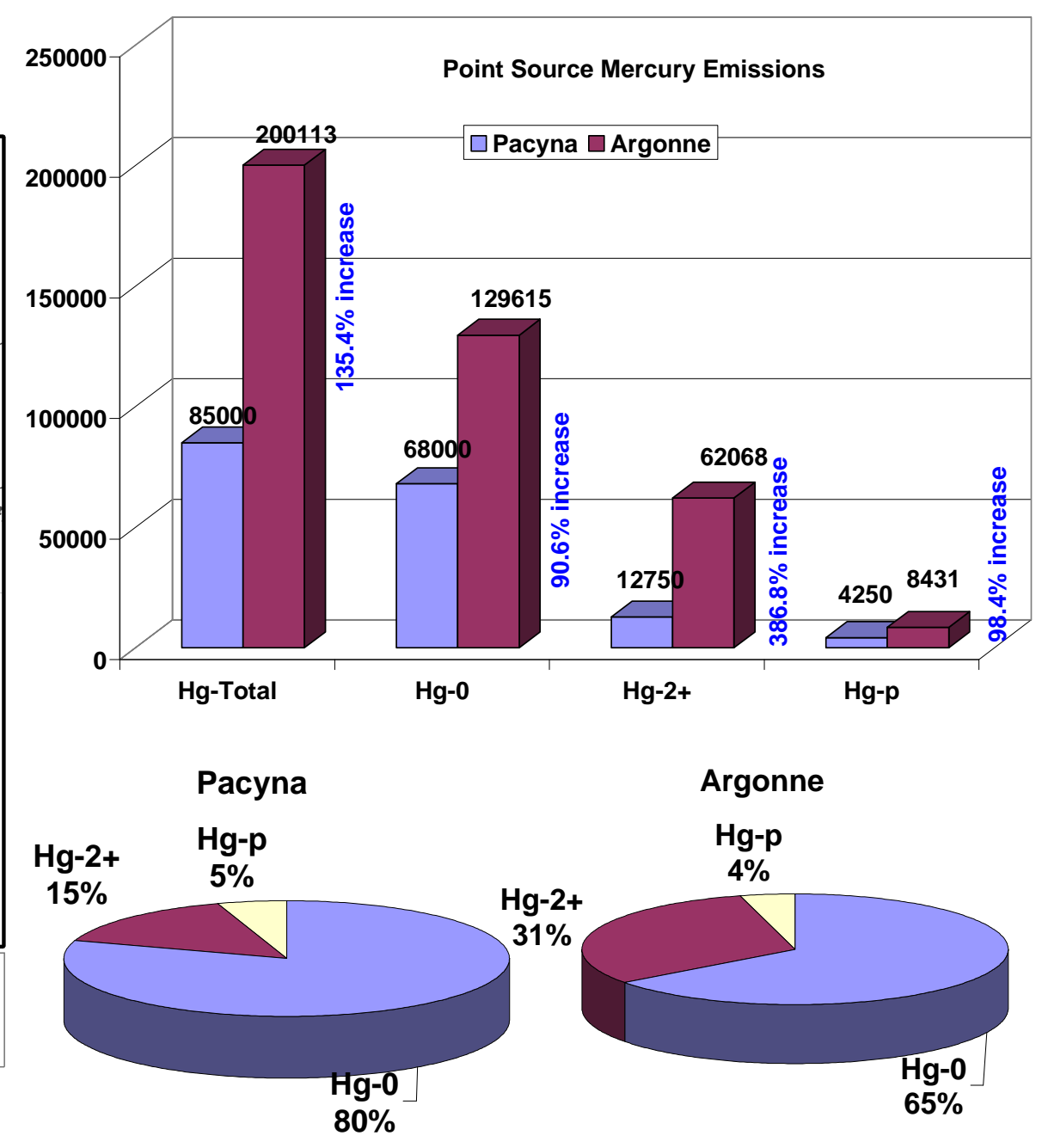


Figure 5. Distributed source mercury emission difference.

(Distributed emission $\Delta=$ Argonne - Pacyna)

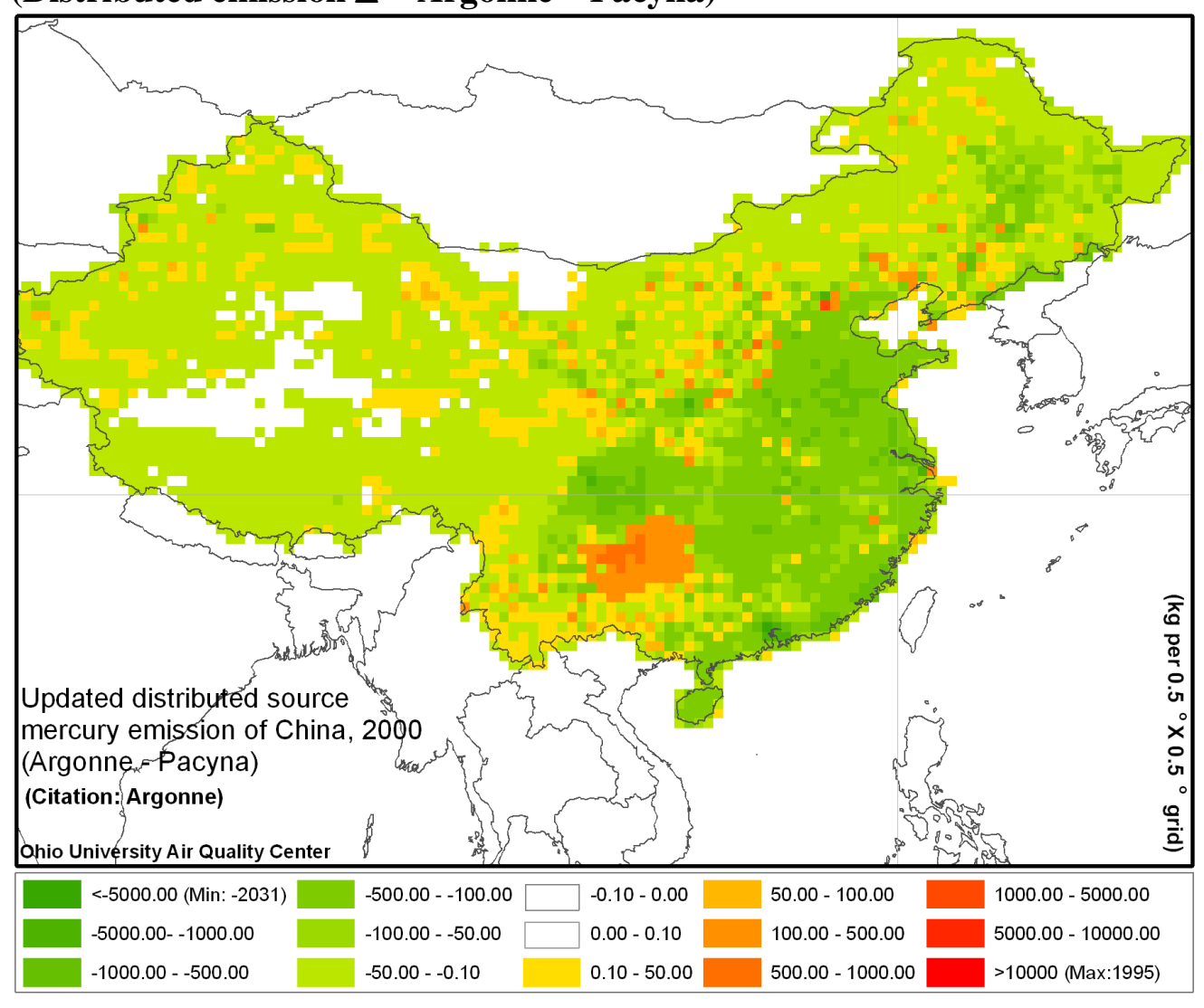

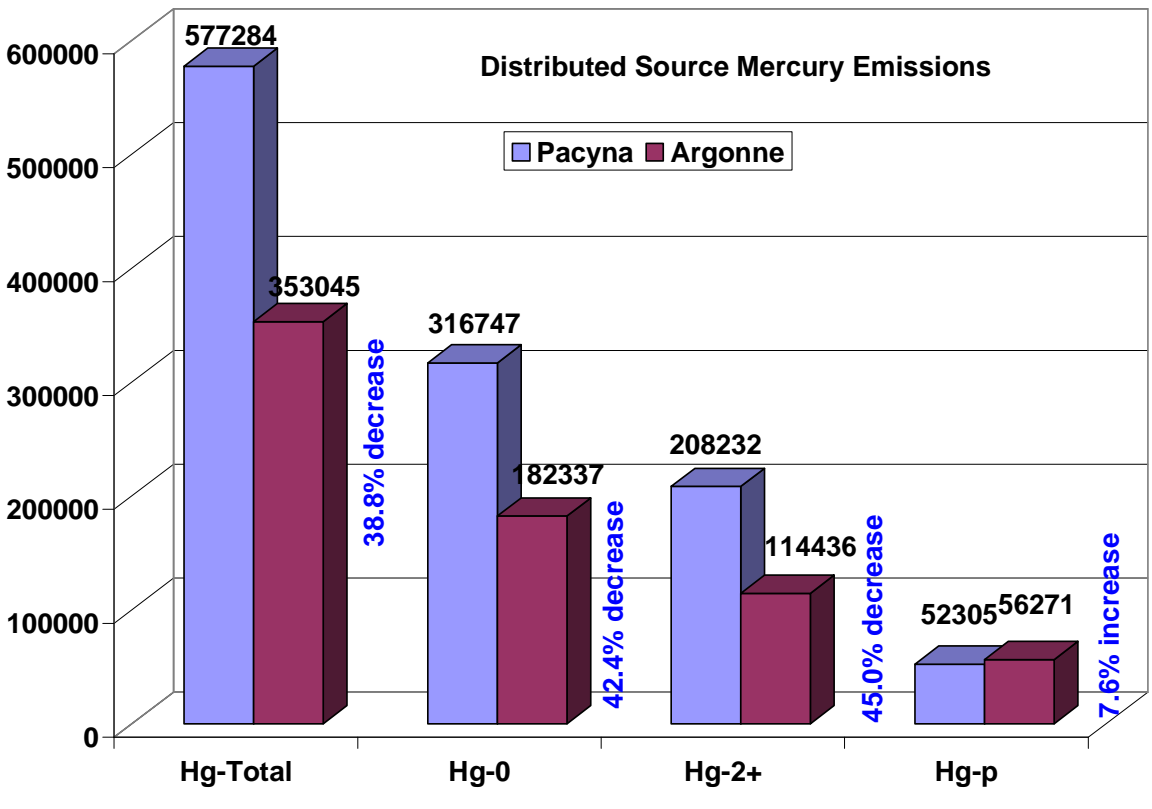

Pacyna



Argonne

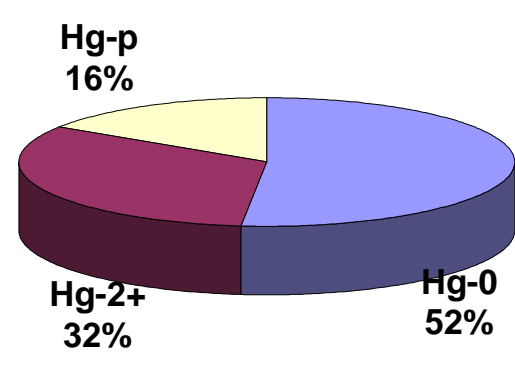


Argonne national laboratory updated China emissions of mercury species for point source and distributed emissions (area emissions) of 2000. Ohio University Air Quality Center investigated the difference between the previous China emissions estimated by Pacyna and Argonne's estimation. Figure 1 shows 2000 total anthropogenic mercury emissions $\left(\mathrm{Hg}^{0}+\mathrm{Hg}^{2+}+\mathrm{Hg}_{\mathrm{p}}\right)$ estimated by Pacyna for surface level. In Figure 2, Pacyna's China emission was replaced with Argonne's updated China emissions.

All sources (Point source + distributed source): Argonne's mercury emission estimation for all sources was less than Pacyna's estimation by $16.5 \%, 18.9 \%, 20.1 \%$, for total mercury, gaseous elemental mercury (GEM) and reactive gaseous mercury (RGM), respectively. In contrast, particulate mercury $\left(\mathrm{Hg}_{\mathrm{p}}\right)$ estimated by Argonne increased by $14.4 \%$.

Point sources: Argonne's mercury emission estimation for point source category increased by $135.4 \%, 90.6 \%, 386.8 \%$, and $98.4 \%$ for total mercury, GEM, RGM, and $\mathrm{Hg}_{\mathrm{p}}$, respectively. Argonne's RGM emission estimation was significantly more than Pacyna's in the point source emission estimation.

Distributed sources (area sources): Argonne's mercury emission estimation for distributed source category were less than Pacyna's emission estimation by $38.8 \%, 42.4 \%$, and $45.0 \%$, for total mecury, GEM, and RGM, respectively. $\mathrm{Hg}_{\mathrm{p}}$ estimation of Argonne increased by $7.6 \%$ compared to Pacyna's estimation. Argonne's $\mathrm{Hg}_{\mathrm{p}}$ emission estimation was significantly more than Pacyna's in the distributed emission estimation. 


\section{Appendix B}

ESTIMATES OF MERCURY FLUX INTO THE UNITED STATES FROM NON-LOCAL AND GLOBAL SOURCES: RESULTS FROM A 3-D CTM SIMULATION 


\title{
Estimates of mercury flux into the United States from non-local and global sources: results from a 3-D CTM simulation
}

\author{
B. A. Drewniak,1 V. R. Kotamarthi,1 D. Streets,2 M. Kim,3 and K. Crist3 \\ [1]\{Environmental Science Division, Argonne National Laboratory, Argonne, IL\} \\ [2] \{Decision and Information Sciences Division, Argonne National Laboratory, Argonne, IL\} \\ [3] Department of Chemical Engineering, Ohio University, Athens, $\mathrm{OH}\}$ \\ Correspondence to: B. A. Drewniak (bbye@anl.gov)
}

\begin{abstract}
The sensitivity of $\mathrm{Hg}$ concentration and deposition in the United States to emissions in China was investigated by using a global chemical transport model: Model for Ozone and Related Chemical Tracers (MOZART). Two forms of gaseous $\mathrm{Hg}$ were included in the model: elemental $\mathrm{Hg}$ (HGE) and oxidized or reactive $\mathrm{Hg}$ (HGO). We simulated three different emission scenarios to evaluate the model's sensitivity. One scenario included no emissions from China, while the others were based on different estimates of $\mathrm{Hg}$ emissions in China. The results indicated, in general, that when $\mathrm{Hg}$ emissions were included, HGE concentrations increased both locally and globally. Increases in $\mathrm{Hg}$ concentrations in the United States were greatest during spring and summer, by as much as 7\%. Ratios of calculated concentrations of $\mathrm{Hg}$ and $\mathrm{CO}$ near the source region in eastern Asia agreed well with ratios based on measurements. Increases similar to those observed for HGE were also calculated for deposition of HGO. Calculated increases in wet and dry deposition in the United States were 5-7\% and 5-9\%, respectively. The results indicate that long-range transcontinental transport of $\mathrm{Hg}$ has a non-negligible impact on $\mathrm{Hg}$ deposition levels in the United States.
\end{abstract}

\section{Introduction}

Mercury in the environment poses a risk to human health [NRC, 2000]. Environmental $\mathrm{Hg}$ levels around the world have increased considerably in recent years, and even regions with no significant emissions, such as the Arctic, are affected by the transcontinental transport of $\mathrm{Hg}$. Modeling studies and measurements have confirmed the ability of elemental Hg (HGE) to be transported over long distances [Seigneur et al., 2001; Travnikov and Ryaboshapko, 2002; Banic et al., 2003; Dastoor and Larocque, 2004]. This finding has generated concern in the United States that substantial quantities of long-range-transported atmospheric $\mathrm{Hg}$ might interfere with the ability of domestic sources to comply with future emission limitations [Steding and Flegal, 2002; Seigneur et al., 2004]. Mercury emissions from anthropogenic sources in rapidly growing economies in Asia and their impact on global $\mathrm{Hg}$ concentrations are of concern [Jaffe et al., 2005]. Seigneur et al. [2004] estimated that anthropogenic emission of $\mathrm{Hg}$ in Asia contributed $21 \%$ of the total $\mathrm{Hg}$ deposition in the contiguous United States in 1998.

In this study, we coupled new emission inventories for China with a global chemical transport model (CTM) to perform a fresh assessment of the relative contributions of local and distant sources to $\mathrm{Hg}$ deposition in the United States. An existing global-scale three-dimensional (3-D) CTM, the Model for Ozone and Related Chemical Tracers (MOZART), was modified to include gas-phase $\mathrm{Hg}$ chemistry. Simulations were performed by using the National Center for Environmental Prediction (NCEP) assimilated dynamic fields for the year 2004. Several 
calculations were performed to test the sensitivity of U.S. atmospheric $\mathrm{Hg}$ concentrations and deposition fluxes to a set of emission estimates from China, as follows:

- The first calculation was performed by using the global-scale emissions developed by Pacyna et al. [2006].

- A second estimate of emissions from China, developed by Streets et al. [2005], was substituted for the Pacyna et al. [2006] estimate in the second calculation.

- In a third calculation, we assign net zero emissions of $\mathrm{Hg}$ from China, while retaining the Pacyna et al. [2006] estimate for the rest of the world.

We present results from these simulations, particularly the expected contribution of sources in Asia to the U.S. atmosphere. Our primary aim was to investigate the impact of this range of emissions from China on the United States, rather than focusing on uncertainties in the chemical mechanism leading to the formation of oxidized or reactive Hg (HGO) from HGE.

\section{Methods}

\section{Model Framework}

We used MOZART as described in Horowitz et al. [2003] and Wei et al. [2002], modified to include $\mathrm{Hg}$ chemistry. The grid resolution was based on meteorology data at 2.8 degrees latitude $\times 2.8$ degrees longitude, with 28 vertical levels extending from the surface to $2.7 \mathrm{mb}$. This model accounts for surface emissions (including $\mathrm{N}_{2} \mathrm{O}, \mathrm{CH}_{4}, \mathrm{CO}, \mathrm{NO}_{\mathrm{x}}, \mathrm{NMHC}$, $\mathrm{CH}_{2} \mathrm{O}$, isoprene, acetone, etc.), chemical and photochemical reactions, advection, convection, and wet and dry deposition. The emission fluxes in MOZART for anthropogenic species were based on the Emission Database for Global Atmospheric Research (EDGAR) [Olivier et al., 1996]. The version of MOZART used here provides spatial and temporal distributions for 52 chemical tracers, with a chemistry scheme similar to the one described by Brasseur et al. [1998], which incorporates 107 gas-phase, 5 heterogeneous, and 29 photochemical reactions. Empirical first-order heterogeneous reactions involving $\mathrm{N}_{2} \mathrm{O}_{5}$ and $\mathrm{NO}_{3}$ on sulfate aerosols are implemented in the model (see Müller and Brasseur [1995] for details). Advection of the trace gases was simulated by using the flux-form semi-Lagrangian (FFSL) formulation of Lin and Rood [1996], which replaces the previous shape-preserving semi-Lagrangian scheme [Williamson and Rasch, 1989]. The FFSL scheme is conservative and upstream biased. In addition, it contains monotonic constraints and conserves tracer correlations. Convective transport of trace gases was parameterized by using the schemes developed by Hack [1994] for shallow convection and by Zhang and McFarlane [1995] for deep convection, as in the National Center for Atmospheric Research Community Climate Model CCM3. Vertical diffusion with the boundary layer was represented by the parameterization of Holtslag and Bonville [1993]. Dry deposition velocities for species including $\mathrm{O}_{3}, \mathrm{NO}_{\mathrm{x}}, \mathrm{HNO}_{3}, \mathrm{PAN}$, organic nitrates, $\mathrm{H}_{2} \mathrm{O}_{2}$, organic peroxides, $\mathrm{CH}_{2} \mathrm{O}$, $\mathrm{CH}_{3} \mathrm{COCHO}, \mathrm{CO}, \mathrm{CH}_{3} \mathrm{COCH}_{3}, \mathrm{CH}_{4}$, and ${ }^{210} \mathrm{~Pb}$ were computed from resistances specified as a sum of species-independent aerodynamic resistance and species-dependent surface resistance. MOZART also contains wet deposition of soluble species (such as $\mathrm{HNO}_{3}, \mathrm{H}_{2} \mathrm{O}_{2}, \mathrm{CH}_{3} \mathrm{OOH}$, $\mathrm{C}_{3} \mathrm{H}_{7} \mathrm{OOH}, \quad \mathrm{C}_{3} \mathrm{H}_{6} \mathrm{OHOOH}, \quad \mathrm{CH}_{3} \mathrm{COCH}_{2} \mathrm{OOH}, \quad \mathrm{CH}_{3} \mathrm{COOOH}, \quad \mathrm{C}_{2} \mathrm{H}_{5} \mathrm{OOH}, \quad \mathrm{HO}_{2} \mathrm{NO}_{2}$, $\left.\mathrm{CH}_{3} \mathrm{COCHO}_{2} \mathrm{CH}_{2} \mathrm{OHNO}, \mathrm{CH}_{2} \mathrm{O}\right)$. For highly soluble gases $\left(\mathrm{HNO}_{3}\right.$ and $\left.\mathrm{H}_{2} \mathrm{O}_{2}\right)$, in-cloud scavenging and below-cloud scavenging by raindrops are included, as given by Brasseur et al. [1998]. In-cloud scavenging is parameterized for all other species according to Giorgi and Chameides [1985]. MOZART version 1 was described by Brasseur et al. [1998] and evaluated by Hauglustaine et al. [1998]. We simulated one full year of $\mathrm{Hg}$ transport, driven with observed 
monthly meteorology data from NCEP for calendar year 2004. Multiyear simulations were created by running one year of data repeatedly until a steady state was achieved.

\section{Mercury Chemistry}

The two $\mathrm{Hg}$ species currently included in the model are HGE and HGO. Atmospheric chemistry for $\mathrm{Hg}$ is included in MOZART for HGE. The following reactions of HGE with $\mathrm{O}_{3}$, $\mathrm{HCl}, \mathrm{Cl}_{2}, \mathrm{H}_{2} \mathrm{O}_{2}$, and $\mathrm{OH}$ are included:

$$
\begin{aligned}
& \mathrm{HGE}+\mathrm{O}_{3} \rightarrow \mathrm{HGO}+\mathrm{O}_{2} \\
& \mathrm{HGE}+\mathrm{H}_{2} \mathrm{O}_{2} \rightarrow \mathrm{Hg}(\mathrm{OH})_{2} \\
& \mathrm{HGE}+\mathrm{OH} \rightarrow \mathrm{HGO}
\end{aligned}
$$

The reaction rate for reaction (1) was set at $3 \times 10^{-20}$ molec $\mathrm{cm}^{-3} \mathrm{~s}^{-1}$ on the basis of Hall [1995]. The rate constant for reaction (2), leading to the production of $\mathrm{Hg}(\mathrm{OH})_{2}$, was $8.5 \times 10^{-19}$ molec $\mathrm{cm}^{-3} \mathrm{~s}^{-1}$ [Tokos et al., 1998], and the rate for reaction (3) involving HGE and OH was $8 \times$ $10^{-14}$ molec $\mathrm{cm}^{-3} \mathrm{~s}^{-1}$ [Sommer et al., 2001; Pal and Ariya, 2004]. All $\mathrm{Hg}$ in the model was considered to be emitted as HGE at the surface. The dry deposition of HGE was set to zero, as in other models, because dry deposition is relatively small and is assumed to be equivalent to soil re-emission [Bergan et al., 1999; Ryaboshapko et al., 2007]. Wet deposition of HGE was also set to zero, because HGE is not very soluble in water.

Dry deposition of HGO was modeled with the parameters used for nitric acid [see Horowitz et al., 2003] because of the similar aqueous solubilities of these species. Wet deposition of HGO (like nitric acid) was represented as a first-order loss rate, on the basis of precipitation rates reported by Horowitz et al. [2003].

\section{Emissions}

The emission of $\mathrm{Hg}$ into the atmosphere is attributable to three different sources: natural emissions from land, natural emissions from oceans, and anthropogenic emissions. All surface emissions are assumed to be in all the form of HGE; these include 2,000 $\mathrm{Mg} \mathrm{y}^{-1}$ from land and $2,000 \mathrm{Mg} \mathrm{y}^{-1}$ from oceans, evenly distributed over Earth's surface as described by Shia et al. [1999]. Some more recent modeling studies have distributed natural $\mathrm{Hg}$ emissions according to locations of $\mathrm{Hg}$ mines and deposition patterns [Bergan et al., 1999; Seigneur et al., 2001; Seigneur et al., 2004; Selin et al., 2007]. Because we are only interested in changes in concentration and deposition due to anthropogenic $\mathrm{Hg}$ sources, and natural emissions primarily increase background concentrations, we did not include the spatial distribution of natural emissions in our model.

Anthropogenic $\mathrm{Hg}$ emissions were spatially distributed according to three cases:

1. Pacyna: Anthropogenic emissions derived from Pacyna et al. [2006].

2. No China: Same as Pacyna but with anthropogenic emissions from China set to zero.

3. Streets: Same as Pacyna but with emissions from China based on Streets et al. [2005].

The No China and the Streets cases had identical emissions except for China. The Pacyna case had higher emissions than the Streets case for China. Figure 1 shows the difference between Streets et al. [2005] emissions and Pacyna et al. [2006] emissions for China. For all Hg sources in China, Streets et al. [2005] estimated 16.5\% lower emissions. Total annual anthropogenic emissions for the three cases were as follows: $2,207 \mathrm{Mg} \mathrm{y}^{-1}$ for the Pacyna case, $1,578 \mathrm{Mg} \mathrm{y}^{-1}$ for the No China case, and $1,935 \mathrm{Mg} \mathrm{y}^{-1}$ for the Streets case. Initial conditions of background $\mathrm{Hg}$ concentrations were assumed to be $1.5 \mathrm{ng} \mathrm{m}^{-3}$ [Ebinghaus et al., 2001; Weiss-Penzias et al., 2003; Swartzendruber et al., 2006] in the form of HGE, distributed evenly over Earth's surface 
and through all layers of the atmosphere [Slemr et al., 1985]. Background concentrations of HGO were set to zero initially, because HGO has a short lifetime, and the model reaches steady state quickly.

\section{Results}

\section{Elemental Mercury}

The global background concentrations of HGE calculated by our model are shown in Fig. 2 for the Pacyna emissions case, as described in Section 2.3. Model results are shown for surface grid levels as averages for the four Northern Hemisphere seasons of winter, spring, summer, and fall. For all seasons, concentrations of HGE were highest for China, with values of $4 \mathrm{ng} \mathrm{m}^{-3}$ and more. Much of the Northern Hemisphere experiences concentrations on the order of 2-3 $\mathrm{ng} \mathrm{m}^{-3}$ during winter and fall. Seasonal trends show the greatest HGE concentrations during winter and the smallest concentrations in summer, consistent with previous observations [Iverfeldt, 1991; Ames et al., 1998; Ebinghaus et al., 2001; Kellerhals et al., 2003; Poissant et al., 2005; Stamenkovic et al., 2007]. Figure 3 compares model-calculated and measured HGE in July-December 2004 at a site in the central Ohio River valley in Athens, Ohio [Crist et al., 2006]. The site is at approximately $900 \mathrm{ft}$ above sea level and is on a small hill, at a height of $250 \mathrm{ft}$ above the surrounding terrain. The model results shown are for a grid location at $950 \mathrm{mb}$, which is approximately $250 \mathrm{ft}$ above the model surface. In general, the model-calculated concentrations are higher than measured values but within the range of the measurement variability.

Figure 4 shows the percent difference in surface concentrations of HGE between the Streets and No China simulations. Although the greatest difference is centered near and over China, evidence of transport in the Northern Hemisphere is suggested by the ubiquitous increases in HGE, with more widespread transport during spring and summer. The spring transport causes HGE concentrations to increase by up to $7 \%$ in parts of the western United States and 3-5\% in the eastern United States. Background concentrations in the Southern Hemisphere are also affected, although the effect is small, with an increase of less than $1 \%$. The average increase in $\mathrm{Hg}$ concentrations globally is $3-4 \%$.

Comparison of the Pacyna and Streets simulations (Fig. 5) also indicates an increase in percent difference of $\mathrm{Hg}$ concentrations, although the increase is smaller than for the Streets and No China comparison (Fig. 4). In spring and summer, patterns for the Pacyna-Streets comparison (Fig. 5) are similar to those for the Streets-No China comparison (Fig. 4), with an increase in concentrations that extends throughout the Northern Hemisphere and smaller increases in the Southern Hemisphere. The variability of $\mathrm{Hg}$ concentration in South Africa, Australia, and Europe (Fig. 5) is the result of differences in gridding the emission distribution input to MOZART. Although most of these effects are localized and most of the variations offset each other, they do have an impact on the regional $\mathrm{Hg}$ budget. Nevertheless, the effects do not make a large contribution to the global $\mathrm{Hg}$ budget (except for South Africa and Australia, where a few differences do not offset each other and cause an increase in $\mathrm{Hg}$ concentrations in excess of $1 \%$ in the Southern Hemisphere). For example, in the spring certain regions in the eastern United States have $\mathrm{Hg}$ concentrations that are 10\% higher in the Pacyna simulation than in Streets simulation. These pockets of high $\mathrm{Hg}$ concentration are small and occur near regions where anthropogenic emissions do not agree between the two simulations.

Previous studies have addressed the relationship between $\mathrm{Hg}$ and $\mathrm{CO}$, because both are emitted through industrial processes, have similar lifetimes, and can be transported long distances in the atmosphere [Jaffe et al., 2005; Friedli et al., 2004; Weiss-Penzias et al., 2007]. 
Figure 6 shows a time series for March 22-June 10, 2004, of calculated CO and HGE concentrations near Okinawa. We chose this time period because it falls within the observations of Jaffe et al. [2005], and spring corresponds to peak continental outflow in the western Pacific. To improve representation of episodic transport events, we removed the contribution of background emissions by subtracting No China HGE from Streets HGE. The largest transport events occurred in April and May, and several corresponded to events observed by Jaffe et al. [2005]. For example, Jaffe et al. [2005] observed a large transport event on April 20, 2004 (day 111), while MOZART calculated a transport event on April 21, 2004 (day 112). Figure 7 shows the same time series for a location near Seattle, Washington. In this case, subtraction of the No China HGE from Streets HGE revealed no episodic transport events. Mercury from China in the atmosphere seems to be fairly well mixed into the background when it has migrated this distance from the source.

Figures 8 and 9 are plots of calculated concentration ratios (HGE:CO) from the No China and Streets simulations, respectively. The slopes for the regression lines of these two graphs are $0.0043 \mathrm{ng} \mathrm{m}^{-3} \mathrm{ppbv}^{-1}$ for the No China simulation (Fig. 8) and $0.0056 \mathrm{ng} \mathrm{m}^{-3} \mathrm{ppbv}^{-1}$ for the Streets simulation (Fig. 9). These values correspond well with results for observations of Jaffe et al. [2005] ( 2004] (slope $=0.0056 \mathrm{ng} \mathrm{m}^{-3} \mathrm{ppbv}^{-1}$ ). The calculated values for HGE and CO in Figs. 8 and 9 are well correlated, with $\mathrm{R}^{2}$ values of 0.80 for the No China simulation and 0.89 for the Streets simulation. The difference in the values for correlation of determination is caused by the variability of HGE, rather than CO, between simulations. Because HGE was the only pollutant from China that was altered, the No China simulation was expected to have a lower correlation. The slope calculated in the Streets simulation is indicative of transport from China; it corresponds to the value calculated by Jaffe et al. [2005] from observations.

\section{Reactive Mercury}

To evaluate the model-calculated HGO, we analyzed wet and dry deposition, as discussed below.

\section{Wet Deposition}

Wet deposition is highly seasonal, being highest in spring and lowest in fall. Observations suggest that wet deposition is usually low during winter in the United States. The calculated wet deposition is high during winter in MOZART simulations because of large concentrations of HGO at that time. Seasonal wet deposition differences between the Streets and No China simulations are shown in Fig. 10. The differences are concentrated over China, with evidence of global transport, particularly during the summer. During winter and fall, decreased transport causes a large flux of HGO deposition over China. During spring and summer, strong winds allow Hg to cross the Pacific Ocean and become well mixed with the air in the Northern Hemisphere. Thus, during spring and summer an increase in wet deposition occurs throughout the entire Northern Hemisphere. This increase in wet deposition amounts to 7-8\% in the eastern and western United States, with larger changes in portions of the western United States. In the Southern Hemisphere, wet deposition of HGO increases globally by an average of $2 \%$. The largest increase in deposition away from the source occurs in spring, when transport is strongest and outflow from western Pacific is dominant. However, the generally greater wet deposition during this season makes the percent increases in wet deposition small. The opposite is true for the fall - though the amount of wet-deposited HGO changes little between simulations, the percent increase is large, because little wet deposition occurs in the fall. 
Differences in wet deposition between the Pacyna and Streets simulations for the spring and summer months are shown in Fig. 11. The impact of a slight increase in emission amounts from China is small. As with the Streets-No China comparison (Fig. 10), the biggest increase in emissions in the Pacyna-Streets comparison (Fig. 11) occurs during the spring; however, the largest percent change occurs during the summer because of the smaller wet deposition in summer. Again, both seasons show transport, with wet deposition increases of $5 \%$ in the southern United States, 6-7\% in the eastern and western United States, and more than 7\% in the northwestern United States and Canada during the summer. During the spring, the percent difference is $5-6 \%$ over the entire United States. The Southern Hemisphere has a difference of $1-2 \%$.

\section{Dry Deposition}

Dry deposition patterns are very similar to the wet deposition patterns. In general, dry deposition peaks in spring in the Northern Hemisphere and in fall in the Southern Hemisphere.

For dry deposition, the percent difference between the Streets and No China simulations is shown in Fig. 12. The largest percent change in dry deposition occurred over China during the winter and fall, when the year's smallest outflow into the western Pacific allowed $\mathrm{Hg}$ to be deposited near its source. However, the change in dry deposition during the spring and summer showed a more global increase. Ready transport across the Northern Hemisphere during these seasons allowed larger differences in deposition patterns between simulations, especially during the spring when transport is the highest. During the spring, differences in dry deposition increased by $7-8 \%$ in the western United States and by 6-7\% in the eastern United States. During the summer, differences in dry deposition increased by $7-9 \%$ in the western United States, by $>9 \%$ in the far northwestern United States, and by $5-6 \%$ in the eastern United States. The change in dry deposition was generally less than $1 \%$ in the Southern Hemisphere.

Although both summer and fall seasons showed large percent increases in dry deposition, absolute differences between Streets and No China were smallest during these months because of the low rates of dry deposition during this period (Section 3.3.1). Figure 11 shows the percent difference between the Pacyna and Streets simulations for spring and summer. As with wet deposition, the increase in differences for the China emissions was smaller during these months. Large increases in deposition differences occurred during spring, although the percent change was small because dry deposition was high. During the summer, a more pronounced increase occurred, particularly over China, but the pattern also extended through the Pacific Ocean and into the northwestern United States. Spring increases in differences in dry deposition were 7-9\% in the western United States and 4-6\% in the eastern United States. During the summer, the percent change in dry deposition was much greater in the northern United States (7-10\%) than in the southern [DID YOU MEAN EASTERN?] United States (2-6\%). Increases in the Southern Hemisphere amounted to $1-2 \%$ for all seasons.

\section{Conclusions}

We used the chemical transport model MOZART with two additional constituents HGE and HGO - as transported species. The model was used to evaluate the sensitivity of calculated HGE and HGO over the United States to anthropogenic emissions in China. The model-calculated $\mathrm{Hg}$ concentrations, in general, fell into the range of current observations. Concentrations of HGE are seasonal, with high values during the winter and low values during the spring. Ratios of HGE:CO also show that although Hg estimates are low in MOZART, the model does capture the relationship between $\mathrm{Hg}$ and the $\mathrm{CO}$ tracer, demonstrating the model's 
ability to simulate the correct HGE pattern. Deposition of $\mathrm{Hg}$ is also seasonal, with peaks in the springtime and minimum values during the fall. With decreased or increased emissions from China, changes in concentration and deposition are experienced globally. Large changes occur locally during winter and fall, and changes in transport occur during spring and summer. Including emissions from China in the simulations increased calculated $\mathrm{Hg}$ concentrations in the United States by up to $7 \%$.

Uncertainties in $\mathrm{Hg}$ emissions and distribution (both anthropogenic and natural) are still significant, creating difficulties in estimating the circulation of $\mathrm{Hg}$. Wu et al. [2006] found that $\mathrm{Hg}$ emissions from China are increasing at a rate of about $3 \%$ per year. In addition, the much higher $\mathrm{Hg}$ emission rates from China estimated by Jaffe et al. [2005] and Weiss-Penzias et al. [2007] could be explained by missing or underestimated sources, such as underreported point sources, natural sources, re-emission, and errors in emission fractions. Some of the missing or underestimated emissions have been accounted for as originating in natural sources, through an evaluation of emissions by vegetation, soil, and water by Shetty et al. [personal communication]. Including these new estimates would lead to an increase in transport to the western United States, as well as an increase in the global background of $\mathrm{Hg}$. Other studies have demonstrated the effect of aqueous chemistry on $\mathrm{Hg}$ concentrations and deposition [Shia et al., 1999; Seigneur et al., 2006]. Including aqueous chemistry can increase HGE concentrations by a factor of 2-4 [Seigneur et al., 2006] and decrease wet and dry deposition of HGO by $18 \%$ and $9 \%$,

respectively [Shia et al., 1999]. To improve understanding of the Hg cycle, we will address this chemistry and will also incorporate a better estimate of $\mathrm{Hg}$ emissions in future work.

\section{Acknowledgements}

The work at Argonne National Laboratory was supported by the U.S. Department of Energy, Office of Science, Office of Biological and Environmental Research, under contract DEAC02-06CH11357. [OTHER SUPPORT AT OHIO UNIVERSITY?] 


\section{References}

Ames, M., Gullu, G., and Olmex, I.: Atmospheric mercury in the vapor phase, and in fine and coarse particulate matter at Perch River, New York, Atmos. Environ., 32, 865-872, 1998.

Banic, C.M., Beauchamp, S.T., Tordon, R.J., Schroeder, W.H., Steffen, A., Anlauf, K.A., and Wong, H.K.T.: Vertical distribution of gaseous HGE in Canada, J. Geophys. Res., 108(D9), 4264, doi:10.1029/2002JD002116, 2003.

Bergan, T., Gallardo, L., and Rodhe, H.: Mercury in the global troposphere: A three-dimensional model study, Atmos. Environ., 33, 1575-1585, 1999.

Dastoor, A.P., and Larocque, Y.: Global circulation of atmospheric mercury: A modeling study, Atmos. Environ., 38, 147-161, 2004.

Ebinghaus, R., Kock, H.H., and Schmolke, S.R.: Measurements of atmospheric mercury with high time resolution: Recent application in environmental research and monitoring, Fresen. J. Anal. Chem., 371, 806-815, 2001.

Friedli, H.R., Radke, L.F., Prescott, R., Li, P., Woo, J.H., and Carmichael, G.R.: Mercury in the atmosphere around Japan, Korea, and China as observed during the 2001 ACE-Asia field campaign: Measurements, distributions, sources, and implications, J. Geophys. Res., 109, D19S25, doi:10.1029/2003JD004244, 2004.

Hall, B.: The gas-phase oxidation of elemental mercury by ozone, Water Air Soil Poll., 80, 235250, 1995.

Hall, B., and Bloom, N., Report to EPRI, Electric Power Research Institute, Palo Alto, Calif., 1993.

Horowitz, L.W., Walters, S., Mauzerall, D.L., Emmons, L.K., Rasch, P.J., Granier, C., Tie, X., Lamarque, J.F., Schultz, M.G., Tyndall, G.S., Orlando, J.J., and Brasseur, G.P.: A global simulation of tropospheric ozone and related tracers: Description and evaluation of MOZART, version 2, J. Geophys. Res., 108, 4784, doi:10.1029/2002JD002853, 2003.

Iverfeldt, A.: Occurrence and turnover of atmospheric mercury over the Nordic countries, Water Air Soil Poll., 56, 251-265, 1991.

Jaffe, D., Prestbo, E., Swartzendruber, P., Weiss-Penzias, P., Kato, S., Takami, A., Hatakeyama, S., and Kajii, Y.: Export of atmospheric mercury from Asia, Atmos. Environ., 39, 30293038, 2005.

Kellerhals, M., Beauchamp, S., Belzer, W, Blanchard, P., Froude, F., Harvey, B., McDonald, K., Pilote, M., Poissant, L., Puckett, K., Schroeder, B., Steffen, A., and Tordon, R.: Temporal and spatial variability of total gaseous mercury in Canada: Results from the Canadian Atmospheric Measurement Network (CAMNet), Atmos. Environ., 37, 1003-1011, 2003.

National Research Council, Toxicological Effects of Methylmercury, Committee on the toxicological effects of Methylmercury, National Academy Press, Washington, DC, 2000.

Pacyna, E.G., Pacyna, J.M., Steenhuisen, F., and Wilson, S.: Global anthropogenic mercury emission inventory for 2000, Atmos. Environ., 40, 4048-4063, 2006.

Pal., B., and Ariya, P.A.: Gas-phase HO-initiated reactions of elemental mercury: Kinetics, product studies and atmospheric implications, Environ. Sci. Technol., 38, 5555-5566, 2004.

Poissant, L., Pilote, M., Beauvais, C., Constant, P., and Zhang, H.H.: A year of continuous measurements of three atmospheric mercury species (GEM, RGM, and $\mathrm{Hg}_{\mathrm{p}}$ ) in southern Quebec, Canada, Atmos. Environ., 39, 1275-1287, 2005.

Ryaboshapko, A., Bullock Jr., O.R., Christensen, J., Cohen, M., Dastoor, A., Ilyin, I., Peterson, G., Syrakov, D., Travnikov, O., Artx, R.S., Davignon, D., Draxler, R.R., Munthe, J., and 
Pacyna, J.: Intercomparison study of atmospheric mercury models: 2. Modeling results vs. long-term observations and comparison of country deposition budgets, Sci. Total Environ., 377, 319-333, 2007.

Seigneur, C., Karamchandani, P., Lohman, K., Vijayaraghavan, K., and Shia, R.-L.: Multiscale modeling of the atmospheric fate and transport of mercury, J. Geophys. Res., 106 (D21), 27,795-27,809, 2001.

Seigneur, C., Vijayaraghavan, K., Lohman, K., Karamchandani, P., and Scott, C.: Global source attribution for mercury deposition in the United States, Environ. Sci. Technol., 38(2), 555-569, 2004.

Seigneur, C., K. Vijayaraghavan, and K. Lohman, Atmospheric mercury chemistry: Sensitivity of global model simulations to chemical reactions, J. Geophys. Res., 111, D22306, doi:10.1029/2005JD006780, 2006.

Selin, N.E., Jacob, D.J., Park, R.J., Yantosca, R.M., Strode, S., Jaegle L., and Jaffe, D.: Chemical cycling and deposition of atmospheric mercury: Global constraints from observations, J. Geophys. Res., 112, D02308, doi:10.1029/2006JD007450, 2007.

Shia, R.-L., Seigneur, C., Pai, P., Ko, and M., and Sze, N.D.: Global simulation of atmospheric mercury concentrations and deposition fluxes, J. Geophys. Res., 104, 23747-23760, 1999.

Slemr, F., Schuster, and G., and Seiler, W.: Distribution, speciation, and budget of atmospheric mercury, J. Atmos. Chem., 3, 407-434, 1985.

Sommer, J., Gårdfeldt, K., Strömberg, D., and Feng, X.: A kinetic study of the gas-phase reaction between the hydroxyl radical and atomic mercury, Atmos. Environ., 35, 30493054, 2001.

Stamenkovic, J., Lyman, S., and Gustin, M.S.: Seasonal and diel variation of atmospheric mercury concentrations in the Reno (Nevada, USA) airshed, Atmos. Environ., 41, $6662-$ 6672, 2007.

Steding, D.J., and Flegal, A.R.: Mercury concentrations in coastal California precipitation: evidence of local and trans-Pacific fluxes of mercury to North America. J. Geophys. Res., 107(D24), 4764, doi:10.1029/2002JD002081, 2002.

Streets, D.G., Jiming, H., Wu, Y., Jiang, J., Chan, M., Tian, H., and Feng, X.: Anthropogenic mercury emissions in China, Atmos. Environ., 39, 7789-7806, 2005.

Swartzendruber, P.C., Jaffe, D.A., Prestbo, E.M., Weiss-Penzias, P., Stelin, N.E., Park, R., Jacob, D.J., Strode, S., and Jaegle, L.: Observations of reactive gaseous mercury in the free troposphere at the Mount Bachelor Observatory, J. Geophys. Res., 111, D24301, doi:10.1029/2006JD007415, 2006.

Tokos, J.S.S., Hall, B., Calhoun, J.A., and Prestbo, E.M.: Homogeneous gas-phase reaction of $\mathrm{HGO}$ with $\mathrm{H}_{2} \mathrm{O}_{2}, \mathrm{O}_{3}, \mathrm{CH}_{3} \mathrm{I}$, and $\left(\mathrm{CH}_{3}\right)_{2} \mathrm{~S}$ : Implication for atmospheric $\mathrm{Hg}$ cycling, Atmos. Environ., 32, 823-827, 1998.

Travnikov, O., and Ryaboshapko, A.: Modelling of mercury hemispheric transport and depositions. MSC-E Technical Report 6/2002. Meteorological Synthesizing Centre-East, Moscow, Russia, 67 pp, 2002.

Wei, C. F., V. R. Kotamarthi, O. J. Ogunsola, L. W. Horowitz, S. Walters, D. J. Wuebbles, M. A. Avery, D. R. Blake, E. V. Browell and G. W. Sachse, Seasonal variability of ozone mixing ratios and budgets in the tropical southern Pacific: A GCTM perspective. In press J. Geophys. Res., 107,10.1029/2001JD000772, 2002. 
Weiss-Penzias, P., Jaffe, D.A., McClintick, A., Prestbo, E.M., and Landis, M.S.: Gaseous elemental mercury in the marine boundary layer: Evidence for rapid removal in anthropogenic pollution, Environ. Sci. Technol., 37, 3755-3763, 2003.

Weiss-Penzias, P., et al. (2007), Quantifying Asian and biomass burning sources of mercury using the $\mathrm{Hg} / \mathrm{CO}$ ratio in pollution plumes observed at the Mount Bachelor observatory, Atmospheric Environment, 41(21), 4366-4379.

Wu, Y., Wang, S., Streets, D.G., Hao, J., Chan, and M., Jiang, J.: Trends in anthropogenic mercury emissions in China from 1995 to 2003, Environ. Sci. Technol., 40, 5312-5318, 2006. 


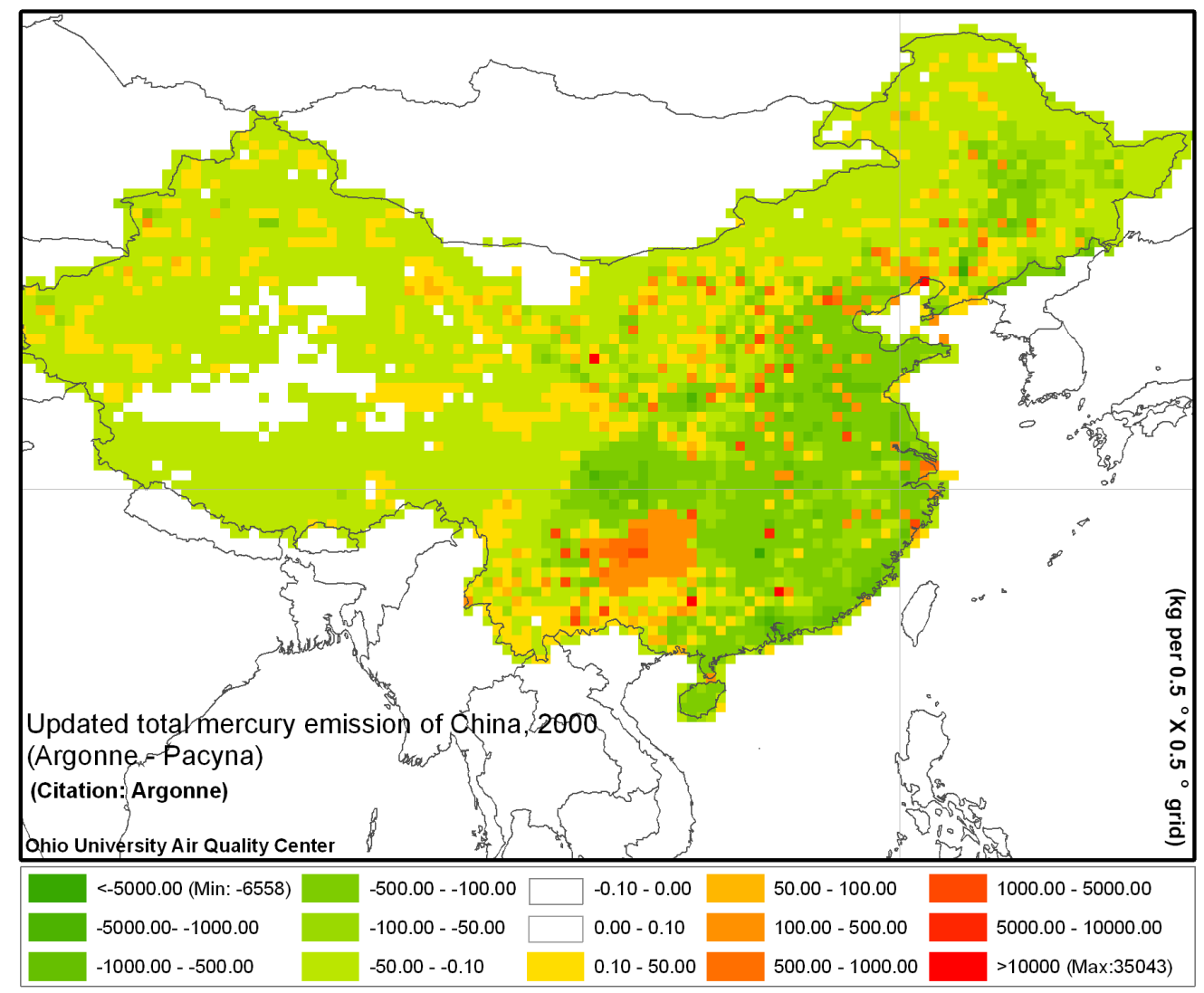

Figure 1. Differences between the lower Streets et al. (2005) and higher Pacyna et al. [2006] estimates of anthropogenic emissions for China. 


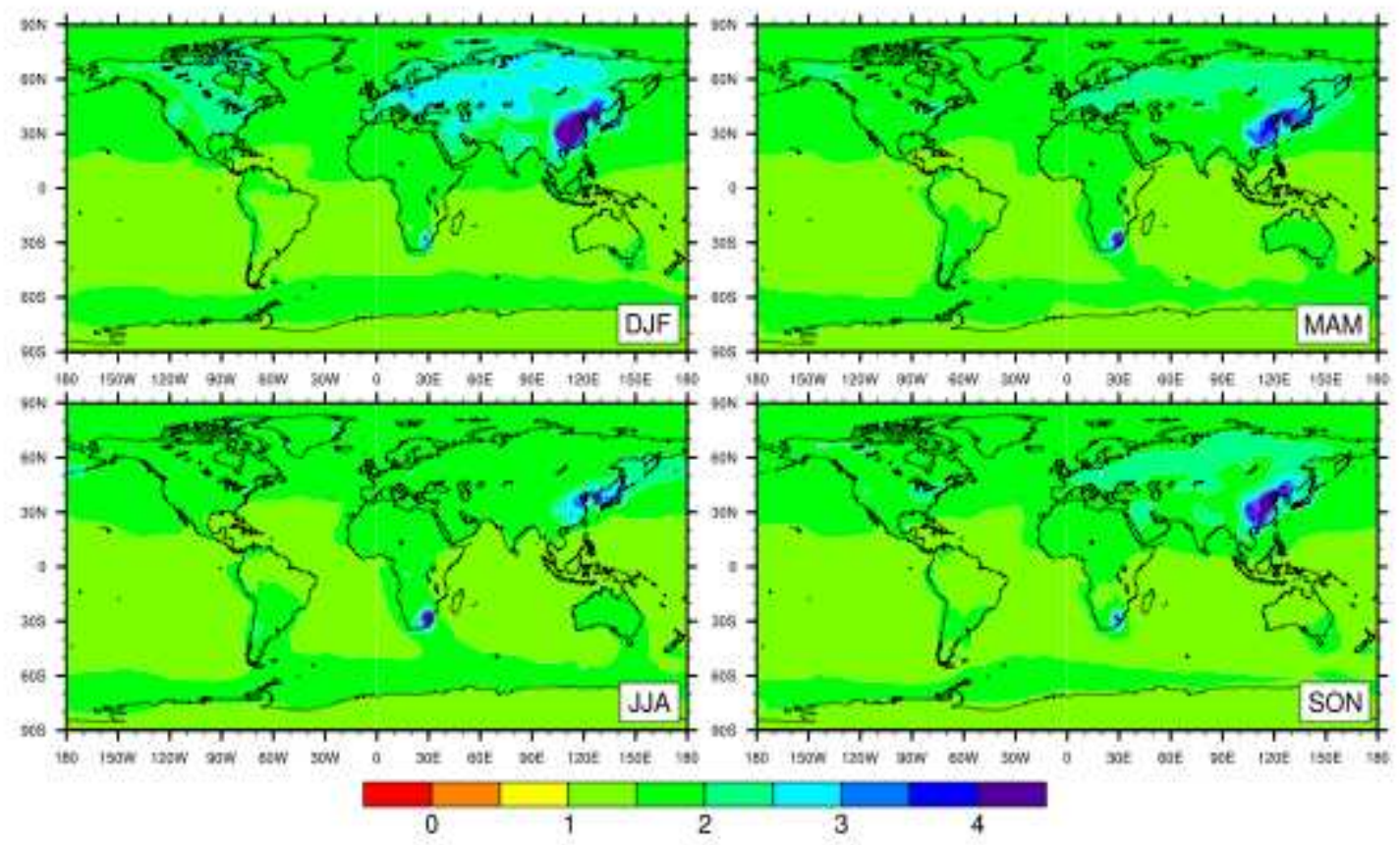

Figure 2. Model-calculated background HGE concentrations $\left(\mathrm{ng} \mathrm{m}^{-3}\right)$ at the model surface for the Northern Hemisphere in winter (upper left), spring (upper right), summer (lower left), and fall (lower right), in the Pacyna emissions case. 


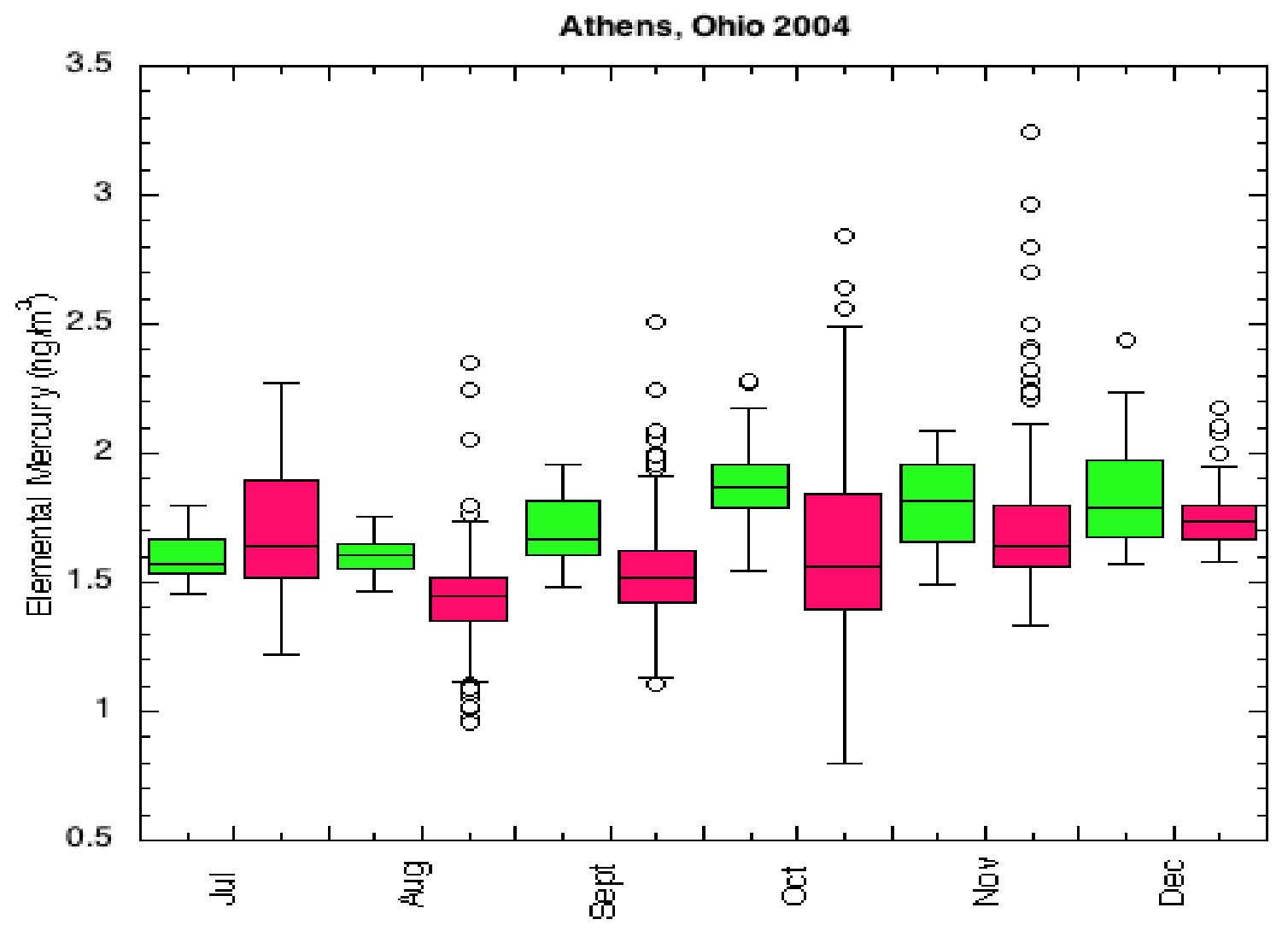

Figure 3: Observed and modeled concentrations of HGE for a model grid located over Athens, Ohio, USA. The site is located at a height of $900 \mathrm{ft}$ above sea level and approximately about $300 \mathrm{ft}$ above the surrounding terrain. The model results (green) are for an altitude of $950 \mathrm{mb}$ above the model surface pressure of $995 \mathrm{mb}$. The observations shown are for the year 2004 (the year simulated with the model); the site became operational in July 2004 [Crist et al., 2006]. 




Figure 4. Percent difference in HGE concentrations between a simulation using the HGE emissions estimate of Streets et al. (2006) and a simulation with no emissions from China. Results for the Northern Hemisphere are shown at the model surface in winter (upper left), spring (upper right), summer (lower left), and fall (lower right). 


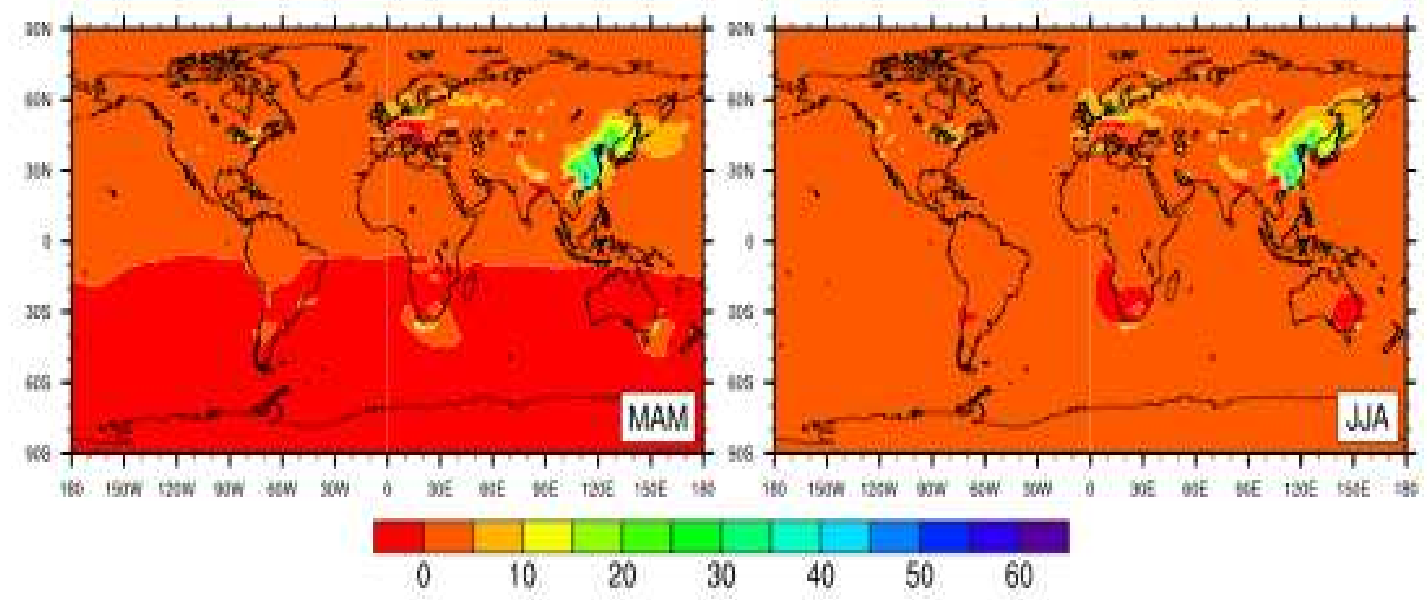

Figure 5. Percent difference in HGE concentrations in spring (left) and summer (right), as simulated with the Pacyna and Streets estimates of $\mathrm{Hg}$ emissions. 


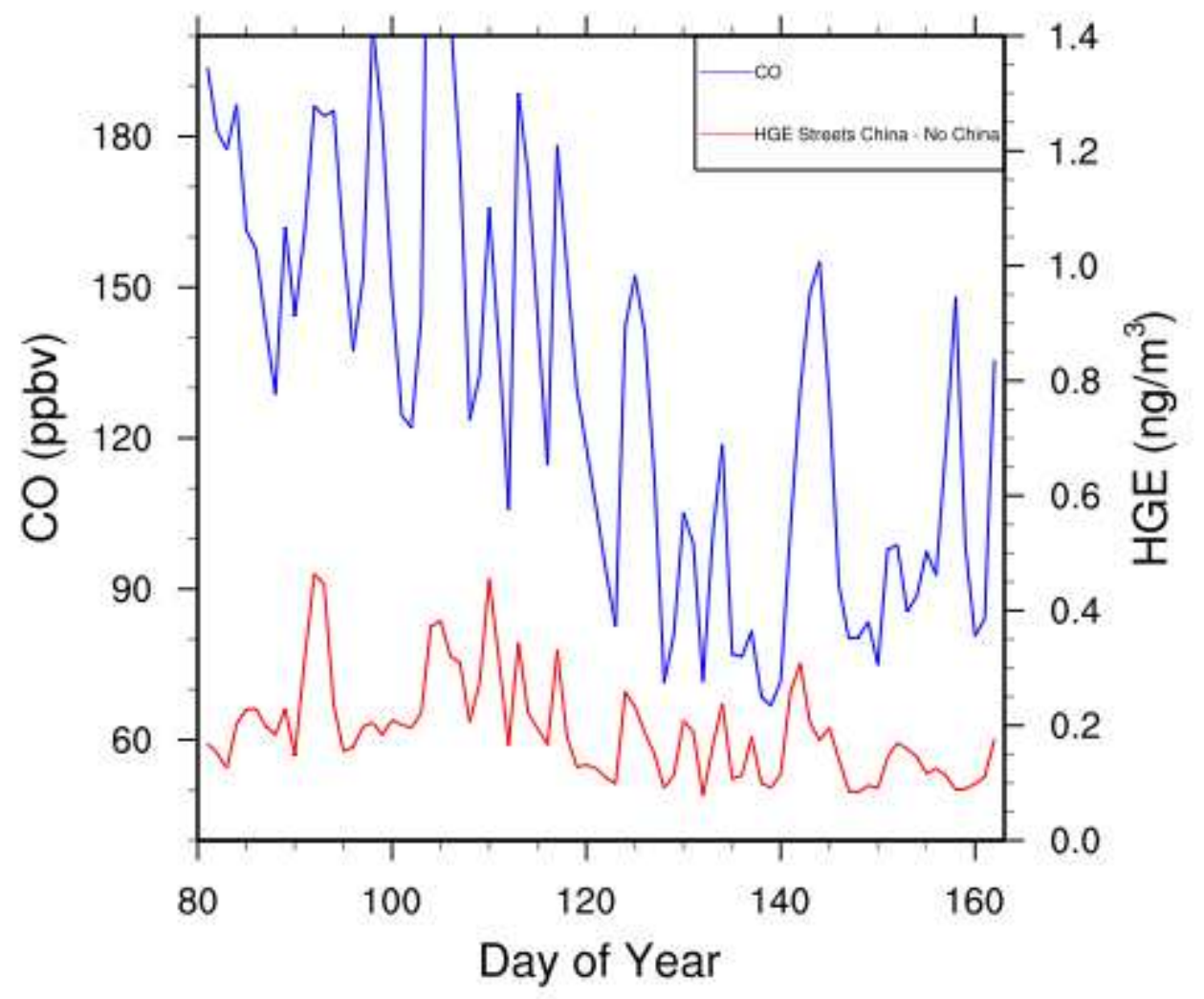

Figure 6. Calculated concentrations of $\mathrm{CO}$ (ppbv) and HGE $\left(\mathrm{ng} \mathrm{m}^{-3}\right)$ near Okinawa for the period March 22-June 10, 2004. 


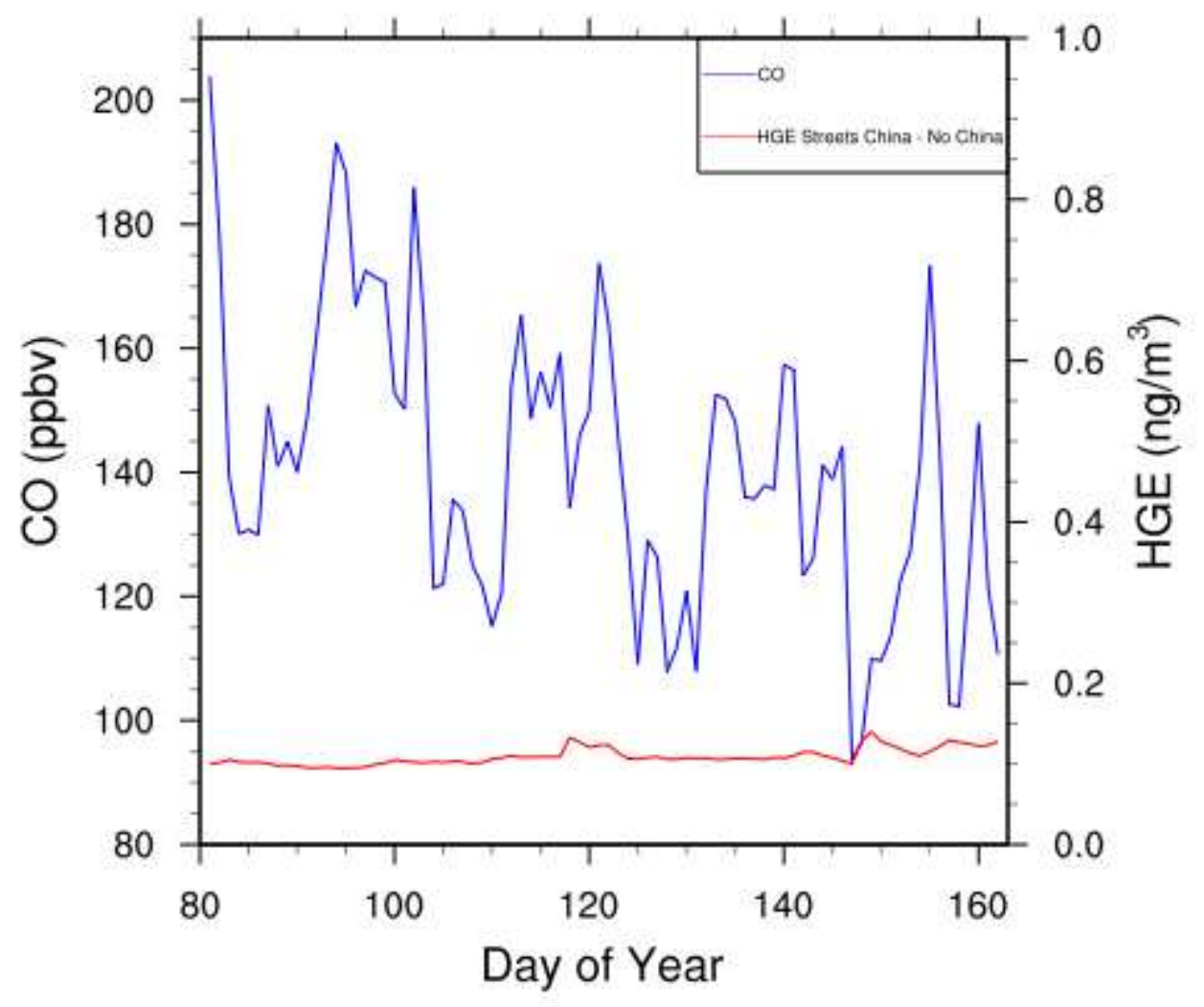

Figure 7. Calculated concentrations of $\mathrm{CO}$ (ppbv) and HGE $\left(\mathrm{ng} \mathrm{m}^{-3}\right)$ near Seattle, Washington, for the period March 22-June 10, 2004. 


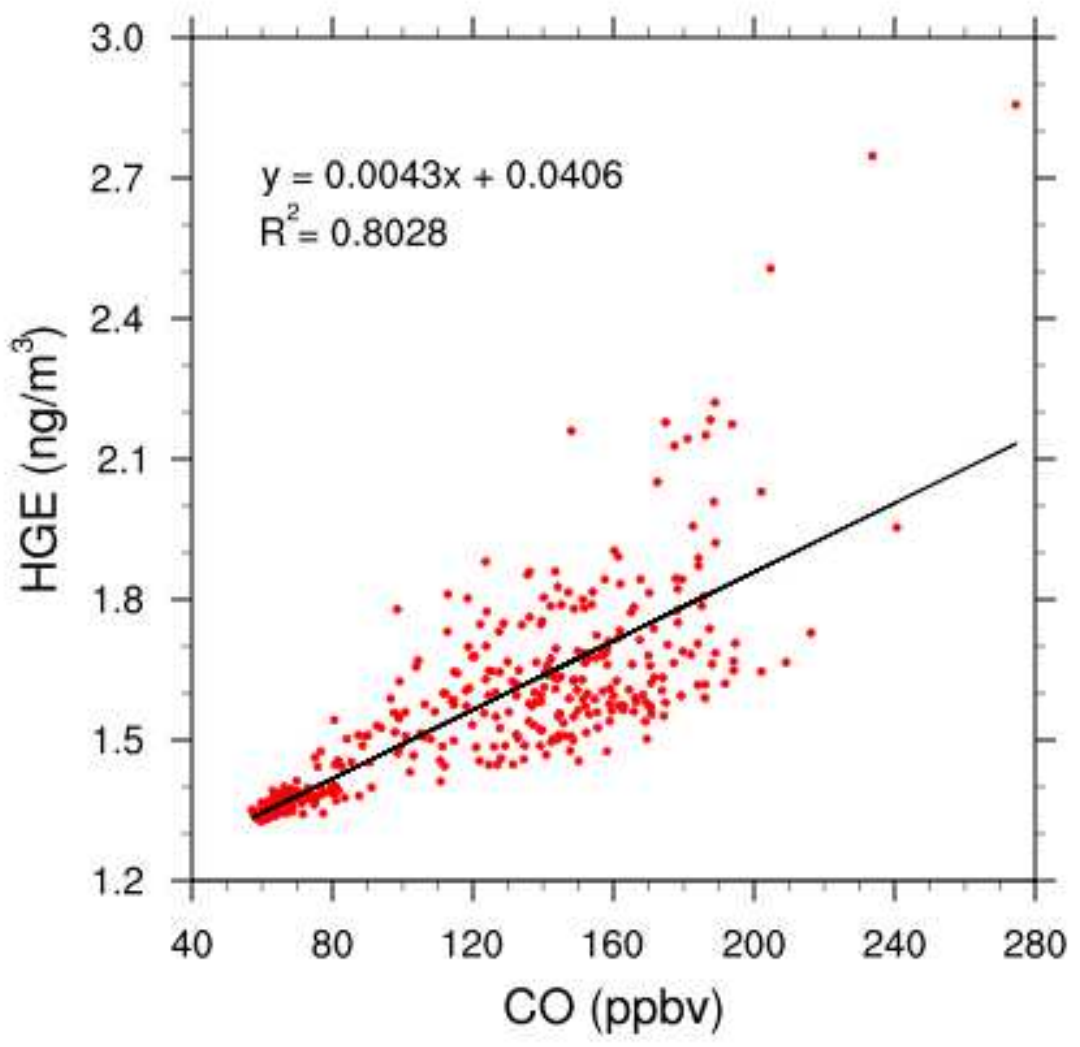

Figure 8. Scatter plot of calculated HGE $\left(\mathrm{ng} \mathrm{m}^{-3}\right.$ ) vs. CO concentrations (ppbv) near Okinawa for the period March 22-June 10, 2004, and the No China simulation. 


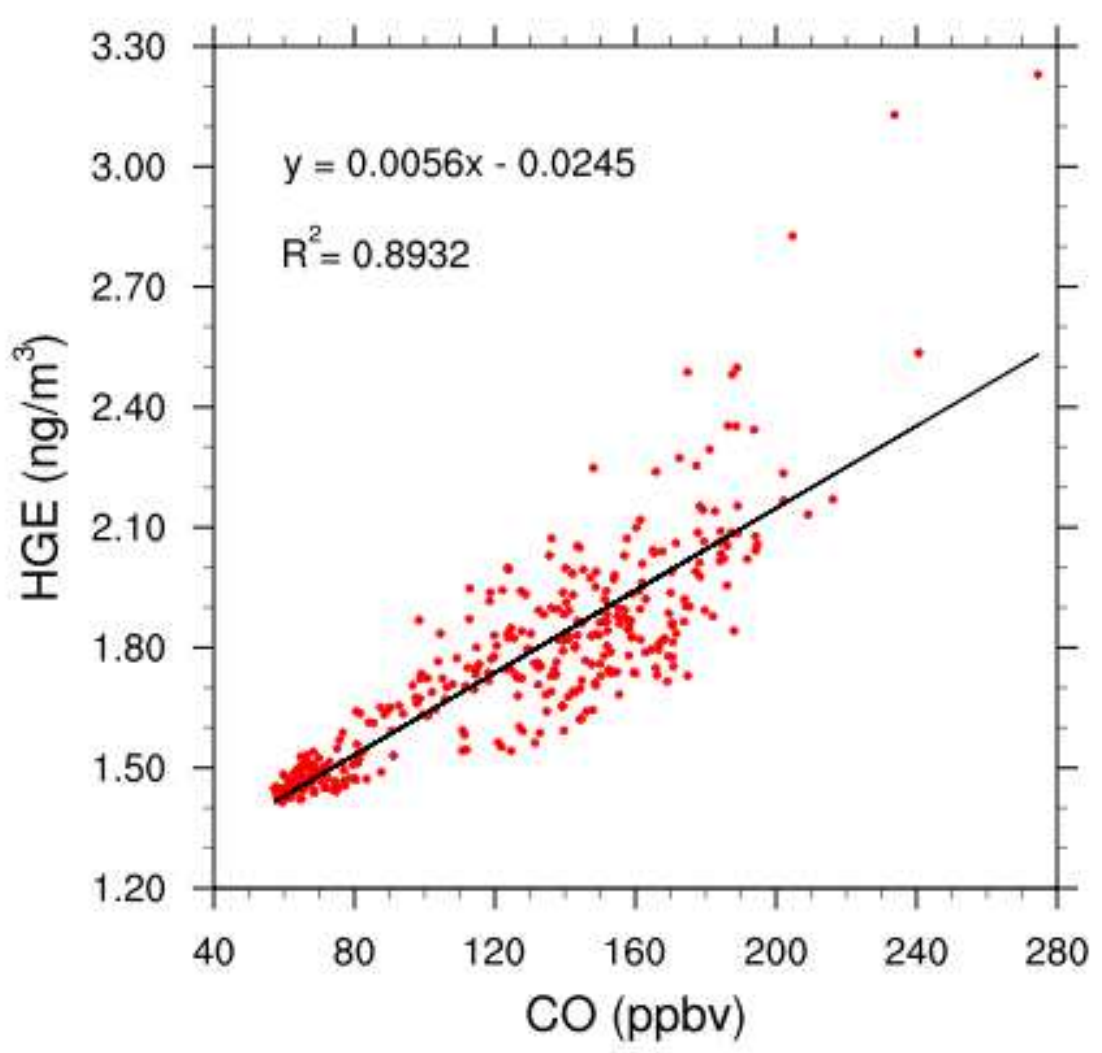

Figure 9. Scatter plot of calculated HGE $\left(\mathrm{ng} \mathrm{m}^{-3}\right.$ ) vs. CO (ppbv) concentrations near Okinawa for the period March 22-June 10, 2004, and the Streets simulation. 


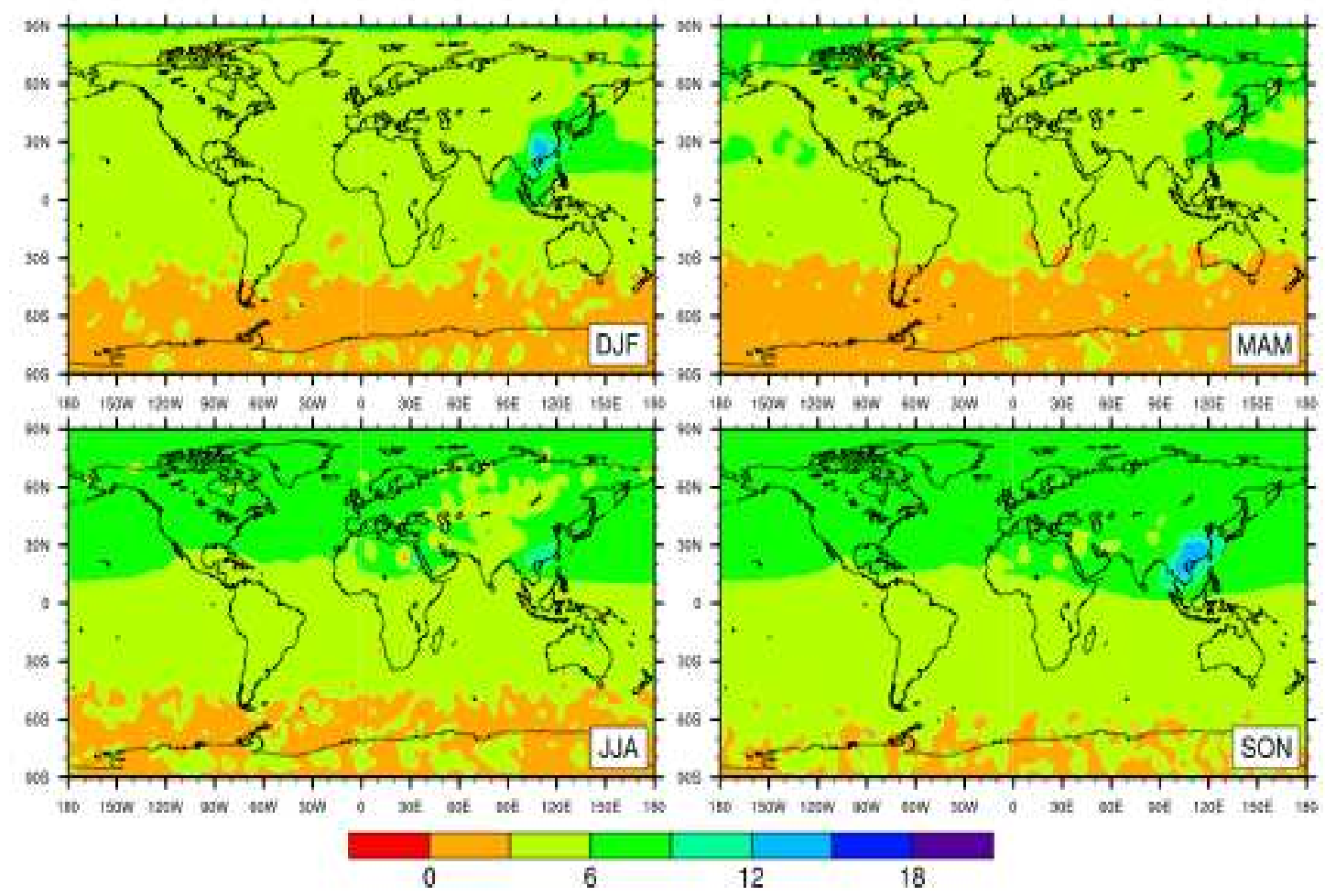

Figure 10. Percent differences in HGO wet deposition in winter (upper left), spring (upper right), summer (lower left), and fall (lower right) for the Streets and No China simulations. 


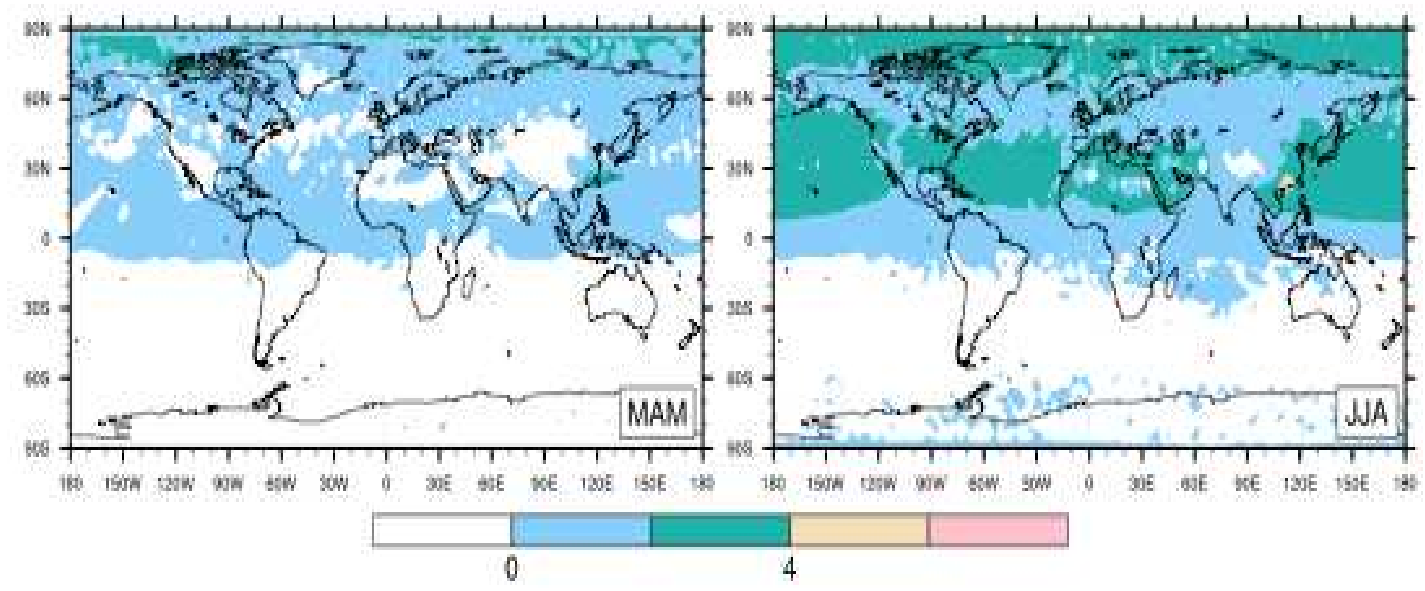

Figure 11. Percent differences in HGO wet deposition in spring (left) and summer (right) for the Pacyna and Streets simulations. 


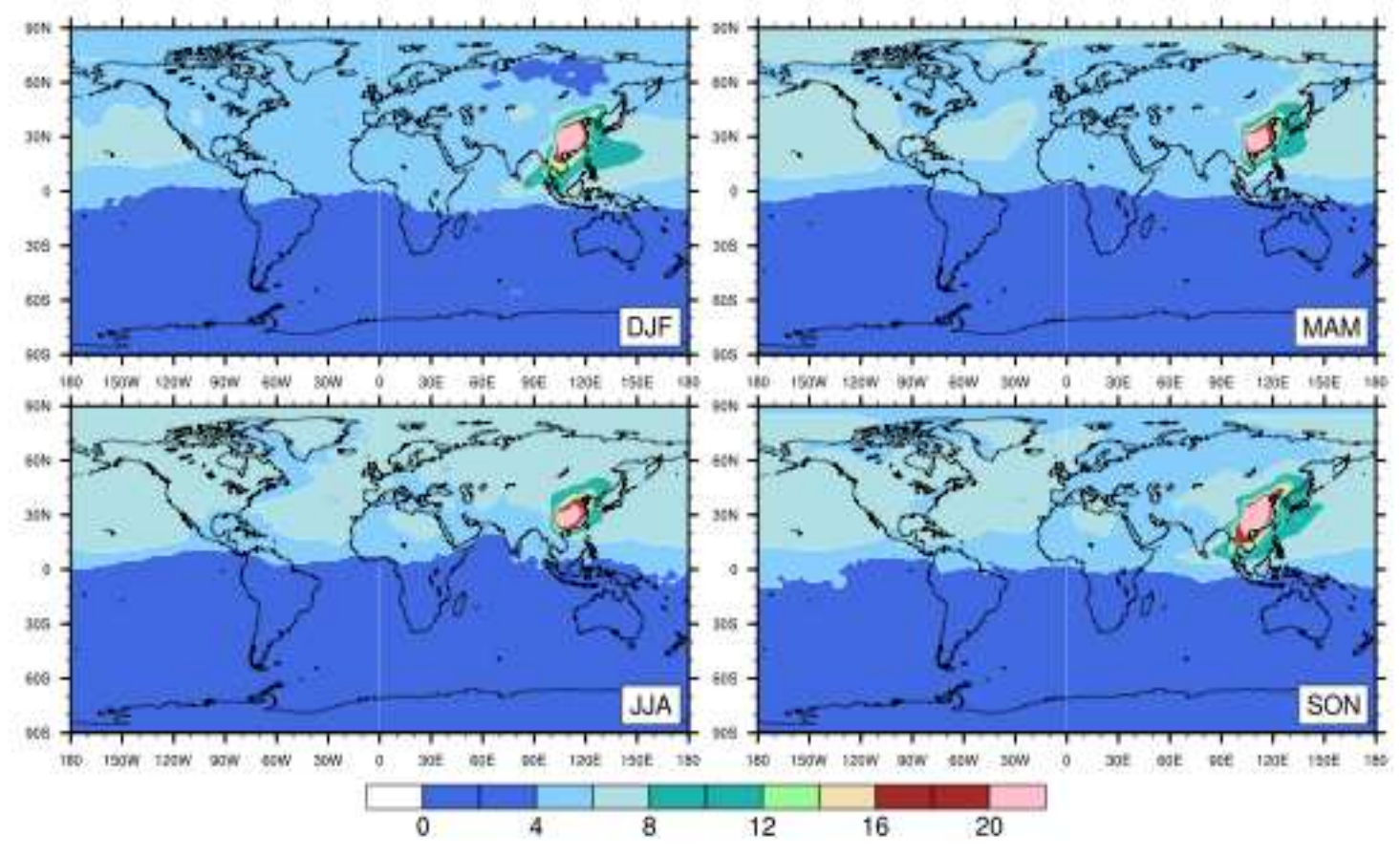

Figure 12. Percent differences in HGO dry deposition in winter (upper left), spring (upper right), summer (lower left), and fall (lower right) for the Streets and No China simulations. 


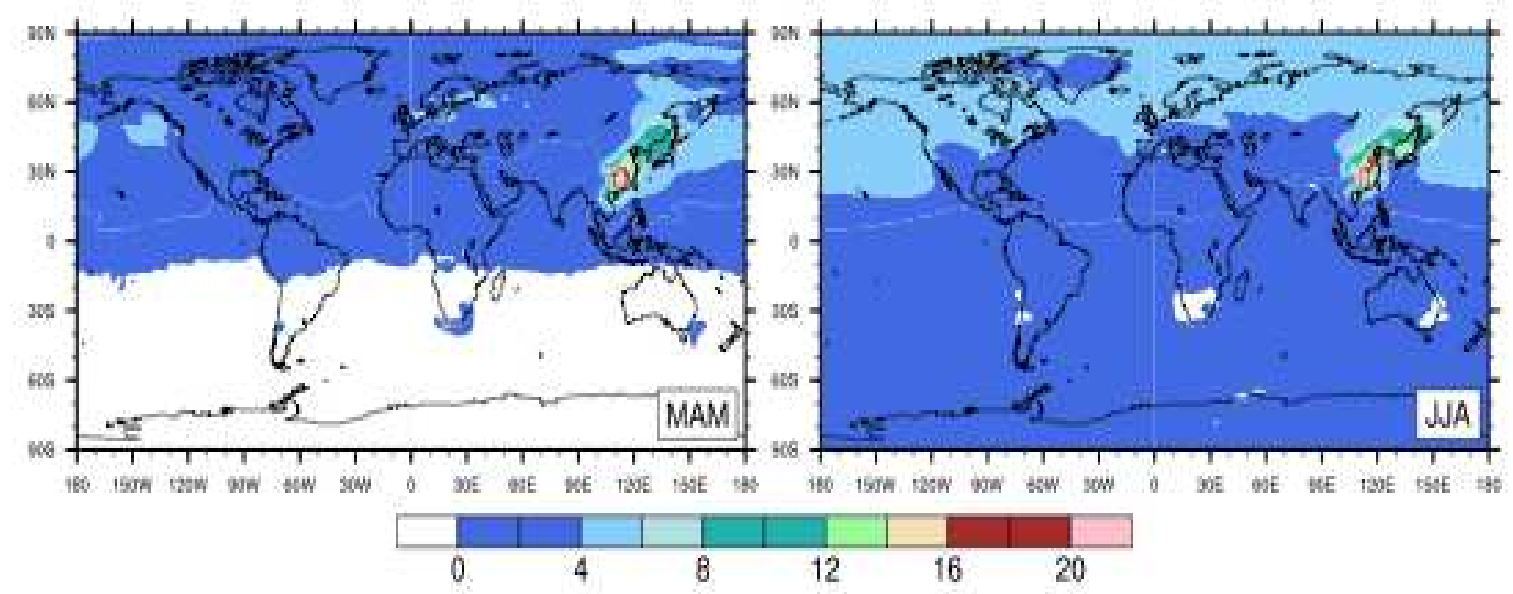

Figure 13. Percent differences in HGO dry deposition in spring (left) and summer (right) for the Pacyna and Streets simulations. 
Appendix C

GRAPHS FOR RESULTS OF SMOKE EMISSION MODELING FOR 36KM 
Figs. 1 to 3 present $36 \mathrm{~km}$ grid resolution SMOKE emission results from the national emissions inventory (NEI) of aircraft locomotive and marine vessel (ALM) data for $\mathrm{Hg}^{0}$, $\mathrm{RGM}$, and $\mathrm{Hg}_{\mathrm{p}}$, respectively. Results reflect emission data from 19:00:00 on July 13, 2004. The highest levels of $\mathrm{Hg}^{0}$ were observed along the eastern coast of the U.S, and in the western states of California and Washington. Similar trends can be observed in the spatial distribution of ALM RGM and $\mathrm{Hg}_{\mathrm{p}}$ emissions.

\section{Layer 1 HGNRVAg}

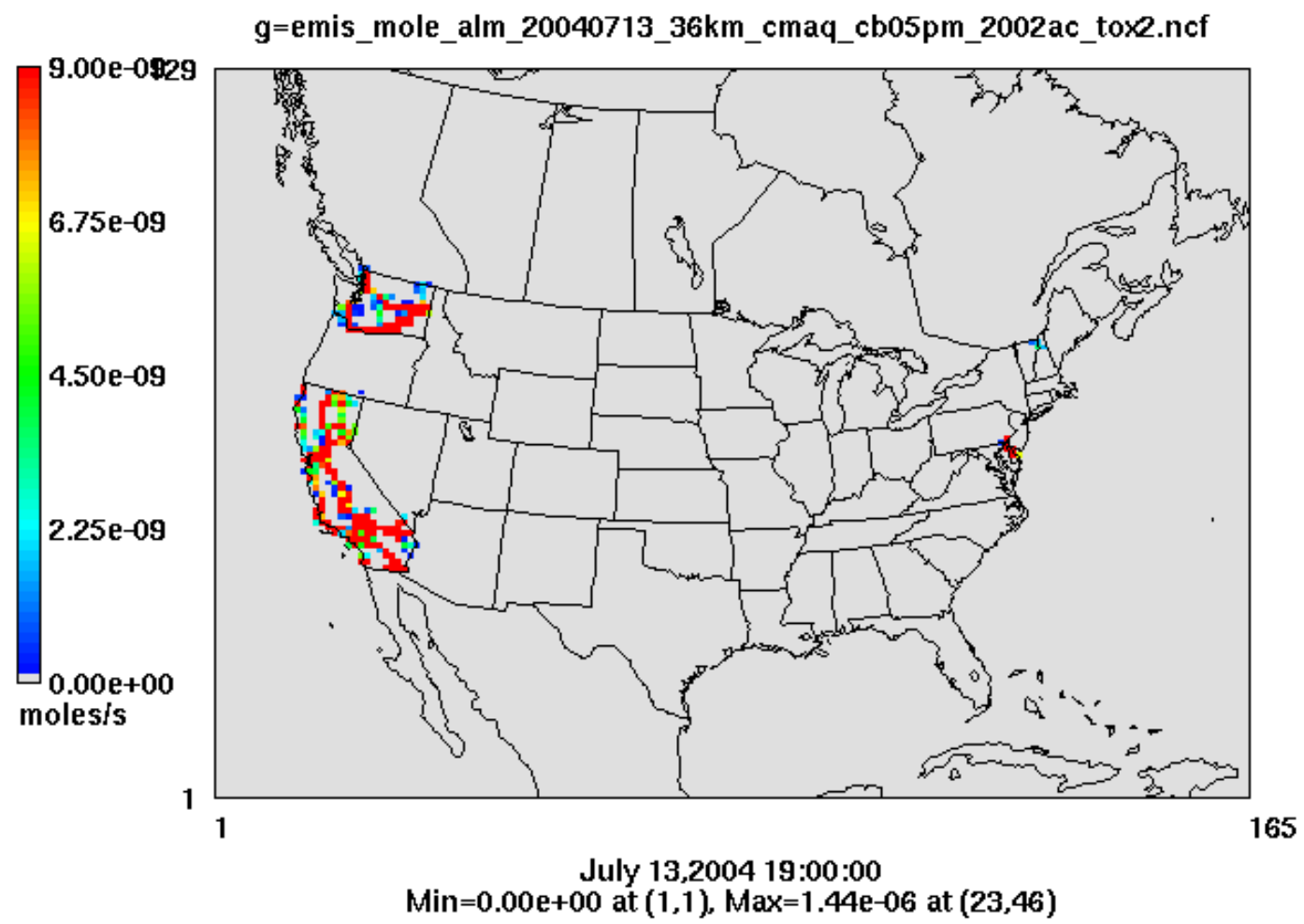

Figure 1. SMOKE emission results for ALM emissions of elemental mercury $\left(\mathrm{Hg}^{0}\right)$ in $36 \mathrm{~km}$ grid resolution. 


\section{Layer 1 HGIIGASg}

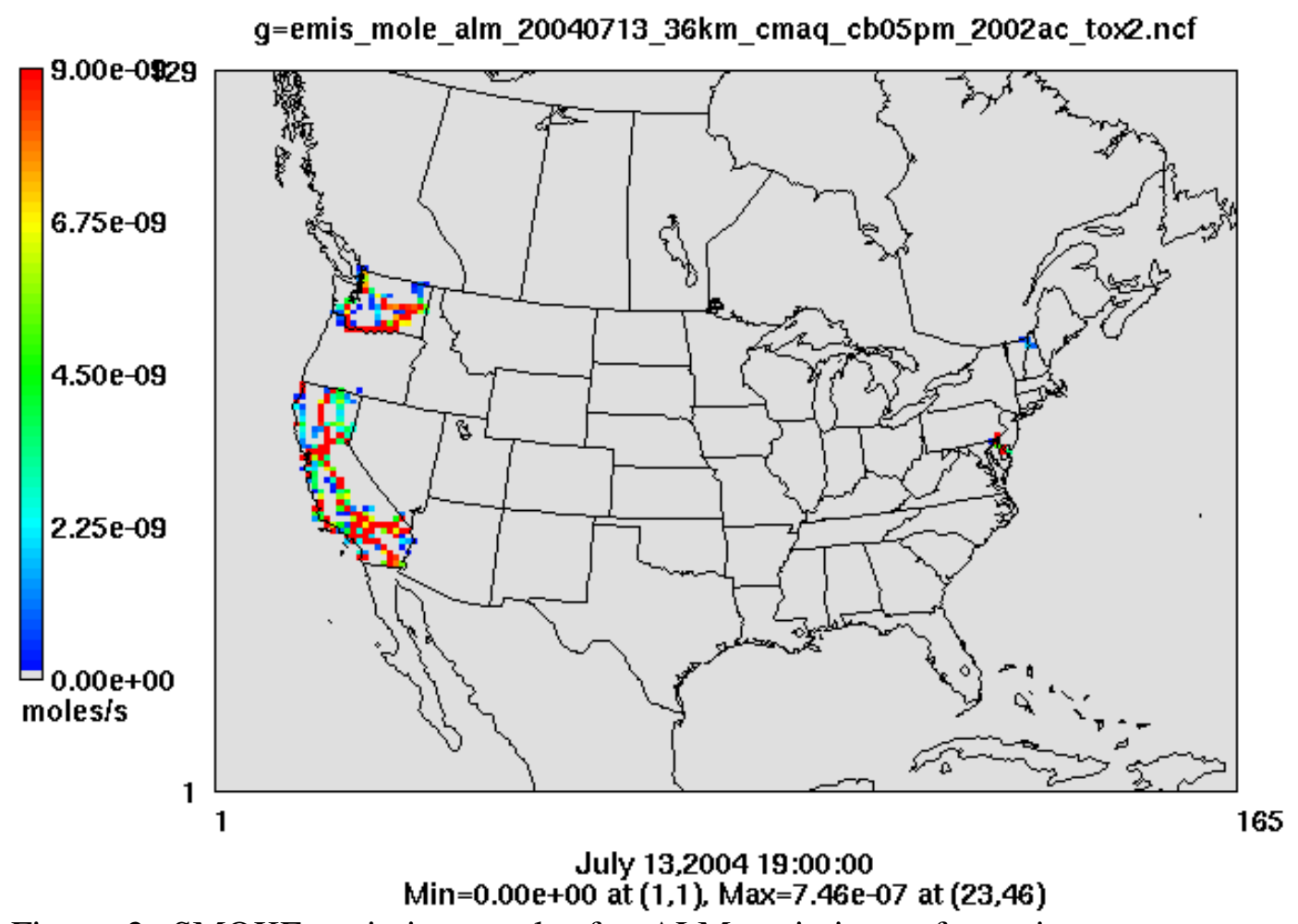

Figure 2. SMOKE emission results for ALM emissions of reactive gaseous mercury (RGM) in $36 \mathrm{~km}$ grid resolution. 


\section{Layer 1 PHGIg}

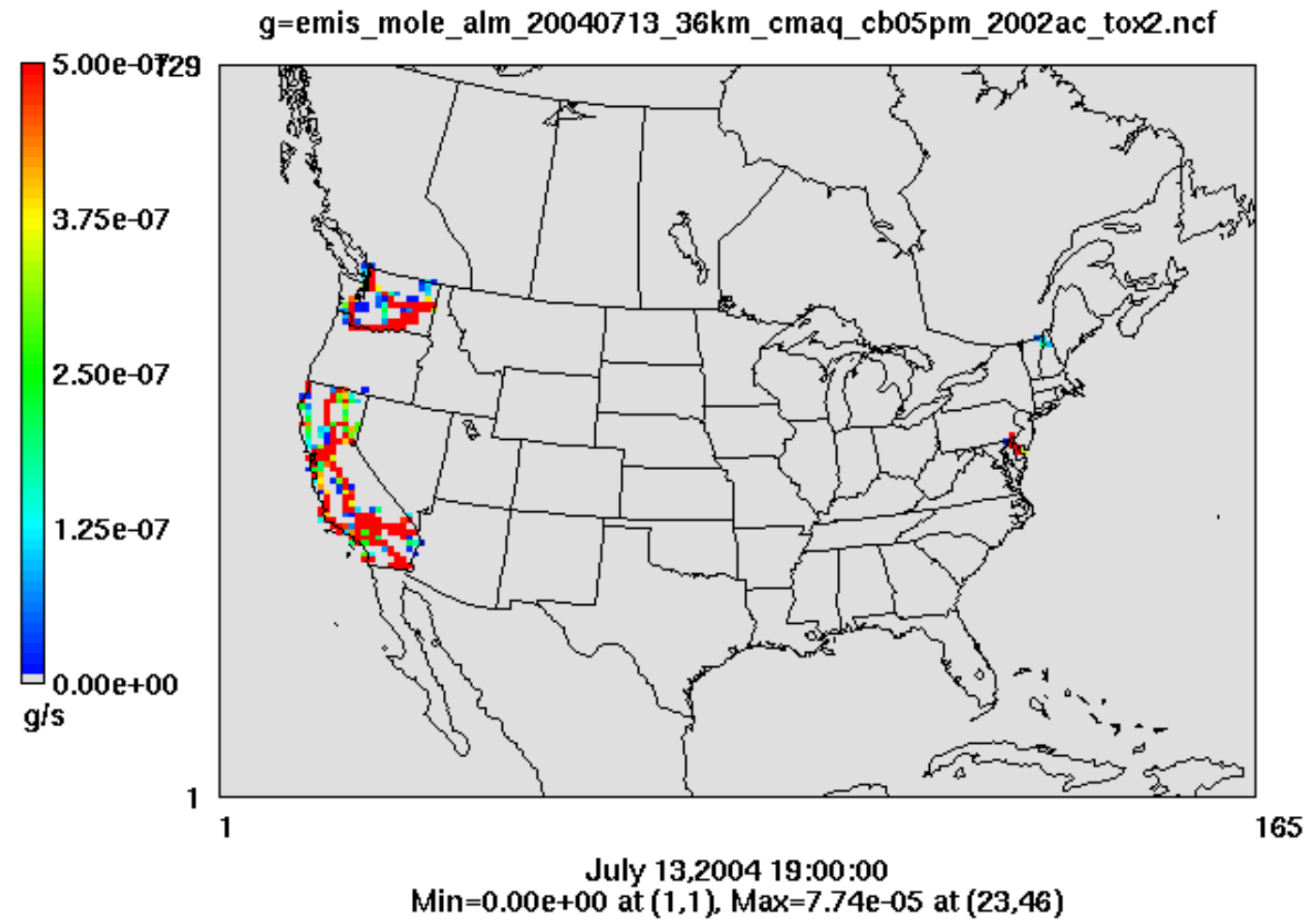

Figure 3. SMOKE emission results for ALM emissions of particulate mercury $\left(\mathrm{Hg}_{\mathrm{p}}\right)$ in $36 \mathrm{~km}$ grid resolution. 
Figs. 4 to 6 present $36 \mathrm{~km}$ grid resolution SMOKE emission results from the national emissions inventory (NEI) of nonpoint source data for $\mathrm{Hg}^{0}, \mathrm{RGM}$, and $\mathrm{Hg}_{\mathrm{p}}$, respectively. Results reflect emission data from 19:00:00 on July 13, 2004. The highest levels of $\mathrm{Hg}^{0}$ were observed in the eastern U.S. and western coastal regions. Similar trends can be observed in the spatial distribution of nonpoint source RGM and $\mathrm{Hg}_{\mathrm{p}}$ emissions.

Elevated levels of $\mathrm{Hg}^{0}$, RGM and $\mathrm{Hg}_{\mathrm{P}}$ nonpoint source emissions were observed in the Ohio River Valley, and in Northeast and Central Ohio.

\section{Layer 1 HGNRVAe}

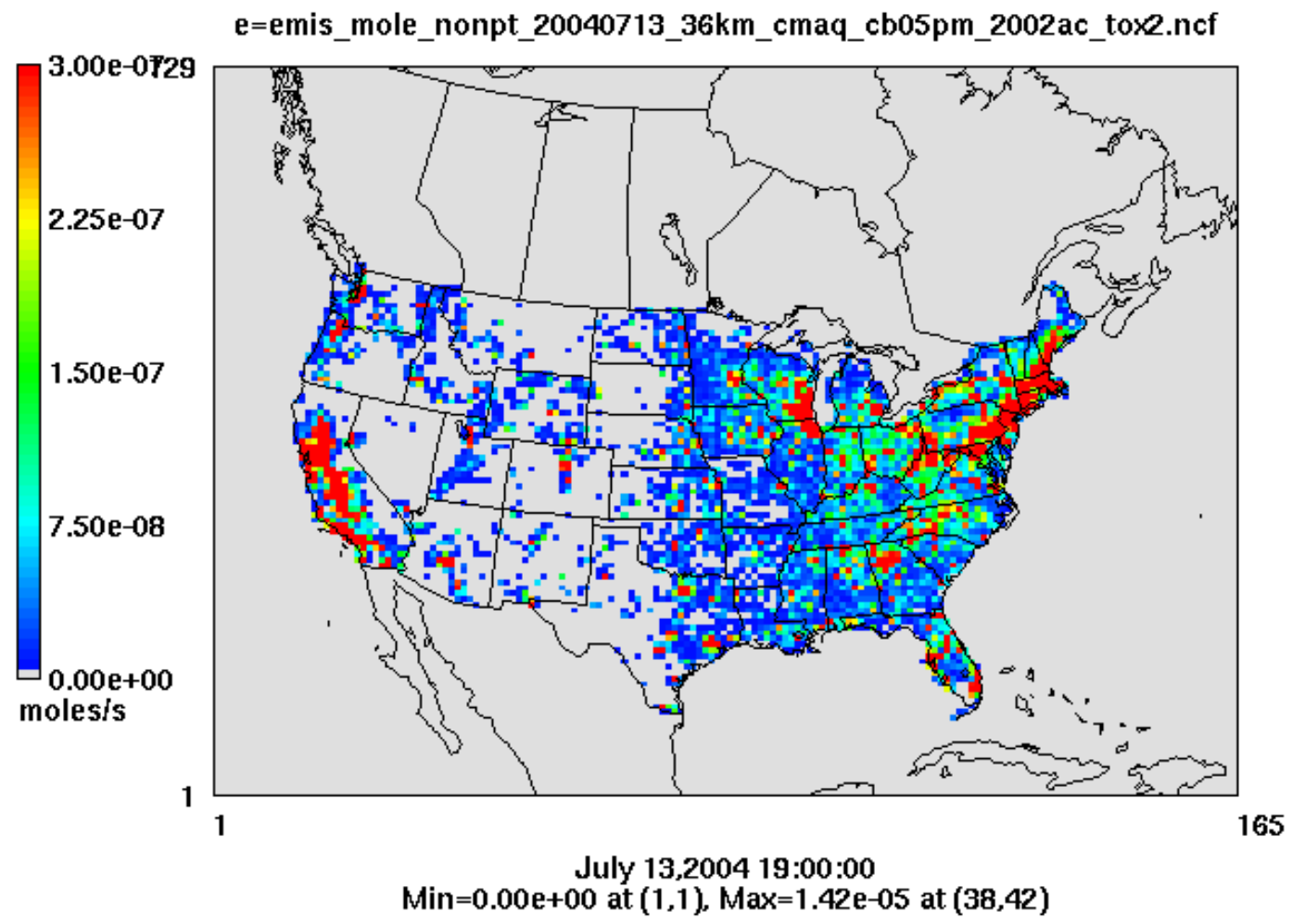

Figure 4. SMOKE emission results for nonpoint source emissions of elemental mercury $\left(\mathrm{Hg}^{0}\right)$ in $36 \mathrm{~km}$ grid resolution. 


\section{Layer 1 HGIIGASe}

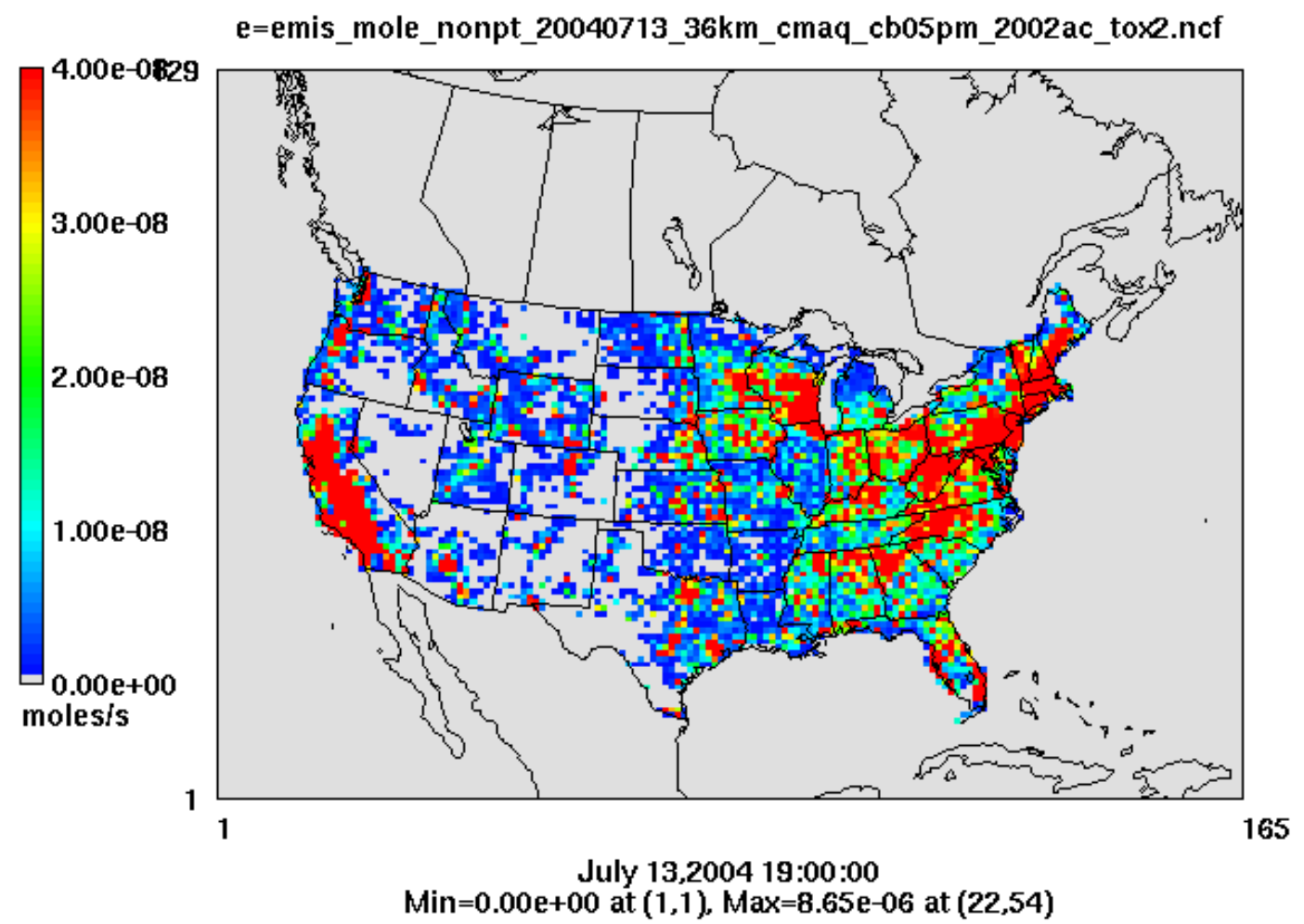

Figure 5. SMOKE emission results for nonpoint source emissions of reactive gaseous mercury (RGM) in $36 \mathrm{~km}$ grid resolution. 


\section{Layer 1 PHGIe}

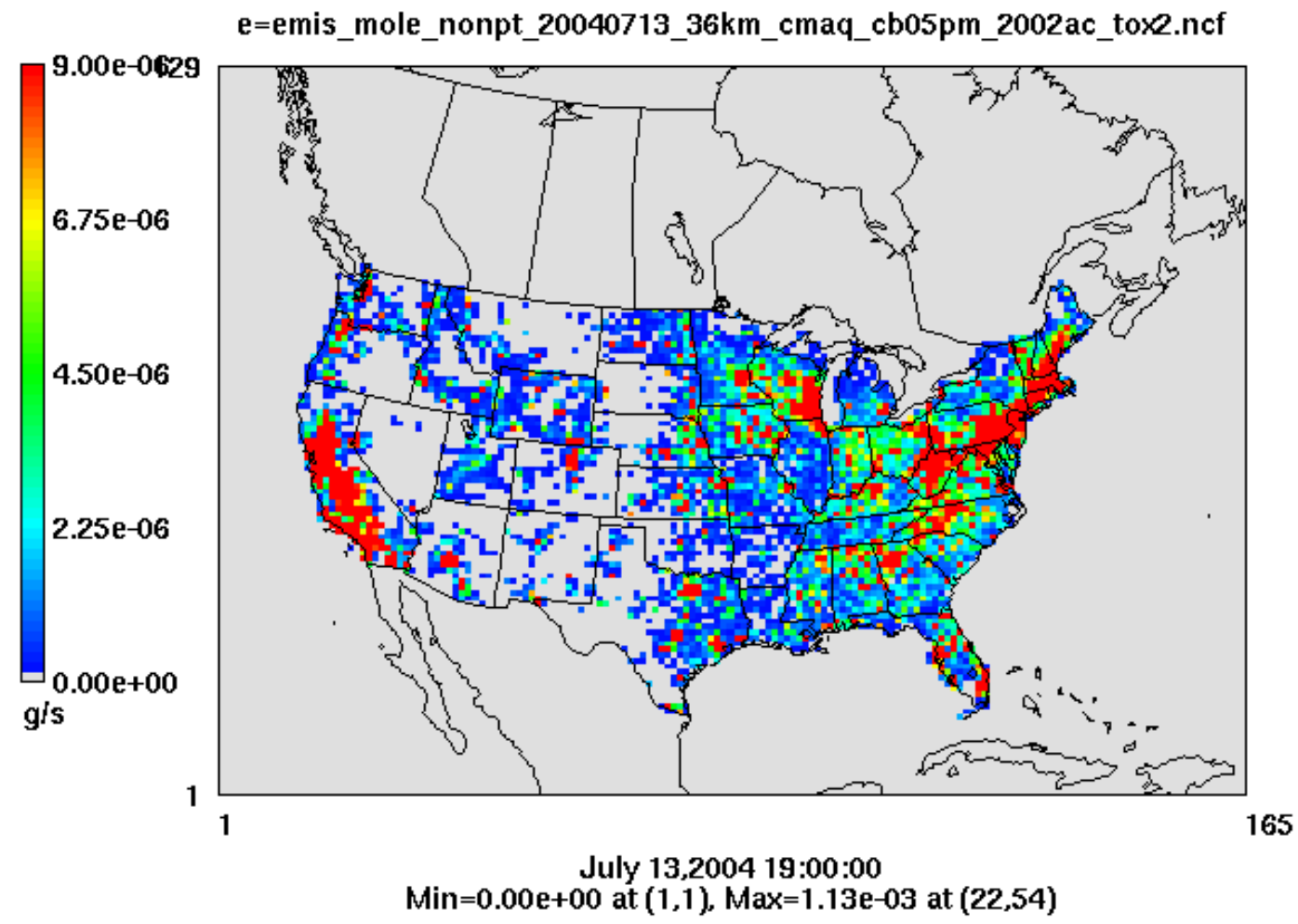

Figure 6. SMOKE emission results for nonpoint source emissions of particulate mercury $\left(\mathrm{Hg}_{\mathrm{p}}\right)$ in $36 \mathrm{~km}$ grid resolution. 
Figs. 7 to 9 present $36 \mathrm{~km}$ grid resolution SMOKE emission results from the national emissions inventory (NEI) of nonroad source data for $\mathrm{Hg}^{0}$, RGM, and $\mathrm{Hg}_{\mathrm{p}}$, respectively. Results reflect emission data from 19:00:00 on July 13, 2004. Elevated levels of $\mathrm{Hg}^{0}$ were observed in the eastern U.S., eastern Texas, and central Colorado. California presents a highly concentrated spatial distribution of elevated emissions of $\mathrm{Hg}^{0}$. Similar trends can be observed in the spatial distribution of nonroad RGM and $\mathrm{Hg}_{\mathrm{p}}$ emissions.

Elevated levels of $\mathrm{Hg}^{0}, \mathrm{RGM}$ and $\mathrm{Hg}_{\mathrm{P}}$ nonroad emissions were observed in northeastern and

Ohio.

\section{Layer 1 HGNRVAa}

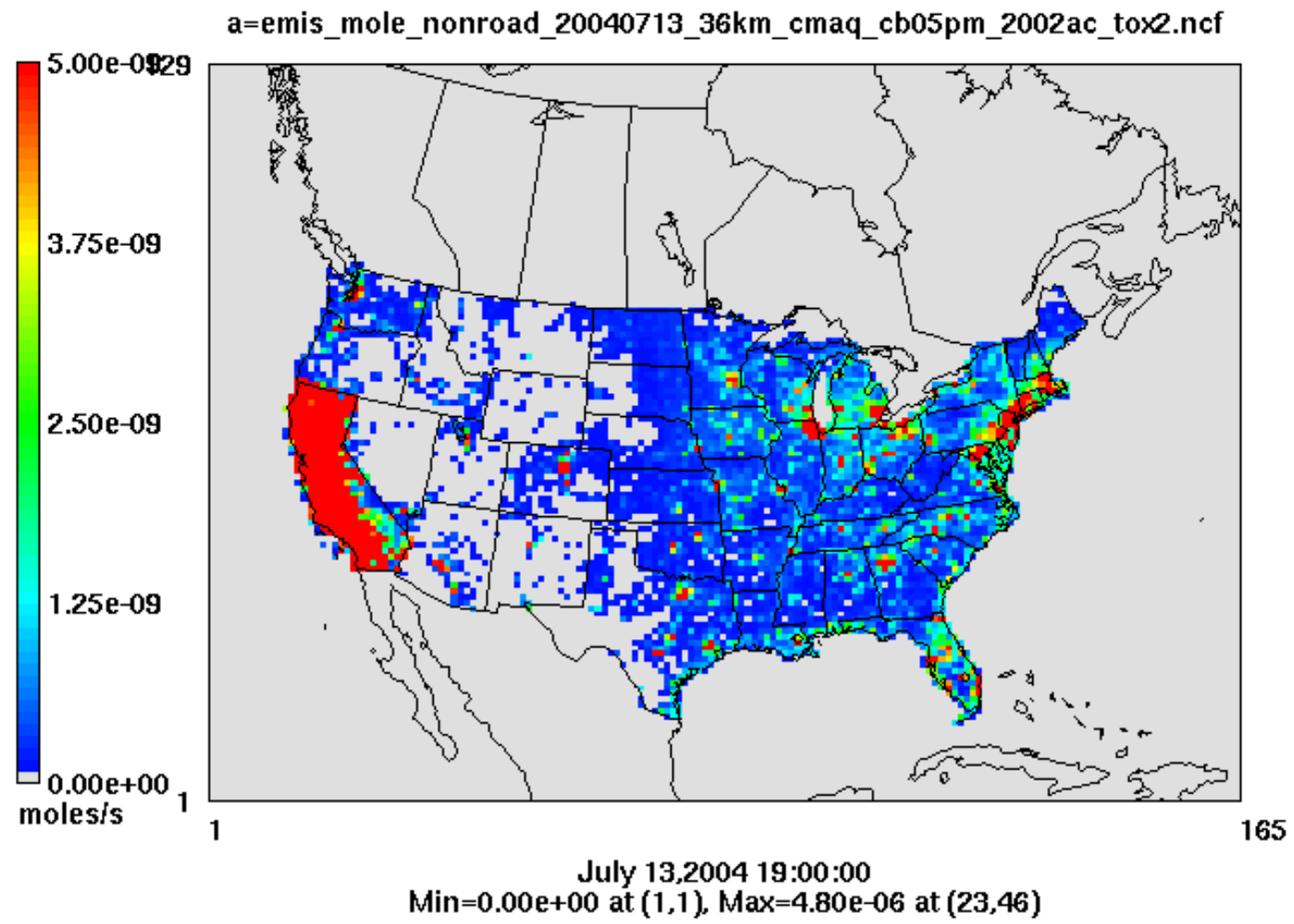

Figure 7. SMOKE emission results for nonroad emissions of elemental mercury $\left(\mathrm{Hg}^{0}\right)$ in $36 \mathrm{~km}$ grid resolution 


\section{Layer 1 HGIIGASa}

a=emis_mole_nonroad_20040713_36km_cmaq_cb05pm_2002ac_tox2.ncf

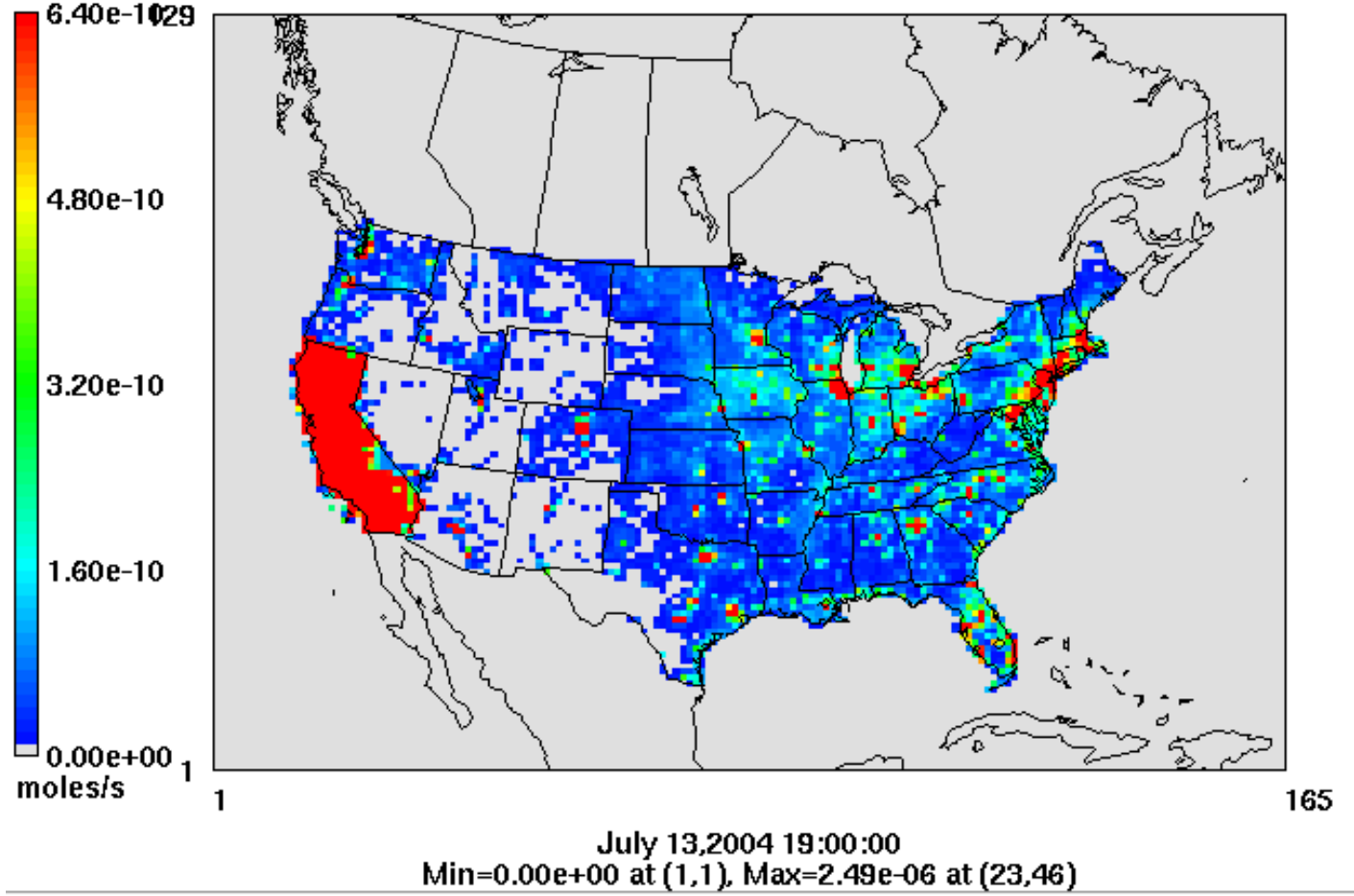

Figure 8. SMOKE emission results for nonroad emissions of reactive gaseous mercury (RGM) in 36km grid resolution. 


\section{Layer 1 PHGIa}

a=emis_mole_nonroad_20040713_36km_cmaq_cb05pm_2002ac_tox2.ncf

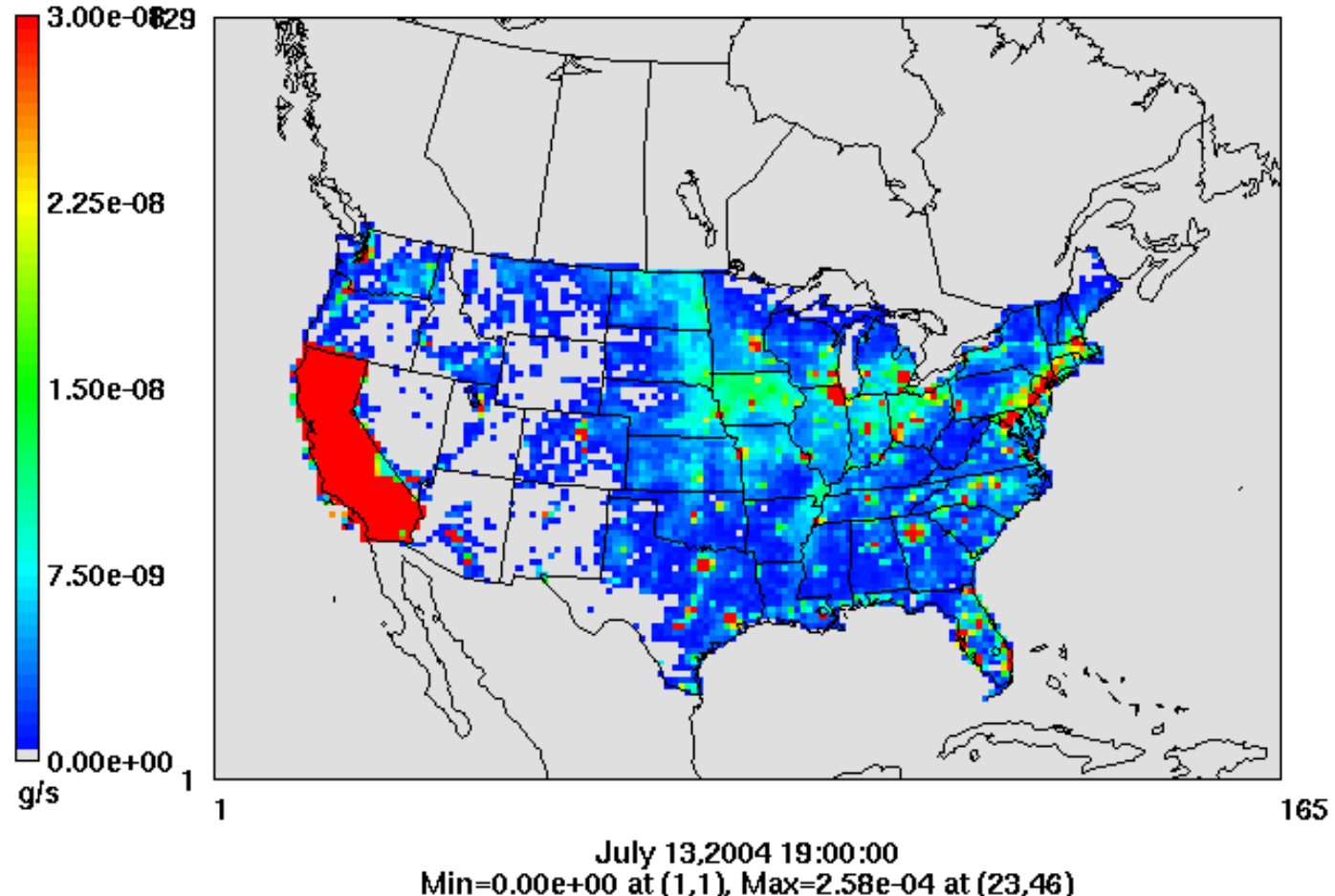

Figure 9. SMOKE emission results for nonroad emissions of particulate mercury $\left(\mathrm{Hg}_{\mathrm{p}}\right)$ in $36 \mathrm{~km}$ grid resolution. 
Figs. 10 to 12 present $36 \mathrm{~km}$ grid resolution SMOKE emission results from the national emissions inventory (NEI) of onroad source data for $\mathrm{Hg}^{0}, \mathrm{RGM}$, and $\mathrm{Hg}_{\mathrm{p}}$, respectively. Results reflect emission data from 19:00:00 on July 13, 2004. Elevated levels of $\mathrm{Hg}^{0}$ were observed along the northeastern coastline, eastern metropolitan areas, and regions along the western coast of the U.S. Similar trends can be observed in the spatial distribution of onroad RGM and $\mathrm{Hg}_{\mathrm{p}}$ emissions.

Elevated levels of $\mathrm{Hg}^{0}, \mathrm{RGM}$ and $\mathrm{Hg}_{\mathrm{P}}$ onroad emissions were observed in northeastern, central, and southwestern Ohio

\section{Layer 1 HGNRVAd}

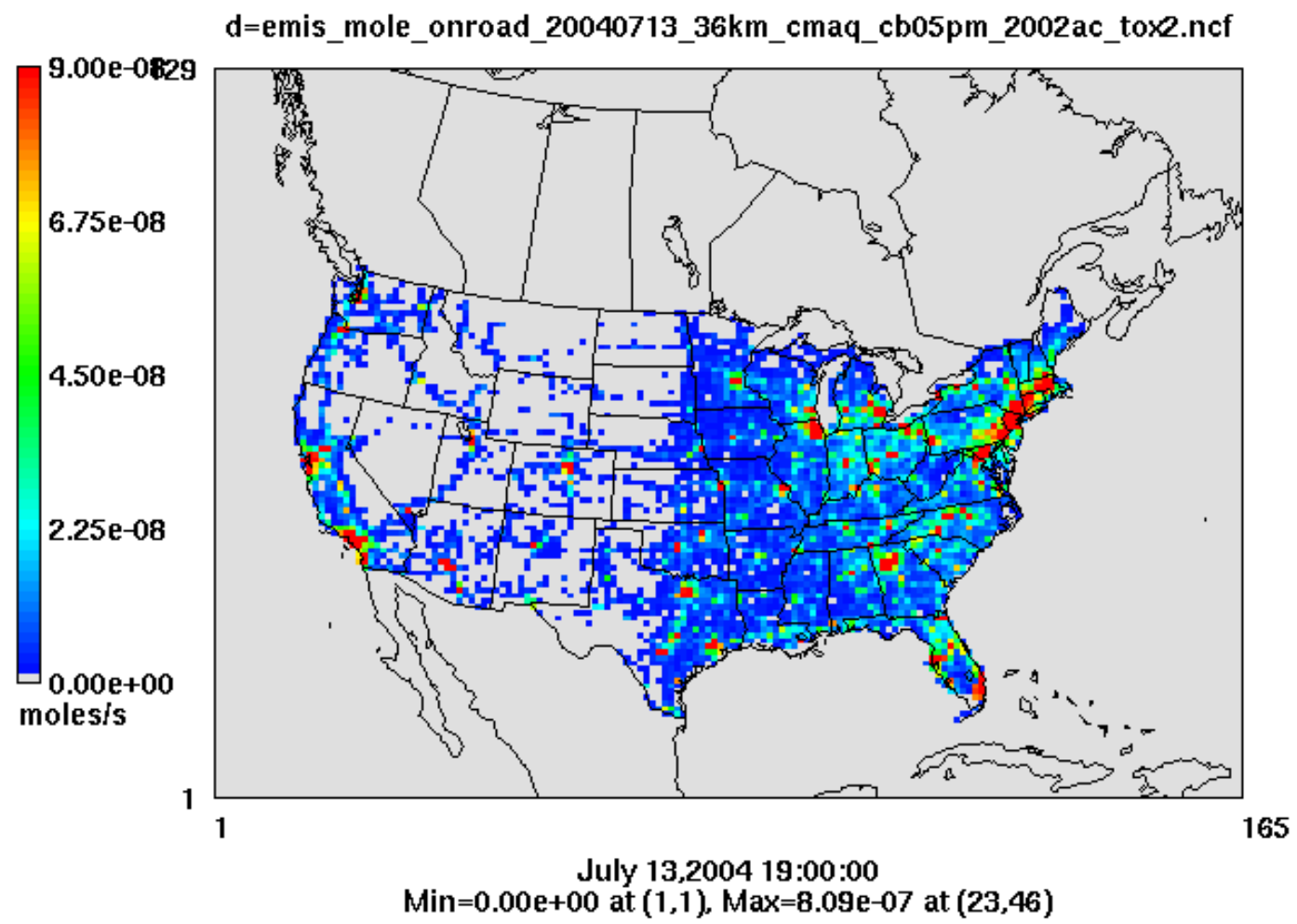

Figure 10. SMOKE emission results for onroad emissions of elemental mercury $\left(\mathrm{Hg}^{0}\right)$ in $36 \mathrm{~km}$ grid resolution 


\section{Layer 1 HGIIGASd}

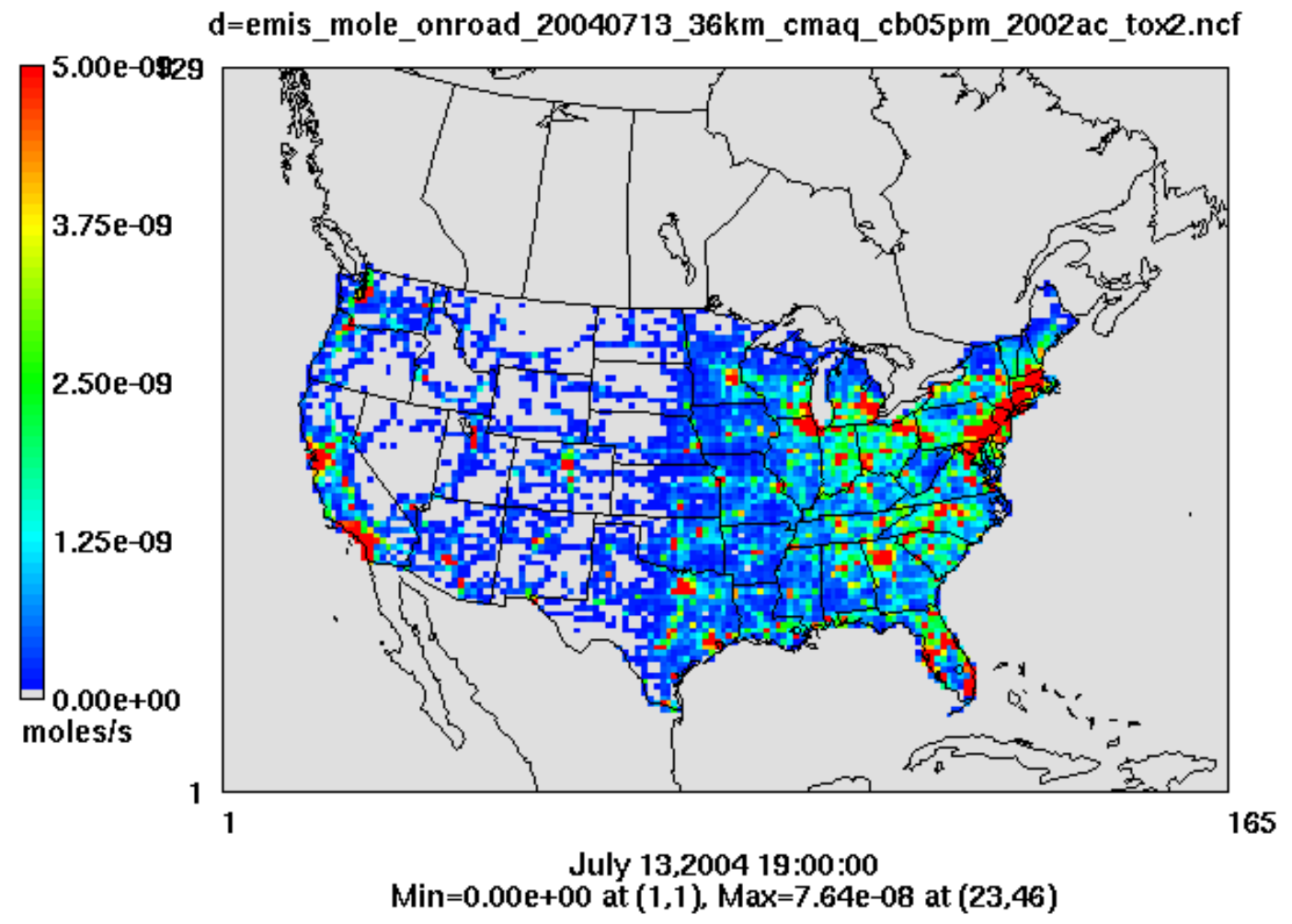

Figure 11. SMOKE emission results for onroad emissions of reactive gaseous mercury (RGM) in $36 \mathrm{~km}$ grid resolution. 


\section{Layer 1 PHGId}

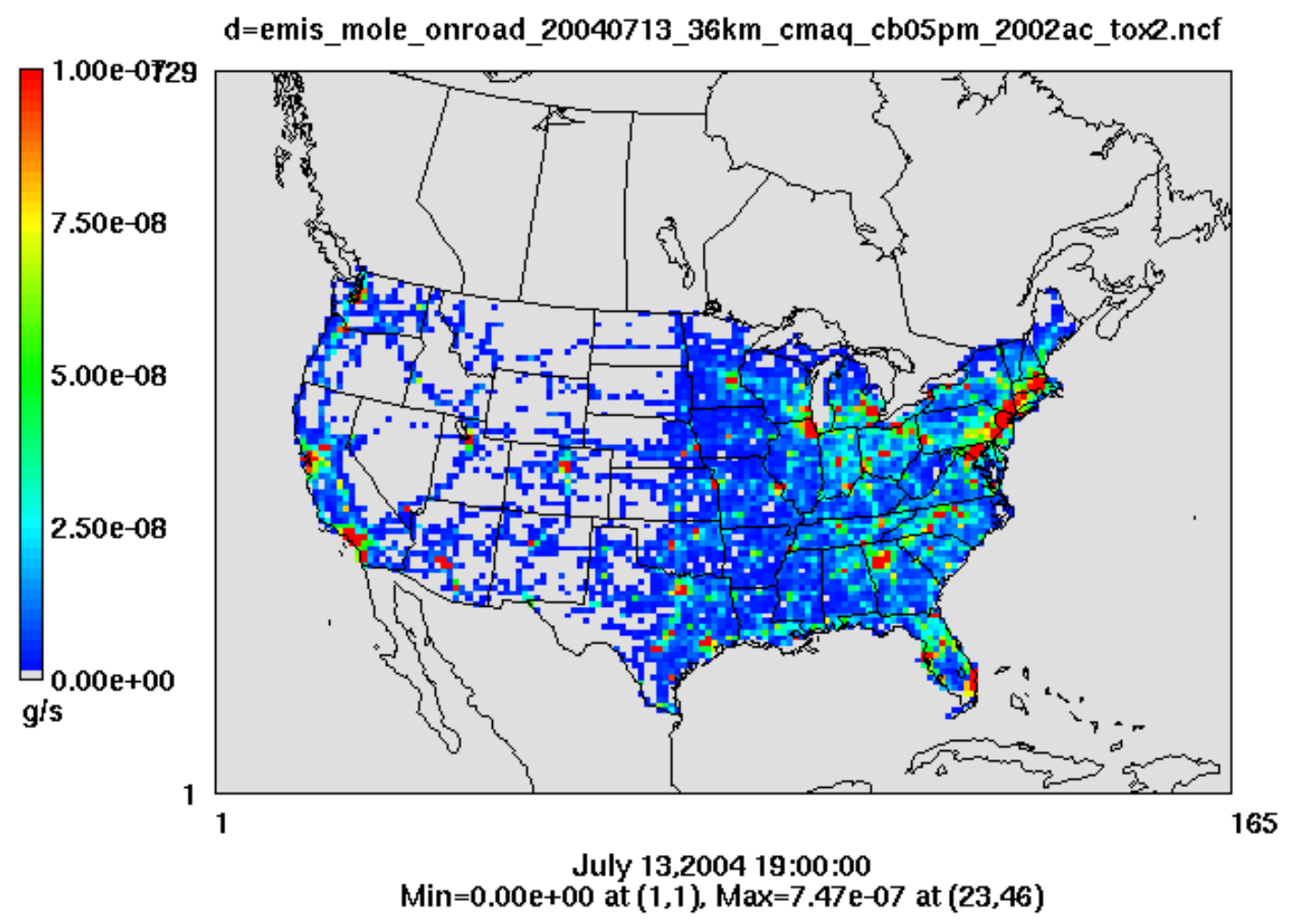

Figure 12. SMOKE emission results for onroad emissions of particulate mercury $\left(\mathrm{Hg}_{\mathrm{p}}\right)$ in $36 \mathrm{~km}$ grid resolution. 
Figs. 13 to 15 present $36 \mathrm{~km}$ grid resolution SMOKE emission results from the national emissions inventory (NEI) of Canadian area source data for $\mathrm{Hg}^{0}, \mathrm{RGM}$, and $\mathrm{Hg}_{\mathrm{p}}$, respectively. Results reflect emission data from 19:00:00 on July 13, 2004. Elevated levels of $\mathrm{Hg}^{0}$ were observed along the southeastern border and in the western portion of Canada. Similar trends can be observed in the spatial distribution of area source RGM and $\mathrm{Hg}_{\mathrm{p}}$ emissions in Canada.

\section{Layer 1 HGNRVAf}

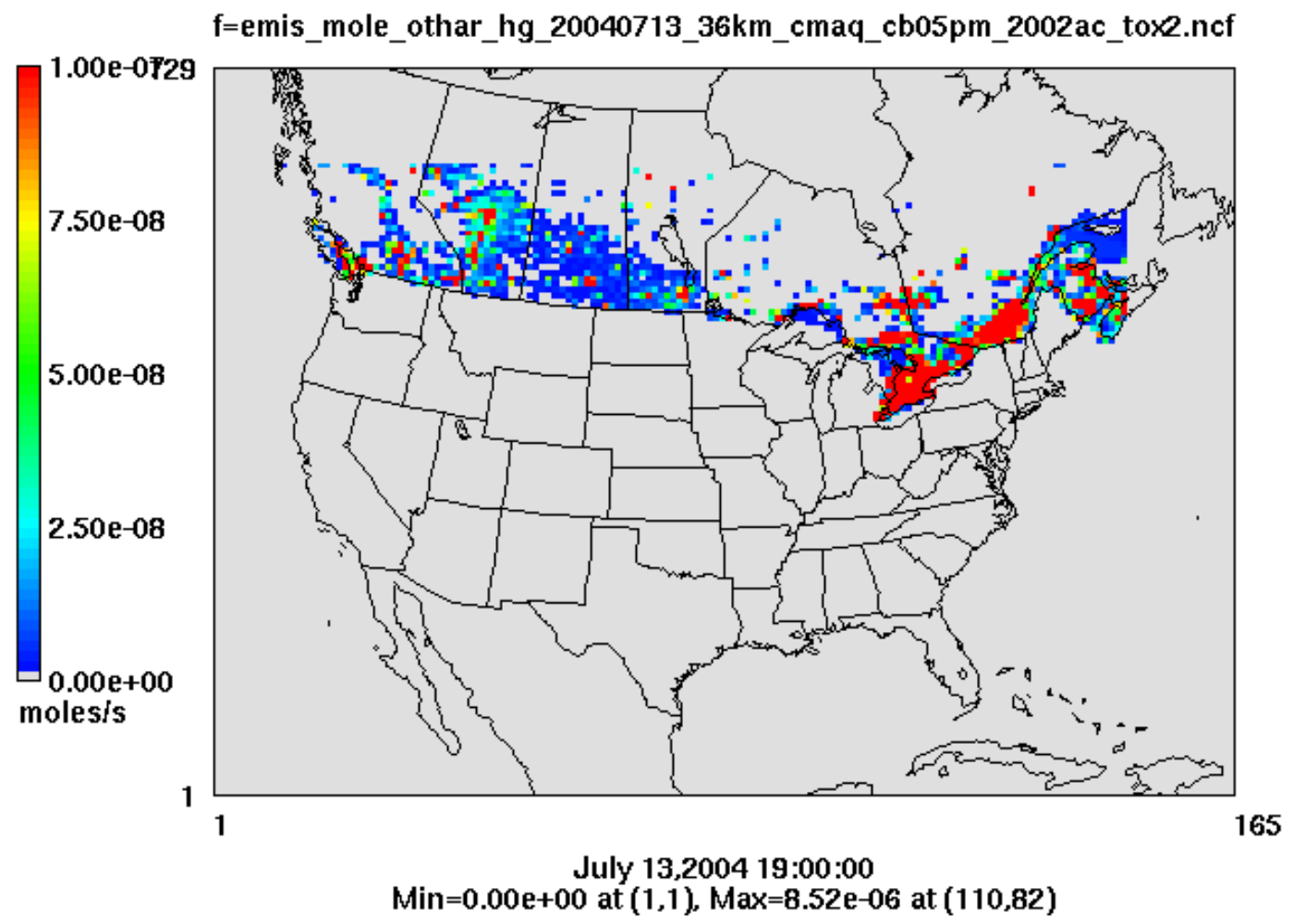

Figure 13. SMOKE emission results for Canadian area source emissions of elemental mercury $\left(\mathrm{Hg}^{0}\right)$ in $36 \mathrm{~km}$ grid resolution 


\section{Layer 1 HGIIGASf}

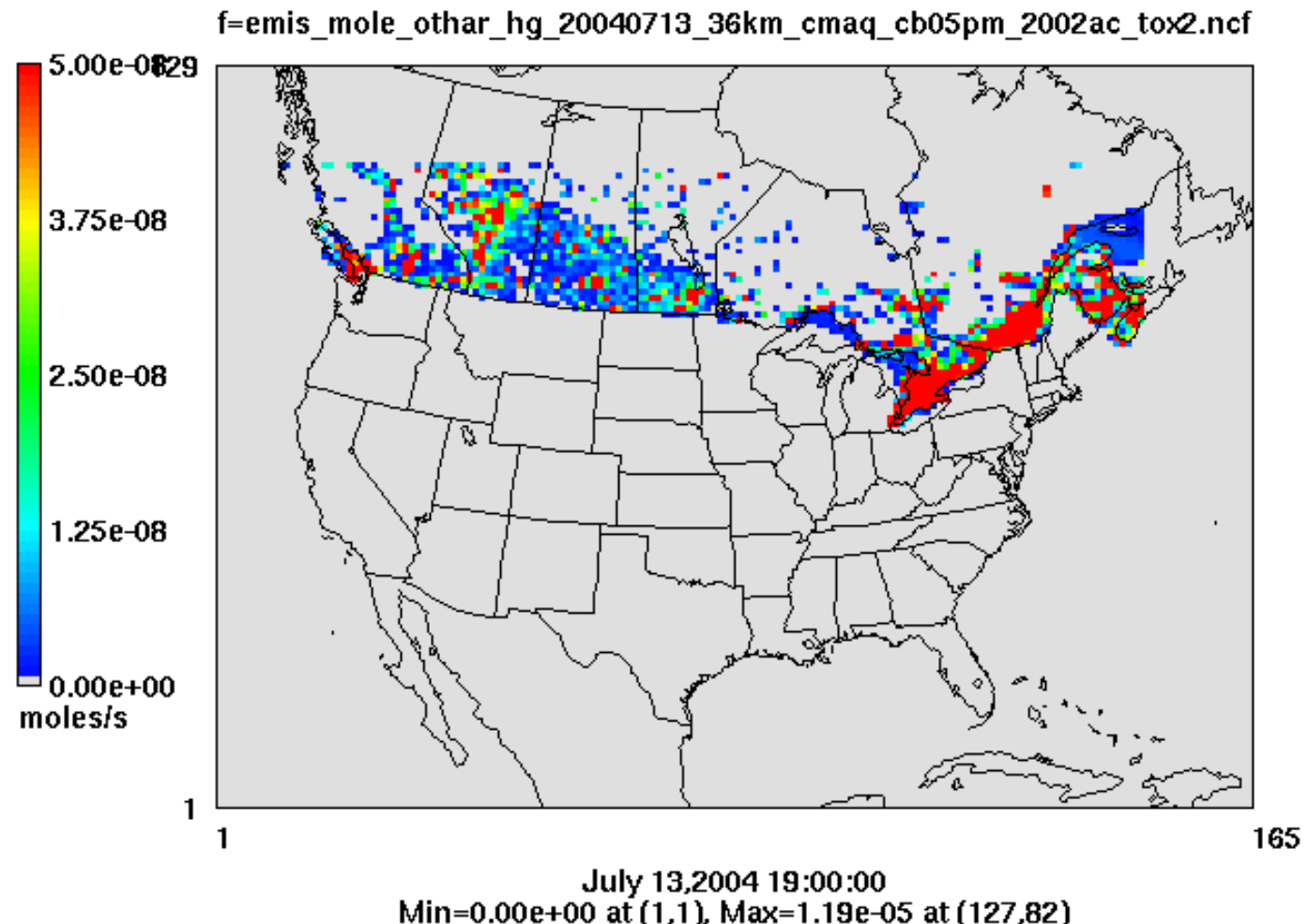

Figure 14. SMOKE emission results for Canadian area source emissions of reactive gaseous mercury (RGM) in $36 \mathrm{~km}$ grid resolution. 


\section{Layer 1 PHGIf}



Figure 15. SMOKE emission results for Canadian area source emissions of particulate mercury $\left(\mathrm{Hg}_{\mathrm{p}}\right)$ in $36 \mathrm{~km}$ grid resolution. 
Figs. 16 to 18 present $36 \mathrm{~km}$ grid resolution SMOKE emission results from the national emissions inventory (NEI) of point source emissions excluding EGUs and IPM input data for $\mathrm{Hg}^{0}, \mathrm{RGM}$, and $\mathrm{Hg}_{\mathrm{p}}$, respectively. Results reflect emission data from 19:00:00 on July 13, 2004. Elevated levels of $\mathrm{Hg}^{0}$ were observed in eastern U.S. and along western coastal regions. Similar trends can be observed in the spatial distribution of $\mathrm{RGM}$ and $\mathrm{Hg}_{\mathrm{p}}$ point source emissions excluding EGUs and IPM input data.

Elevated levels of $\mathrm{Hg}^{0}, \mathrm{RGM}$ and $\mathrm{Hg}_{\mathrm{P}}$ non EGU and IPM input data point source emissions were observed in northeastern Ohio and the Ohio Valley Region.

\section{Layer 1 HGNRVAh}

h=emis_mole_ptnonipm_20040713_36km_cmaq_cb05pm_2002ac_tox2.ncf

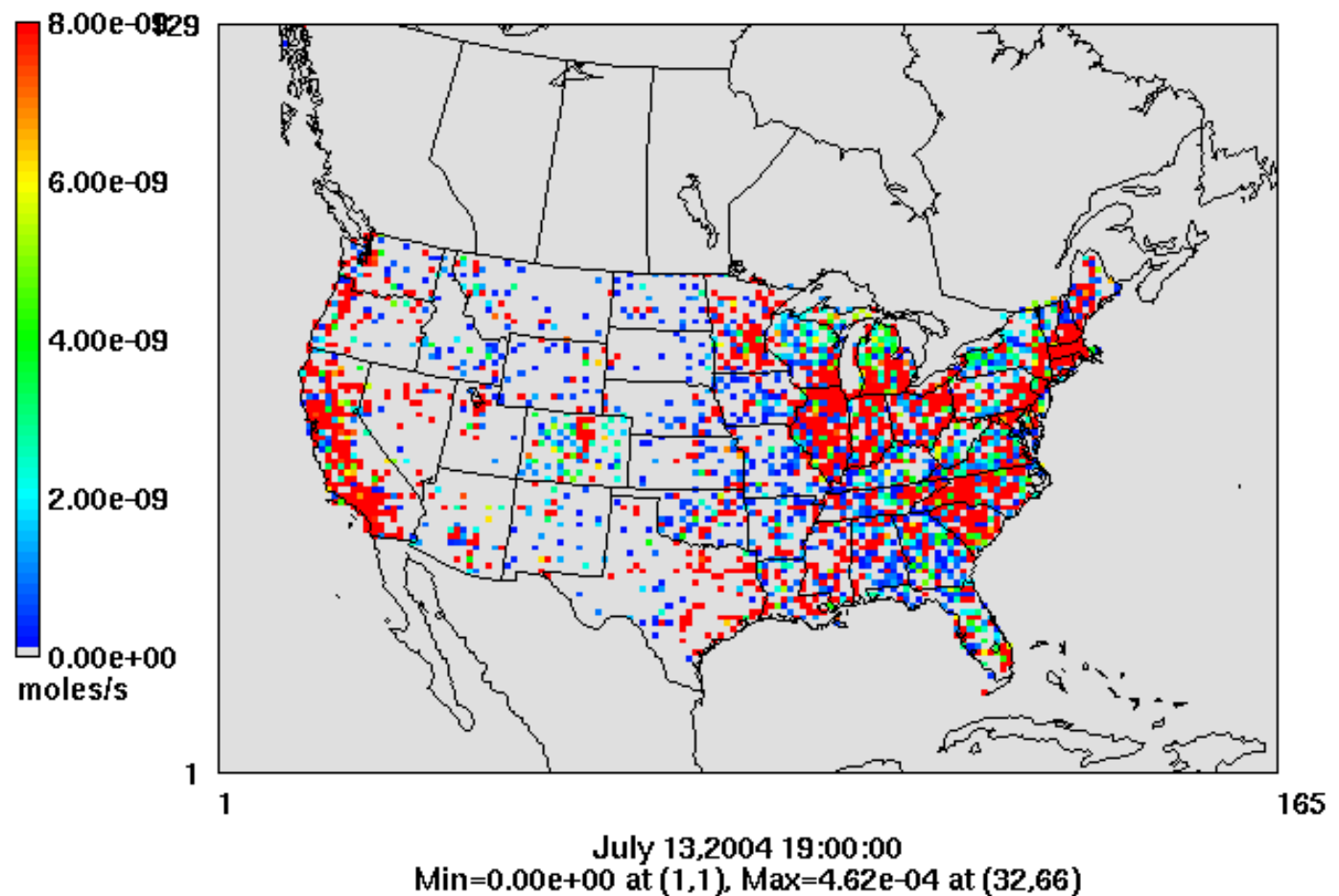

Figure 16. SMOKE emission results for point source emissions excluding EGUs and IPM input data of elemental mercury $\left(\mathrm{Hg}^{0}\right)$ in $36 \mathrm{~km}$ grid resolution 


\section{Layer 1 HGIIGASh}

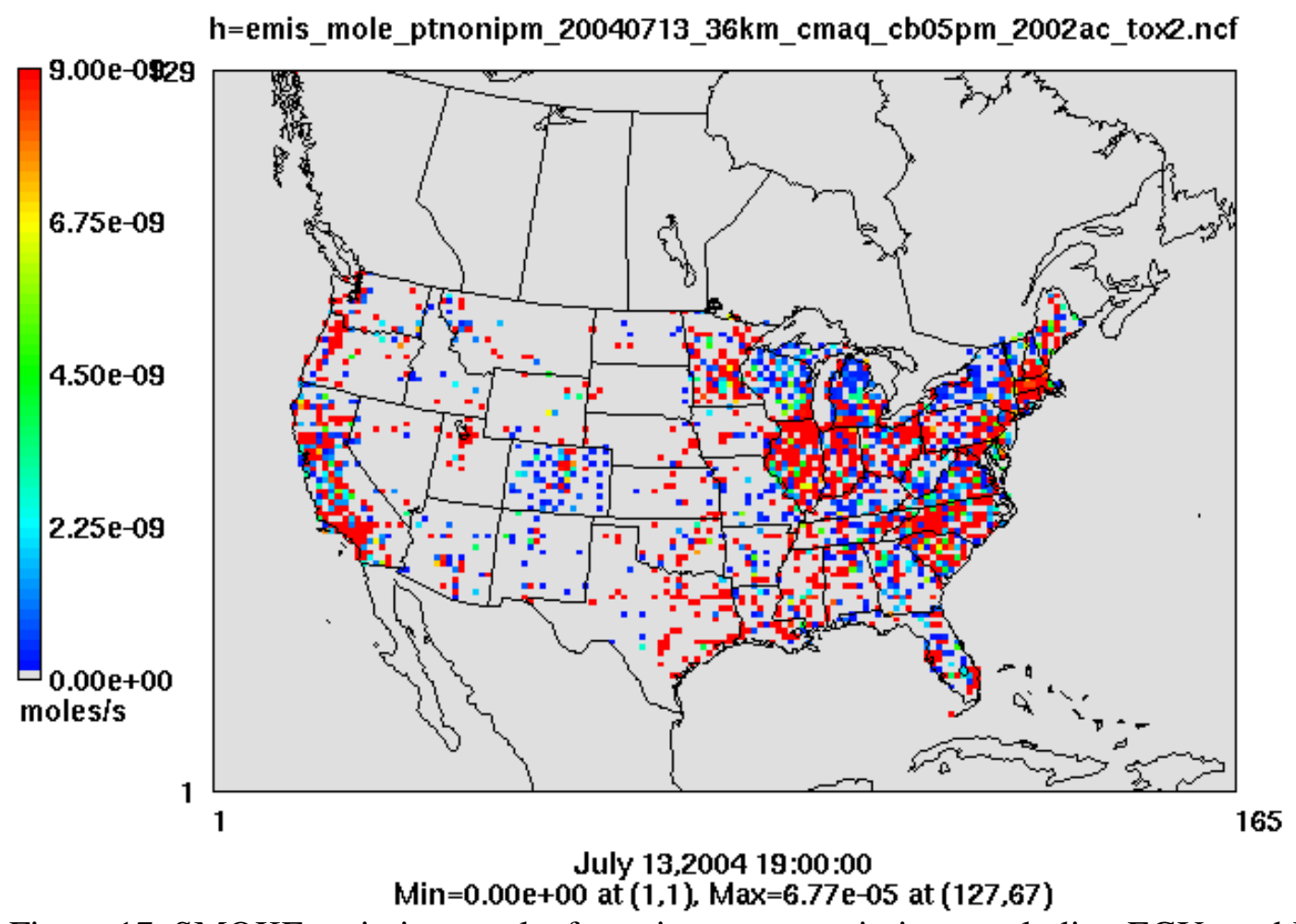

Figure 17. SMOKE emission results for point source emissions excluding EGUs and IPM input data of reactive gaseous mercury $(\mathrm{RGM})$ in $36 \mathrm{~km}$ grid resolution. 


\section{Layer 1 PHGIh}

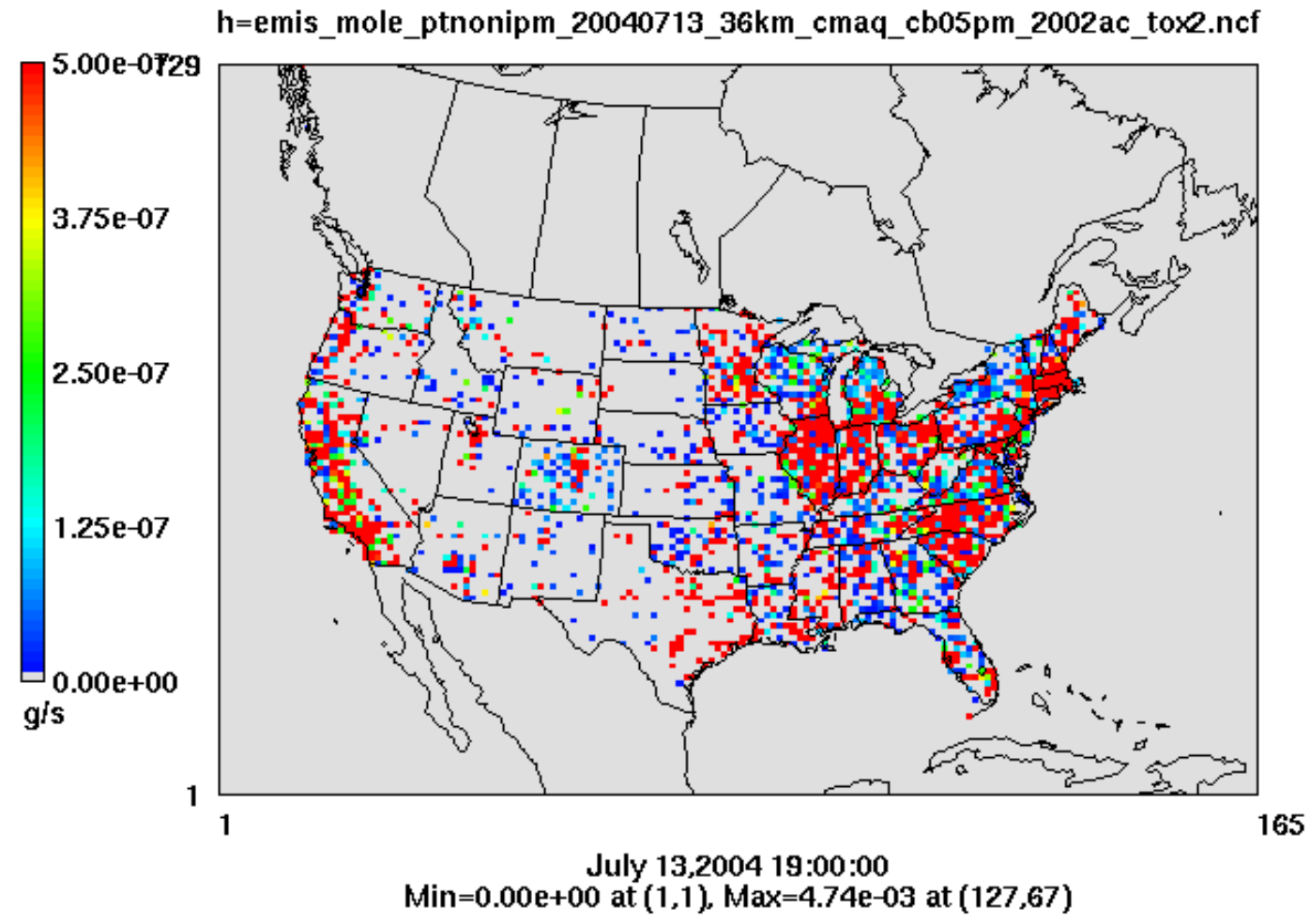

Figure 18. SMOKE emission results for point source emissions excluding EGUs and IPM input data of particulate mercury $\left(\mathrm{Hg}_{\mathrm{p}}\right)$ in $36 \mathrm{~km}$ grid resolution. 